\title{
ELAINE HILLESHEIM
}

Validação de um questionário semiquantitativo de frequência

alimentar e de seu Índice de Qualidade da Dieta Revisado para crianças e adolescentes de 9 a 13 anos utilizando biomarcadores dietéticos - Ribeirão Preto, SP.

Ribeirão Preto 


\section{ELAINE HILLESHEIM}

Validação de um questionário semiquantitativo de frequência alimentar e de seu Índice de Qualidade da Dieta Revisado para crianças e adolescentes de 9 a 13 anos utilizando biomarcadores dietéticos - Ribeirão Preto, SP.

Dissertação de mestrado apresentada à Faculdade de Medicina de Ribeirão Preto da Universidade de São Paulo para obtenção do título de mestre em Saúde da Criança e do Adolescente.

Área de concentração: Saúde da Criança e do Adolescente

Orientadora: Profa. Dra. Jacqueline Pontes Monteiro 
Autorizo a reprodução e divulgação total ou parcial deste trabalho, por qualquer meio convencional ou eletrônico, para fins de estudo e pesquisa, dede que citada a fonte.

Hillesheim, Elaine.

Validação de um questionário semiquantitativo de frequência alimentar e de seu Índice de Qualidade da Dieta Revisado para crianças e adolescentes de 9 a 13 anos utilizando biomarcadores dietéticos - Ribeirão Preto, SP. / Elaine Hillesheim ; orientadora Jacqueline Pontes Monteiro . - Ribeirão Preto, 2017.

124 f. : il.

Dissertação (Mestrado) -- Faculdade de Medicina de Ribeirão Preto da Universidade de São Paulo. Departamento de Puericultura e Pediatria. Área de concentração: Saúde da Criança e do Adolescente.

1. Validação. 2. Questionário de Frequência Alimentar. 3. Índice de Qualidade da Dieta Revisado. 4. Biomarcadores. I. Validação de um questionário semiquantitativo de frequência alimentar e do Índice de Qualidade da Dieta Revisado para crianças e adolescentes de 9 a 13 anos utilizando biomarcadores dietéticos - Ribeirão Preto, SP.. II. Monteiro, Jacqueline Pontes. 
Nome: Elaine Hillesheim

Título: Validação de um questionário semiquantitativo de frequência alimentar e de seu Índice de Qualidade da Dieta Revisado para crianças e adolescentes de 9 a 13 anos utilizando biomarcadores dietéticos - Ribeirão Preto, SP.

Dissertação apresentada à Faculdade de Medicina de Ribeirão Preto da Universidade de São Paulo para obtenção do título de Mestre em Saúde da Criança e do Adolescente.

Aprovado em:

Banca Examinadora

$\operatorname{Prof}(\mathrm{a}) . \operatorname{Dr}(\mathrm{a})$. Instituição:

Julgamento: Assinatura:

Prof (a). Dr (a). Instituição:

Julgamento: Assinatura:

Prof (a). Dr (a). Instituição: Assinatura: 
Ao meu pai, Benedito, meu irmão, Elesio, e ao meu namorado, Rogerio, por todo amor, carinho, compreensão e incentivo em todos os momentos desta caminhada. 


\section{AGRADECIMENTOS}

Agradeço a Deus, pelo dom da vida, pelo amparo e proteção em todos os momentos, especialmente naqueles mais difíceis, permitindo a constante evolução intelectual e moral.

À Universidade de São Paulo, ensino público de excelência, pela oportunidade e conhecimentos ofertados durante esses dois anos.

Ao Conselho Nacional de Desenvolvimento Científico e Tecnológico, pela concessão da bolsa de estudos, a qual permitiu dedicação exclusiva em um importante momento dessa dissertação.

Ao Nestlé Institute of Health Sciences, pelo financiamento da pesquisa da qual essa dissertação faz parte.

Aos funcionários do Hospital das Clínicas de Ribeirão Preto e aos alunos do curso de graduação em Nutrição e Metabolismo da FMRP-USP, que contribuíram de maneira imprescindível para a coleta de dados da pesquisa.

Ao Dr. Jim Kaput, pela motivação inabalável e dedicação que tornaram essa pesquisa possível.

À minha orientadora, Jacque, por me dar a oportunidade de trabalhar consigo e por acreditar em mim. Agradeço pela atenção em cada correção e em cada reunião, por todas as conversas e pelo apoio em relação às escolhas para minha carreira, e também por ser uma amiga nos momentos de confraternização.

À Roseli, Tamiris, Carol, Roberta, Mariana, Maria Olímpia e Joyce, que formaram uma equipe valiosa no cumprimento das tarefas de forma criteriosa e dedicada. A presença de cada uma contribuiu para o êxito deste trabalho.

Às minhas amigas Jowanka e Marceli, pelas conversas e desabafos, mas agradeço principalmente pelos momentos de risada que tornaram essa caminhada mais leve.

Ao meu pai, Benedito, que foi incisivo em ensinar os valores da vida com seus sábios conselhos, e ao meu irmão, Elesio, incentivador e companheiro. Obrigada pelo incentivo de continuar sempre os estudos, por acreditar na minha capacidade e nos meus sonhos, pelo apoio em todos os momentos, especialmente naqueles mais difíceis. Obrigada por compreenderem minha ausência e por sempre se fazerem presentes em minha vida. Amo vocês!

Ao meu namorado, Rogerio, meu amor, amigo, companheiro, que sempre me incentiva e acredita que sou capaz, estimulando meu crescimento pessoal e profissional. Obrigada por ter 
sempre uma palavra de apoio, pelo ombro amigo, por dividir as tristezas, preocupações e alegrias. Obrigada por compartilhar a vida comigo. Te amo!

Agradeço imensamente a todos que fizeram parte deste período da minha vida e que contribuíram para esta conquista.

\section{Muito obrigada!}




\section{RESUMO}

Hillesheim H. Validação de um questionário semiquantitativo de frequência alimentar e de seu Índice de Qualidade da Dieta Revisado para crianças e adolescentes de 9 a 13 anos utilizando biomarcadores dietéticos - Ribeirão Preto, SP [dissertação]. Ribeirão Preto: Universidade de São Paulo, Faculdade de Medicina de Ribeirão Preto, 2017. 124 f.

Introdução: A nutrição desempenha um papel importante no metabolismo humano, na prevenção de doença e na manutenção da saúde. Portanto, validar instrumentos que melhor representem essa ingestão é tarefa fundamental para entender o processo saúde-doença. Objetivos: Descrever e associar a estimativa da ingestão de nutrientes de um Questionário Semiquantitativo de Frequência Alimentar (QSFA) e seu Índice de Qualidade da Dieta Revisado (IQD-R) com biomarcadores de vitaminas lipossolúveis, vitaminas hidrossolúveis, ácidos graxos e creatina, em crianças e adolescentes de 9 a 13 anos de idade do município de Ribeirão Preto - SP. Métodos: O desenho do estudo é transversal. A ingestão alimentar foi estimada por um QFSA e calculada utilizando-se o software Nutrition Data System for Research (NDSR) ${ }^{\circledR}$. Posteriormente, a ingestão alimentar estimada pelo QSFA foi utilizada para calcular as pontuações do IQD-R. Os biomarcadores foram analisados por cromatografia líquida de alta eficiêntcia (HPLC) ou por espectrômetro de massa em amostras de plasma ou eritrócitos (ácidos graxos). A associação da estimativa da ingestão de nutrientes e dos componentes do IQD-R com as concentrações de biomarcadores foram analisadas por correlação de Spearman e correlação parcial ajustada para energia (apenas QSFA), sexo idade e índice de massa corporal para idade (IMC/I). A estimativa da ingestão de nutrientes, os componentes do IQD-R e as concentrações dos biomarcadores foram divididos em quartis e analisados para concordância entre quartis, comparação de médias entre o primeiro e o último quartil e análise de tendência entre quartis. Todas as análises estatísticas foram realizadas no software Statistical Package for the Social Sciences (SPSS) ®, versão 20.0, com nível de significância de 5\%. Resultados: A amostra final constituiu-se de 177 indivíduos que apresentaram média de 11,5 anos de idade (DP 1,1), sendo 48,0\% do sexo masculino. Nas análises do QSFA, os biomarcadores $\beta$-caroteno, $\beta$-caroteno/colesterol, 25-hidroxivitamina $\mathrm{D}_{3}$ $\left(25(\mathrm{OH}) \mathrm{D}_{3}\right)$, ácido graxo mirístico $(\mathrm{C} 14: 0)$ e ácido graxo eicosapentaenoico (EPA) apresentaram correlações positivas com suas respectivas ingestões. Após ajuste para variáveis de confusão, o ácido graxo docosahexaenóico (DHA) apresentou correlação positiva apenas no sexo feminino. Quanto ao IQD-R, os componentes de vegetais foram positivamente 
correlacionados às concentrações plasmáticas de $\beta$-caroteno e $\beta$-caroteno/colesterol, enquanto que os componentes modificados Vegetais Totais sem Leguminosas e Vegetais-Verde-Escuros e Alaranjados sem Leguminosas foram positivamente correlacionados às concentrações plasmáticas de vitamina B12 e 5-metil tetrahidrofolato (5-Me THF), respectivamente. Todos os componentes ricos em proteínas de origem vegetal (leguminosas) e animal (carnes e ovos) foram associados à creatina plasmática $\mathrm{O}$ componente Leite e Derivados foi positivamente correlacionado com os biomarcadores C14:0, vitamina B12, piridoxal 5-fosfato (PLP) e ácido pantotênico. O IQD-R demonstrou, ainda, que concentrações plasmáticas de vitaminas do complexo B foram inversamente correlacionadas com os componentes Cereais Totais e Gordura Saturada. Exceto para os componentes Vegetais Totais e Leguminosas; VegetaisVerde-Escuros, Alaranjados e Leguminosas; Carnes, Ovos e Leguminosas e Cereais Totais, os quais não formaram quartis, todas as correlações positivas citadas foram reforçadas por concordância entre quartis $>70 \%$, diferença significativa da concentração de biomarcadores entre o primeiro e quarto quartil de ingestão e tendência de aumento do valor médio do biomarcador em cada quartil de ingestão. Conclusão: O QSFA e o seu IQD-R foram validados para as associações acima descritas e podem ser utilizados em estudos clínicos e epidemiológicos que investiguem a associação entre desfechos em saúde e consumo alimentar.

Palavras-chave: Validação. Questionário de Frequência Alimentar. Índice de Qualidade da Dieta Revisado. Biomarcadores. 


\begin{abstract}
Hillesheim H. Validation of food frequency questionnaire and Brazilian Healthy Eating Index - Revised in children and adolescents from 9 to 13 years old with dietary biomarkers - Ribeirão Preto, SP [dissertation]. Ribeirão Preto: Universidade de São Paulo, Faculdade de Medicina de Ribeirão Preto, 2017. 124 p.
\end{abstract}

Introduction: Nutrition plays an important role in human metabolism, on preventing disease and maintaining health. Therefore, quantifying food intake and validating instruments that best represent this intake is a fundamental task to understand the health-disease process. Objectives: To describe and associate the estimated nutrient intake from a semiquantitative food frequency questionnaire (SFFQ) and its Brazilian Healthy Eating Index - Revised (BHEI-R) with biomarkers of fat-soluble vitamins, water-soluble vitamins, fatty acids and creatine, in children and adolescents aged 9 to 13 years in Ribeirão Preto - SP. Methods: This is a cross-sectional study. The dietary intake was estimated by a SFFQ and calculated in the software Nutrition Data System for Research (NDSR) ${ }^{\circledR}$. The estimate was used to generate the BHEI-R scores. The biomarkers were analyzed by high performance liquid chromatography (HPLC) or mass spectrometer in plasma or erythrocyte (fatty acid) samples. The association of the estimated nutrient intake and BHEI-R components with biomarkers concentrations were analyzed by Spearman correlation and partial correlation adjusted for energy (QSFA only), sex, age, and body mass index-for-age (BMI/A). Estimates of nutrient intake, BHEI-R components and biomarkers concentrations were divided into quartiles and analyzed for quartile agreement, comparison of means between the first and last quartile and trend analysis among quartile. Statistical analyzes were performed in Statistical Package for Social Sciences (SPSS) ®, version 20.0, with a significance level of 5\%. Results: The sample was composed of 177 subjects, the mean age was 11.5 (SD 1.1) years old and 48\% were male. In the SFFQ analyzes, the biomarkers $\beta$-carotene, $\beta$-carotene/cholesterol, 25-hydroxyvitamin D3 $\left(25(\mathrm{OH}) \mathrm{D}_{3}\right)$, myristic acid (C14:0) and eicosapentaenoic acid (EPA) showed positive correlations with their respective intakes. After adjusting for confounding variables, docosahexaenoic acid (DHA) showed a positive correlation only in females. Regarding BHEI-R, vegetable components were positively correlated with plasma concentrations of $\beta$-carotene and $\beta$-carotene/cholesterol, while the modified components Total Vegetables without Legumes and Dark Green and Orange Vegetables without Legumes were positively correlated with plasma concentrations of vitamin B12 and 5-methyl tetrahydrofolate (5-Me THF), respectively. All components rich in vegetable 
(legumes) and animal protein sources (meat, eggs) were correlated with plasma creatine. The component Milk was positively correlated with biomarkers C14:0, vitamin B12, pyridoxal 5phosphate (PLP) and pantothenic acid. BHEI-R also demonstrated that plasma concentrations of B-complex vitamins were inversely correlated with Whole Grains and Saturated Fat components. Except for the components Total Vegetable and Legumes, Dark Green and Orange Vegetables and Legumes, Meat and Beans, and Total Grains, which did not generate quartiles, all positive correlations were reinforced by quartiles agreement $>70 \%$, significant difference in the biomarkers concentration between the first and fourth quartiles of intake, and trend of increasing biomarkers concentrations with increasing quartiles of intake. Conclusion: The SFFQ and its BHEI-R were validated for the associations described above and can be used in clinical and epidemiological studies investigating the association between health outcomes and dietary intake.

Keywords: Validation. Food Frequency Questionnaire. Healthy Eating Index - Revised. Biomarkers. 


\section{LISTA DE QUADROS}

Quadro 1 - Critérios de pontuação total e por componentes do Índice de Qualidade da Dieta Revisado 


\section{LISTA DE FIGURAS}

Figura 1 - Fluxograma de inclusão dos participantes no estudo .............................. 42 


\section{LISTA DE TABELAS}

Tabela 1 - Estado nutricional das crianças e adolescentes participantes do estudo ..

Tabela 2 - Distribuição da classificação socioeconômica das famílias das crianças e adolescentes participantes do estudo

Tabela 3 - Valores de mediana e de percentis da estimativa de ingestão de nutrientes pelo Questionário Semiquantitativo de Frequência Alimentar

Tabela 4 - Valores de mediana e de percentis das pontuações dos componentes do Índice de Qualidade da Dieta Revisado

Tabela 5 - Valores de mediana e de percentis das concentrações de biomarcadores

Tabela 6 - Coeficientes de correlação de Spearman e de correlações ajustadas entre a estimativa de ingestão de nutrientes por Questionário Semiquantitativo de Frequência Alimentar e as concentrações de biomarcadores

Tabela 7 - Distribuição das concentrações de biomarcadores em quartis definidos pela estimativa de consumo de nutrientes através de Questionário Semiquantitativo de Frequência Alimentar

Tabela 8 - Porcentagem de concordância entre quartis de estimativa da ingestão de nutrientes por Questionário Semiquantitativo de Frequência Alimentar e de concentrações de biomarcadores

Tabela 9 - Coeficientes de correlação de Spearman e de correlação ajustada entre os componentes do Índice de Qualidade da Dieta Revisado e as concentrações de biomarcadores

Tabela 10 - Distribuição das concentrações de biomarcadores em quartis definidos pelos componentes do Índice de Qualidade da Dieta Revisado

Tabela 11 - Porcentagem de concordância entre quartis de componentes do Índice de Qualidade da Dieta Revisado e de concentrações de biomarcadores .. 


\section{LISTA DE ABREVIATURAS E SIGLAS}

$25(\mathrm{OH}) \mathrm{D}_{3} \quad$ 25-hidroxivitamina $\mathrm{D}_{3}$

5-Me THF 5-metil tetrahidrofolato

ALA

Ácido graxo $\alpha$-linolênico

C14:0

Ácido graxo mirístico

C15:0

Ácido graxo pentadecanóico

C16:0

Ácido graxo palmítico

C17:0

Ácido graxo margárico

C18:0

Ácido graxo esteárico

DHA

Ácido graxo docosahexaenóico

DQI

Diet Quality Index

EPA

Ácido graxo eicosapentaenoico

FMRP-USP Faculdade de Medicina de Ribeirão Preto da Universidade de São Paulo

GET Gasto energético total

Gord_AA Calorias provenientes de gordura sólida, álcool e açúcar de adição

HEI Heatlhy Eating Index

IMC Índice de massa corporal

IMC/I Índice de massa corporal para idade

IQD Índice de Qualidade da Dieta

IQD-R Índice de Qualidade da Dieta Revisado

OMS Organização Mundial da Saúde

PLP Piridoxal 5-fosfato

POF Pesquisa de Orçamentos Familiares

PUFA Ácidos graxos poli-insaturados

QFA Questionário de frequência alimentar

QSFA Questionário semiquantitativo de frequência alimentar

R24hs Recordatório de 24 horas

RA Registro alimentar

T0 Tempo basal da coleta de dados

T1 Primeira coleta de dados

TMB Taxa metabólica basal

Vegetal total SL Vegetal total sem leguminosas 
VET

Veveal

Veveal SL
Valor energético total

Vegetais verdes-escuros e alaranjados e leguminosas

Vegetais verdes-escuros e alaranjados sem leguminosas 


\section{SUMÁRIO}

1 INTRODUÇÃO

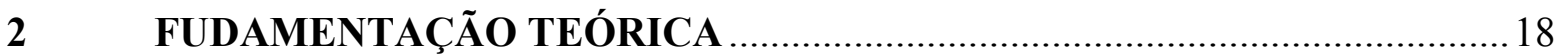

2.1 Hábitos Alimentares e Riscos Nutricionais em Crianças e Adolescentes ......... 18

2.2 Métodos de Avaliação do Consumo Alimentar ................................................. 24

2.2.1 Questionário de frequência alimentar ...............................................................25

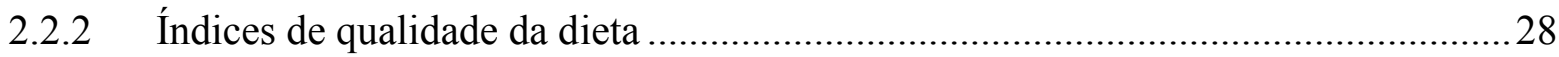

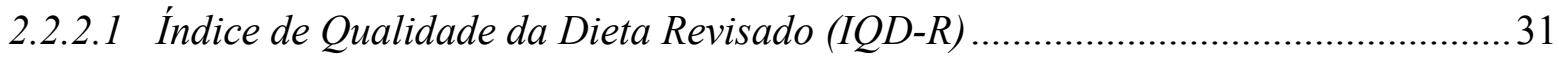

2.2.3 Marcadores bioquímicos do consumo alimentar .................................................... 33

2.3 Validação de Métodos de Avaliação do Consumo Alimentar ............................. 34

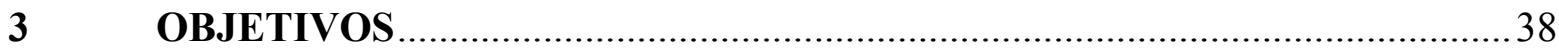

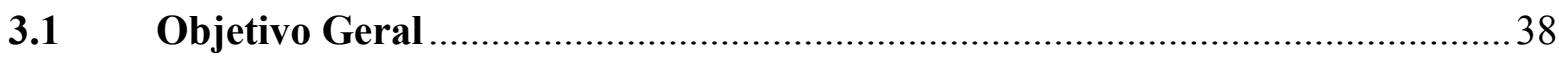

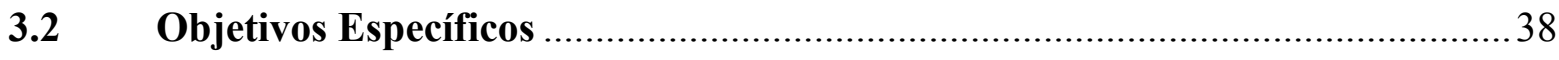

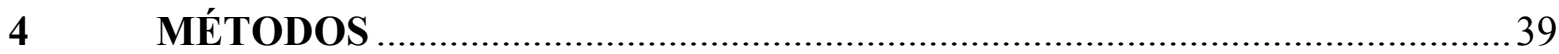

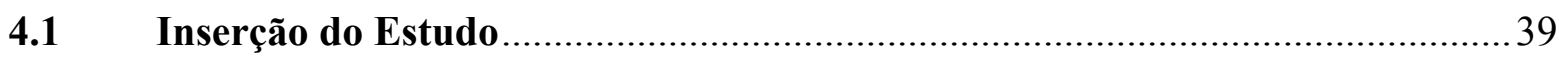

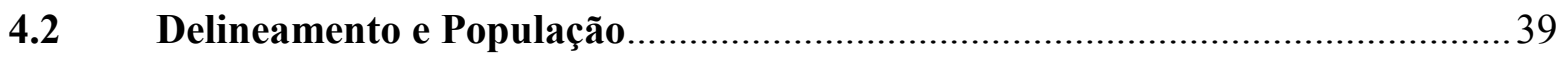

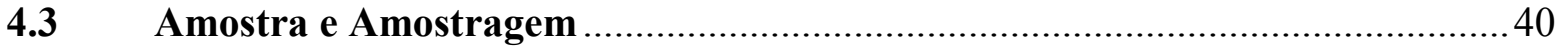

4.3.1 Critérios de Inclusão e Não-Inclusão ........................................................................ 40

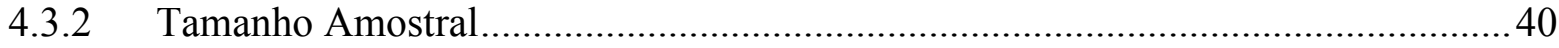

4.4 Instrumentos e Técnicas para Coleta e Análise de Dados ..................................42

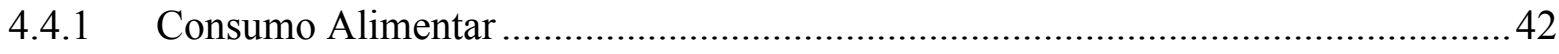

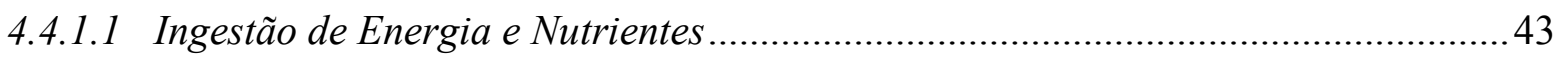

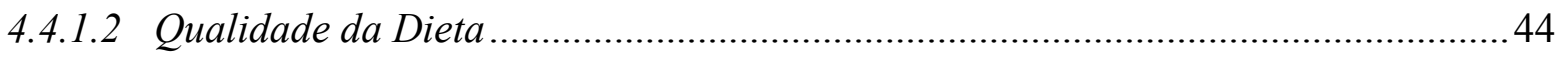

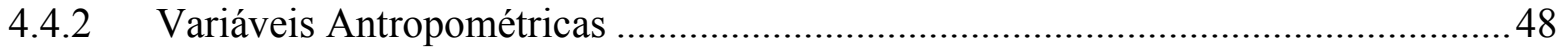

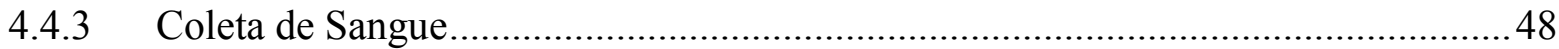

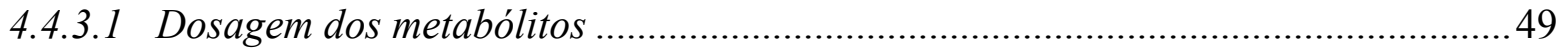

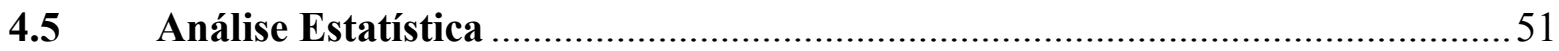

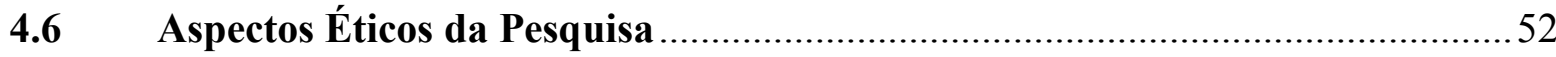


5.1 Validação do Questionário Semiquantitativo de Frequência Alimentar utilizando Biomarcadores

5.2 Validação do Índice de Qualidade da Dieta Revisado gerado por questionário semiquantitativo de frequência alimentar utilizando biomarcadores

6 DISCUSSÃO

6.1 Questionário semiquantitativo de frequência alimentar

6.2 Índice de Qualidade da Dieta Revisado gerado por questionário semiquantitativo de frequência alimentar .73

7 CONCLUSÕES

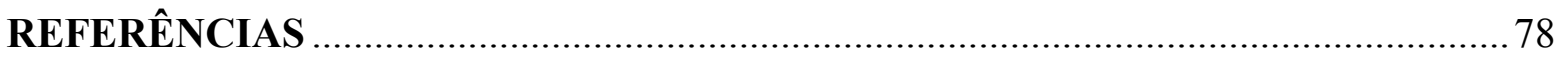

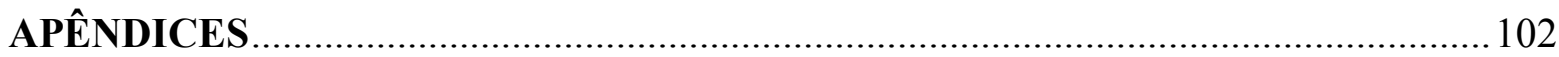

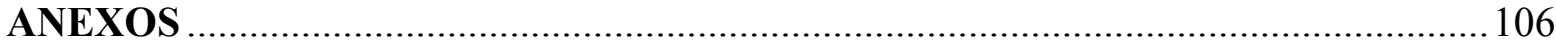




\section{INTRODUÇÃO}

Em todos os estágios da vida a inadequação de nutrientes é fator determinante no aparecimento de carências nutricionais e no surgimento de várias manifestações patológicas, tais como obesidade, doenças cardiovasculares, câncer, diabetes etc. Assim, pode-se dizer que as condições de saúde e nutrição de uma população constituem um reflexo de seu consumo alimentar, principalmente para crianças e adolescentes, os quais constituem o grupo mais biologicamente vulneral. Isso porque, por estarem em fase de pleno crescimento e desenvolvimento do organismo, crianças e adolescentes necessitam de alimentos em proporção ao seu tamanho mais nutritivos do que adultos. Além disso, essa faixa etária apresenta importantes modificações psicológicas que podem interferir negativamente na alimentação ${ }^{1}$.

No Brasil, crianças e adolescentes comumente apresentam elevado consumo de alimentos ricos em gorduras, açúcares e sódio e baixo consumo de cereais integrais, frutas e verduras e leite e derivados, o que converge para elevadas prevalências de consumo inadequado de nutrientes e, consequentemente, para o risco de deficiências nutricionais ${ }^{2,3}$. Nesse contexto, a identificação do consumo alimentar é de grande importância, pois pode ser associada a desfechos em saúde, o que contribui para fundamentar e orientar políticas e práticas de alimentação e nutrição. Para isso, torna-se necessário o desenvolvimento de instrumentos que permitam identificar o consumo alimentar com fidedignidade.

O questionário de frequência alimentar (QFA) tem sido considerado um método prático para a avaliação da ingestão dietética usual. Entre as suas vantagens estão a facilidade de aplicação e de análise dos dados e o menor custo em comparação a outros métodos. Assim, o QFA é indicado para avaliar o consumo de alimentos de grandes grupos populacionais pois permite a categorização dos indivíduos segundo diferentes gradientes de consumo e a associação das categorias de consumo com os desfechos em saúde. O princípio do QFA é avaliar a dieta praticada durante determinado período de tempo no passado (recente ou remoto) estimando a frequência usual do consumo de alimentos ou de grupos alimentares. Basicamente, o QFA possui uma lista de alimentos e um conjunto de categorias de frequência de consumo. O tamanho da porção é um componente opcional. Na aplicação do instrumento, o respondente indica com que frequência cada alimento foi consumido, em média, no período de referência, e o tamanho da porção habitual ${ }^{4}$.

Uma vez que a dieta humana é complexa, novas abordagens têm sido utilizadas para avaliar a associação entre consumo alimentar e desfechos em saúde ${ }^{5}$. Os índices dietéticos 
possuem como objetivo fornecer uma medida resumo das principais características da dieta e são baseados em recomendações dietéticas para a prevenção de doenças crônicas não transmissíveis ${ }^{6}$. No Brasil, o Índice de Qualidade da Dieta Revisado (IQD-R) ${ }^{7}$ contempla as recomendações dietéticas preconizadas pelo Guia Alimentar para a População Brasileira e por outras organizações de saúde e tem sido o índice dietético mais utilizado em estudos na população pediátrica ${ }^{8-12}$.

O QFA, utilizado tanto categorizar os indivíduos de acordo com a ingestão de nutrientes quanto para gerar índices dietéticos, necessita ser validado na população objeto de estudo devido às especificidades dos hábitos alimentares de cada grupo populacional. Validação significa reconhecer a relação entre o consumo estimado e o consumo real da população ${ }^{13}$. $\mathrm{O}$ processo se dá através da comparação da estimativa do QFA com valores obtidos por métodos considerados referência para a estimativa do consumo alimentar ${ }^{4}$.

Nas últimas duas décadas, o uso de biomarcadores como método de referência para estudos de validação do consumo alimentar tem crescido, impulsionado pelo desenvolvimento das técnicas de metabolômica. A principal vantagem do uso de biomarcadores nesse tipo de estudo é que os erros medidos por esses não são relacionados aos erros medidos pelos métodos tradicionais de avaliação do consumo alimentar, os quais, assim como o QFA, dependem do relato de ingestão dos indivíduos ${ }^{4}$. Além disso, muitos biomarcadores podem fornecer uma medida mais próxima do status de nutrientes do que os dados de ingestão dietética, principalmente em estudos cujo desfecho de interesse pode alterar o hábito ou a informação sobre o consumo alimentar ${ }^{14}$.

Diante do exposto e considerando que não existe um QFA validado para a avaliação do consumo alimentar de crianças e adolescentes de 9 a 13 anos de idade residentes no município de Ribeirão Preto - SP, o presente estudo se propõe a realizar o procedimento através da comparação com biomarcadores. Ter um instrumento para identificar o consumo alimentar e a qualidade da dieta desses indivíduos possibilitará seu emprego em estudos clínicos e epidemiológicos. 


\section{FUDAMENTAÇÃO TEÓRICA}

\subsection{Hábitos Alimentares e Riscos Nutricionais em Crianças e Adolescentes}

Casos de subnutrição entre as crianças e adolescentes ainda são uma preocupação em todo o mundo, pois contribuem para diversas disfunções orgânicas ${ }^{15}$. No entanto, o excesso de peso emerge em ritmo claramente epidêmico ${ }^{16}$. Em 2013, 23,8\% dos meninos e 22,6\% das meninas (ambos $<20$ anos de idade) em países desenvolvidos apresentavam sobrepeso ou obesidade, enquanto nos países em desenvolvimento essa prevalência era de 12,9\% e 13,4\% para meninos e meninas, respectivamente ${ }^{17}$. No Brasil, durante o período de 1975 a 2009, a prevalência de excesso de peso em crianças de 5 a 9 anos aumentou de 10,9\% para 34,8\% entre meninos e de 8,6\% para 32,0\% entre meninas. Entre os adolescentes, elevou-se de 3,7\% para $21,7 \%$ no sexo masculino e de $7,6 \%$ para $19,4 \%$ no sexo feminino ${ }^{18}$. Além disso, modelos preditivos sugerem que a proporção mundial de crianças obesas para crianças magras continuará a crescer no futuro ${ }^{19,20}$. Tal situação representa um dos problemas de saúde mais desafiadores do século XXI, pois se associa com posterior morbidade e mortalidade ${ }^{21}$.

A tendência crescente de excesso de peso é explicada por mudanças no estilo de vida dos indivíduos, com destaque para o aumento da ingestão de alimentos ricos em energia e diminuição da prática de atividade física ${ }^{22}$. Monteiro et al. ${ }^{2}$ comentam que em cada país e região do mundo a transição nutricional ocorrida no século XX apresentou-se de modo singular, mas elementos comuns convergem para uma dieta rica em gorduras (principalmente de origem animal), açúcares e outros alimentos refinados, e reduzida em carboidratos complexos e fibras. Ao se analisar os estudos do comportamento alimentar de crianças e adolescentes brasileiros, destacam-se como principais desvios alimentares o consumo insuficiente de frutas e hortaliças, a redução do consumo de leite e derivados e o aumento no consumo de alimentos prontos (congelados e pré-preparados) e refrigerantes ${ }^{23}$.

Embora se saiba que quando os alimentos não estão disponíveis é bem provável que ocorram deficiências, por outro lado a abundância em si não assegura ótima nutrição devido ao componente comportamental que determina a escolha dos alimentos e a forma como esses são ingeridos ${ }^{24}$. Souza et al. ${ }^{3}$, em um estudo observacional com 71.791 adolescentes brasileiros entre 12 e 17 anos de idade, observaram que a ingestão média de energia dos adolescentes variou de $2.036 \mathrm{kcal}$ (meninas de 12 a 13 anos) a $2.582 \mathrm{kcal}$ (meninos de 14 a 17 anos). O 
consumo de ácidos graxos saturados e de açúcar livre ultrapassou o limite máximo recomendado de $10 \%$ da ingestão energética total. As maiores prevalências de inadequação foram observadas para o cálcio e vitamina $\mathrm{E}(>90 \%)$, seguidos de fósforo e vitaminas A $(>50 \%)$, vitamina C $(8-23 \%)$ e ferro $(0,9-14 \%)$. Vitamina B12 e zinco foram os nutrientes com as menores prevalências de inadequação, com taxas que variaram entre 0 e $3 \%$ e entre 0 e $4 \%$ respectivamente, a depender da faixa etária e região brasileira. O consumo de sódio foi acima do limite máximo recomendado em mais de $80 \%$ dos adolescentes.

Segundo a Organização Mundial da Saúde (OMS) ${ }^{25}$, a deficiência de vitamina A está associada com significativa morbidade e mortalidade por infecções comuns da infância e é a principal causa de cegueira infantil evitável em todo o mundo. Atualmente estima-se que 250 milhões de pré-escolares sejam deficientes em vitamina A (retinol sérico $<0,7 \mu \mathrm{mol} / \mathrm{L}$ ), o que torna essa situação um problema de saúde pública, principalmente em países subdesenvolvidos 25. No Brasil, ainda que inquéritos nacionais sejam escassos, a Pesquisa Nacional de Demografia e Saúde da Criança e da Mulher de $2006^{26}$ identificou concentrações inadequadas de vitamina A em 17,4\% das crianças menores de cinco anos de idade (Brasil, 2006). As maiores prevalências encontradas foram no Nordeste $(19,0 \%)$ e Sudeste $(21,6 \%)$ do país. Ribeiro-Silva et al. ${ }^{27}$ encontraram prevalência de deficiência de vitamina A de 27,5\% entre crianças e adolescentes de 7 a 14 anos de idade no município de Salvador, Bahia. Os autores encontraram ainda uma associação entre baixas concentrações plasmáticas de retinol e seu menor consumo.

Mais recentemente, a importância dos precursores da vitamina A, especialmente do $\beta$ caroteno, tem sido amplamente discutida na proteção de doenças cardiovasculares. Estudos observaram menores prevalências de doenças coronarianas em indivíduos com maior consumo de vegetais ricos em carotenoides ${ }^{28}$ e de aterosclerose em indivíduos com maiores concentrações plasmáticas de $\alpha$ - e $\beta$-caroteno ${ }^{29}$. Além disso, elevadas concentrações plasmáticas de carotenoides foram associadas a menor inflamação, estresse oxidativo e disfunção endotelial, três características importantes de aterosclerose ${ }^{30}$. No entanto, há uma disparidade entre os resultados dos estudos que utilizaram o $\beta$-caroteno como um marcador do consumo de frutas e vegetais e aqueles envolvendo suplementação. Uma revisão Cochrane sobre a suplementação de antioxidantes encontrou que as concentrações plasmáticas de $\beta$ caroteno e vitamina A aumentaram significativamente a mortalidade por todas as causas investigadas ${ }^{31}$. Esses achados fortalecem a necessidade de concentrações plasmáticas de carotenoides satisfatórias, decorrentes do consumo de frutas e verduras, a fim prevenir doenças. Silva et al. ${ }^{32}$, em um estudo sobre a deficiência de $\beta$-caroteno (concentração plasmática $<40$ 
$\mu \mathrm{g} / \mathrm{dL}$ ) em crianças e adolescentes na região norte do Rio de Janeiro, verificaram prevalência de 55,8\% ( $\mathrm{n}=471)$. A concentração plasmática média de $\beta$-caroteno foi significativamente menor entre os indivíduos com excesso de peso $(30,4 \mu \mathrm{g} / \mathrm{dL})$ em comparação aos eutróficos $(43,1 \mu \mathrm{g} / \mathrm{dL})$.

Outro importante antioxidante é a vitamina E, a qual consiste em um grupo de oito compostos lipossolúveis, cada um com atividades biológicas específicas, sendo o $\alpha$-tocoferol a forma mais potente e abundante nos tecidos e no plasma. Sinais clínicos de deficiência de vitamina $\mathrm{E}$ incluem hemólise de eritrócitos e neuropatia periférica ${ }^{33}$. Enquanto deficiências clínicas evidentes são raras, a ingestão inadequada de vitamina $\mathrm{E}$ tem sido associada a desfechos como doenças cardiovasculares ${ }^{34,35}$, função imune prejudicada ${ }^{36,37}$ e mortalidade em geral ${ }^{38}$. O ponto de corte para a deficiência de vitamina E é controverso e um estudo com adultos americanos encontrou prevalência de deficiência que variou de $0,6 \%$, quando adotada a recomendação do Institute of Medicine $(<12 \mu \mathrm{mol} / \mathrm{L}$ ), a $62,5 \%$ quando o ponto de corte foi 30 $\mu \mathrm{mol} / \mathrm{L}$, valor esse associado à necessidade média estimada (EAR), à concentração em que o marcador urinário de $\alpha$-tocoferol ( $\alpha$-carboxietil hidroxicroman) aumenta e à concentração associada a menor mortalidade no Alpha-Tocopherol Beta-Carotene Study ${ }^{39}$. Em crianças americanas e mexicanas as prevalências de deficiência de vitamina E foram de $69 \%(<12$ $\mu \mathrm{mol} / \mathrm{L})$ e $70 \%(<11,6 \mu \mathrm{mol} / \mathrm{L})$, respectivamente ${ }^{40,41}$. Não foram encontrados estudos sobre prevalência de deficiência de vitamina E na totalidade da população brasileira saudável.

A vitamina $\mathrm{D}$, também lipossolúvel, tem como principal função a regulação do metabolismo de cálcio e fósforo, sendo, portanto, essencial para o desenvolvimento normal de ossos e dentes. Assim, a deficiência de vitamina D, além de prejudicar o crescimento infantil, pode ter o raquitismo como uma grave consequência ${ }^{42}$; porém concentrações moderadas de insuficiência também podem ter efeitos importantes na saúde ao longo da vida adulta. Diversos estudos têm encontrado associações entre a inadequação de 25 -hidroxivitamina $\mathrm{D}_{3}\left[5(\mathrm{OH}) \mathrm{D}_{3}\right]$ e o aumento do risco de doenças crônicas, incluindo doenças cardiovasculares ${ }^{43,44}$, diabetes tipo $1^{45}$ e tipo $2^{46,47}$, câncer ${ }^{48}$ e doenças imunológicas ${ }^{49}$. Os mecanismos fisiopatológicos dessas interações ainda necessitam ser esclarecidos.

A principal fonte de vitamina D é a síntese cutânea ${ }^{50}$, por meio da exposição solar, tendo a dieta uma contribuição inferior a $10 \%$ na biodisponibilidade dessa vitamina ${ }^{51}$. No entanto, mesmo em países ensolarados, prevalências consideráveis de hipovitaminose D em crianças e adolescentes têm sido divulgadas ${ }^{52}$. Esse fato pode ocorrer devido ao menor tempo de exposição solar por mudanças no estilo de vida, à utilização de filtro solar, ao aumento do nível de poluição, aos maiores índices de obesidade e ainda aos fatores genéticos que podem 
influenciar o metabolismo da vitamina $\mathrm{D}^{53}$. Entre os alimentos fontes de vitamina $\mathrm{D}$ estão os peixes gordos, ovos, manteiga, fígado bovino e óleo de fígado de bacalhau ${ }^{51}$. Alimentos fortificados com vitamina $\mathrm{D}$, tais como leites e margarinas, ainda que disponíveis no mercado, não fazem parte do hábito alimentar da população brasileira.

A deficiência de vitamina $\mathrm{D}$ é um problema de saúde pública em todo o mundo e em todas as faixas etárias. Estima-se que mais de um bilhão de indivíduos apresente insuficiência $\left(25(\mathrm{OH}) \mathrm{D}_{3}<30 \mathrm{ng} / \mathrm{mL}\right)$ ou deficiência $\left(25(\mathrm{OH}) \mathrm{D}_{3}<20 \mathrm{ng} / \mathrm{mL}\right)$ de vitamina $\mathrm{D}^{50}$. Um estudo de base populacional, realizado com crianças menores de 10 anos residentes na Região Norte do Brasil $^{54}$, identificou cerca de $30 \%$ da amostra como sendo insuficiente em vitamina $\mathrm{D}$. Na Região Sul, em um estudo com meninas de 7 a 18 anos, a prevalência de insuficiência e deficiência de vitamina $\mathrm{D}$ foi de $90,6 \%{ }^{55}$.

Outras vitaminas menos investigadas em relação à prevalência de deficiência, mas com funções igualmente essenciais na manutenção da saúde e prevenção de doenças são as vitaminas do complexo B, as quais compreendem, entre outras, a riboflavina (vitamina B2), a niacina (vitamina B3), o ácido pantotênico (vitamina B5), a piridoxina (vitamina B6), o ácido fólico (vitamina B9) e a cianocobalamina (vitamina B12).

Riboflavina, niacina e ácido pantotênico são vitaminas essenciais para o metabolismo energético e de macronutrientes. Sob as formas flavina adenina dinucleotídeo (FAD) e flavina adenina mononucleotídeo (FMN), a riboflavina participa de reações de oxi-redução que estão envolvidas em diversos processos celulares, tais como transporte de elétrons; metabolismo de lipídios, drogas e xenobióticos; sinalização celular e enovelamento de proteínas. Devido a seu importante papel no metabolismo, as deficiências de riboflavina são inicialmente evidentes nos tecidos que possuem rápida regeneração, como pele e epitélios. As manifestações da deficiência de riboflavina incluem glossite, estomatite angular, dermatite e manifestações oculares ${ }^{56}$. Apesar da deficiência de riboflavina ser conhecidamente endêmica entre populações que apresentam baixo consumo de laticínios e carnes, dados do The National Diet and Nutrition Survey no Reino Unido são surpreendentes. A proporção de indivíduos que apresentaram baixo status de riboflavina foi de $59 \%$ dos meninos entre 4 e 6 anos, $78 \%$ dos meninos entre 7 e 10 anos e 95\% das meninas entre 15 e 18 anos. O status de riboflavina correlacionou-se significativamente com o consumo alimentar. Além disso, foi verificada importante redução do consumo de leite (rica fonte de riboflavina) com o aumento da idade entre meninos e meninas, sendo que entre as meninas de 15 a 18 anos o leite contribuiu apenas com $10 \%$ da ingestão diária de riboflavina ${ }^{57}$. 
tNiacina e ácido pantotênico são vitaminas ainda pouco estudadas. A niacina atua como nicotinamida adenina dinucleotídeo oxidada (NADH), nicotinamida adenina dinucleotídeo reduzida (NADH) e componente das coenzimas do nucleotídeo de piridina, os quais são essenciais em todas as células para a produção de energia. As principais fontes alimentares de niacina são carnes magras, carnes de aves, peixes e amendoim; leites e ovos contêm pequenas quantidades, mas são excelentes fontes de triptofano e fornecem quantidades suficientes de niacina equivalente. Os sintomas iniciais de deficiência de niacina incluem fraqueza muscular, anorexia, indigestão e erupções cutâneas, enquanto a deficiência grave leva à pelagra ${ }^{56}$. Estudos com modelos animais têm demostrado instabilidade genômica em resposta a deficiência de niacina e modelos experimentais de câncer, saúde da pele, doenças pulmonares e doenças hepáticas têm sido utilizados para a investigação dos benefícios da suplementação ${ }^{58}$. O ácido pantotênico é parte integrante da coenzima A, que é essencial para a produção de energia a partir de macronutrientes, e de proteínas carreadoras, que são utilizadas nas reações de síntese. Como é amplamente distribuído nos alimentos, sua deficiência é rara e tem sido observada apenas em indivíduos gravemente subnutridos. Os sintomas incluem parestesia na sola e nos dedos dos pés, sensações de queimação nos pés, depressão, fadiga, insônia e fraqueza ${ }^{56}$.

As deficiências de folato e das vitaminas metabolicamente relacionadas, dentre elas vitamina B6 e vitamina B12, são consideradas um fator de risco para doenças cardiovasculares, defeitos do tubo neural, problemas cognitivos e alguns tipos de cânceres devido a sua participação como cofatores em diversas vias metabólicas, como o ciclo da metionina, entre outras ${ }^{59}$. Essas vitaminas também são fatores chave no crescimento e desenvolvimento por seu papel na replicação do DNA, e, portanto, importantes na infầncia e adolescência ${ }^{60}$. A manutenção de um status ideal de folato, vitamina B6 e vitamina B12 nessas fases da vida é necessária para a prevenção de complicações por deficiências de longo-prazo, tal como anemia ${ }^{61}$. Curiosamente, Barnabé et al. ${ }^{62}$, ao avaliarem as concentrações plasmáticas de folato e vitamina B12 de crianças de 0 a 6 anos no município de Campinas - SP, não encontraram casos de deficiência. Ao contrário, na Europa onde a fortificação de alimentos com folato não é obrigatória, adolescentes avaliados no HELENA Study apresentaram 15\% de prevalência de deficiência de folato; meninas que foram avaliadas de acordo com a referência para mulheres adultas apresentaram $71 \%$ de prevalência da deficiência. Esse estudo ainda verificou $2 \%$ de prevalência de deficiência de vitamina B12 e 5\% de prevalência de deficiência de vitamina B6 63. Morris et al. ${ }^{64}$, ao avaliarem crianças e adolescentes, menores de 13 anos e participantes do National Health and Nutrition Examination Survey (NHANES) 2003-2004, encontraram 24\% de prevalência de deficiência de vitamina B6. 
Entre os macronutrientes, os lipídios têm recebido grande atenção nos últimos anos, com diversas investigações relacionadas aos tipos de lipídios e seus efeitos metabólicos específicos. Os ácidos graxos poli-insaturados (PUFA) ômega-3 têm sido intensivamente estudados em relação à prevenção e ao tratamento de doenças cardiovasculares ${ }^{65-67}$. Os efeitos protetores desses ácidos graxos, especialmente do ácido graxo eicosapentaenoico (EPA) e do ácido graxo docosahexaenóico (DHA), podem ser parcialmente devidos às suas ações imunomoduladoras e anti-inflamatórias ${ }^{68,69}$. Apesar de menos intensivamente estudado, o efeito benéfico do ácido graxo $\alpha$-linolênico (ALA) nas doenças cardiovasculares tem sido comparado ao efeito de EPA e DHA ${ }^{70}$. Esse dado é importante visto que o ALA é encontrado em linhaça, óleo de linhaça, óleo de canola, nozes, entre outros alimentos, sendo essas fontes mais acessíveis financeiramente e de maior distribuição global do que as fontes marinhas de EPA e DHA. Ainda sobre doenças cardiovasculares, por décadas as recomendações médicas e nutricionais promoveram a mensagem para diminuição do consumo de ácidos graxos saturados. A recomendação se baseia no fato de que a maioria dos ácidos graxos saturados são capazes de elevar as lipoproteínas de baixa densidade (LDL-c), o que poderia aumentar o risco para doenças cardiovasculares e, assim, justificar a investigação do consumo de suas fontes alimentares ${ }^{71}$. No entanto, diversas revisões sistemáticas e meta-análises têm falhado em demonstrar uma relação direta entre consumo de gorduras saturadas e maior prevalência de eventos cardiovasculares ou, ainda, maior prevalência de diabetes tipo 2 e maior risco de morte 72-76. Alguns resultados demonstraram que a substituição parcial da gordura saturada por gorduras poli-insaturadas reduz a ocorrência de eventos cardiovasculares ${ }^{73,76}$, enquanto a substituição por carboidratos pode ter efeito contrário ${ }^{76}$.

Em outras áreas de estudo, o consumo de EPA e DHA têm sido associados ao desenvolvimento fetal adequado e à melhor função cognitiva ${ }^{77}$. Resultados ainda inconclusivos, porém promissores, têm sido encontrados para a associação entre o consumo de EPA e DHA e a redução do risco de doenças ósseas ${ }^{78}$ e de alguns tipos de cânceres tais como câncer de mama ${ }^{79}$ e colo retal ${ }^{80}$.

Conforme descrito, crianças e adolescentes apresentam elevadas prevalências de consumo inadequado de nutrientes e, consequentemente, estão em risco de deficiências nutricionais, o que pode repercutir na incidência de doenças. Assim, com a finalidade de promover a alimentação saudável e de identificar padrões alimentares de crianças e adolescentes, torna-se necessário o desenvolvimento de ferramentas que permitam avaliar e identificar a qualidade da dieta com maior confiabilidade. 


\subsection{Métodos de Avaliação do Consumo Alimentar}

É consenso entre experts que não há método considerado ideal para a avaliação do consumo alimentar, e sim o mais adequado para cada situação ${ }^{81}$. A definição do método a ser utilizado depende do tipo de informação dietética necessária (ingestão de nutrientes vs. grupos alimentares, consumo individual vs. populacional, ingestão absoluta vs. relativa, avaliação sobre comportamentos alimentares específicos etc.), do período de consumo alimentar a ser investigado e do grau necessário de acurácia do método ${ }^{82}$. Devem ser consideradas também as características dos entrevistados e a disponibilidade de recursos financeiros, tempo e local para a realização do inquérito ${ }^{81,82}$.

O consumo alimentar pode ser avaliado por diferentes métodos. Os métodos quantitativos visam determinar a quantidade de energia e nutrientes ingeridos, os quais podem ser utilizados para posterior comparação com as necessidades nutricionais, a depender especificamente do instrumento utilizado. Quando o interesse consiste em identificar padrões e hábitos alimentares, técnicas dietéticas e outras características da alimentação, os métodos são denominados qualitativos ${ }^{83,84}$.

Os inquéritos dietéticos ainda são a maneira mais utilizada para a obtenção de informações sobre o consumo alimentar. Entre eles, destacam-se o Recordatório de 24 horas (R24hs), o Registro Alimentar (RA) e o QFA.

O R24hs é aplicado na forma de entrevista. O entrevistado é solicitado a lembrar de todos os alimentos e bebidas consumidos nas últimas 24 horas ou no dia anterior e a reportálos com detalhes (variedade do alimento, a forma de preparo e seu tamanho de porção). $\mathrm{O}$ inquérito precisa ser conduzido por entrevistadores treinados e que tenham conhecimentos sobre os tipos de alimentos disponíveis na região e suas técnicas de preparo. As vantagens do R24hs são a rápida aplicação, a possibilidade de ser utilizado para qualquer faixa etária e nível de escolaridade e a não alteração do consumo alimentar, pois os dados coletados são retrospectivos $81,82,85$.

O RA, também conhecido como diário alimentar, consiste de formulários previamente estruturados nos quais devem ser anotados todos os alimentos e bebidas consumidos ao longo de um ou mais dias. A porção dos alimentos pode ser estimada, pesada ou registrada através de fotos. Os avaliados precisam ser adequadamente orientados sobre a forma correta de preenchimento dos formulários de modo que forneçam a maior quantidade possível de detalhes sobre sua alimentação. Na devolução desses, é desejável que haja conferência na presença do 
avaliado para a complementação de descrições inadequadas quanto aos itens consumidos e suas quantidades e aos alimentos possivelmente esquecidos ou ignorados. Uma das principais vantagens do RA é que ele independe de memória. No entanto, sua utilização pode interferir no padrão alimentar, necessita que o indivíduo seja alfabetizado e requer tempo e alto nível de motivação, já que o resultado dependerá de cooperação do avaliado ${ }^{81,82,85}$.

Tanto o R24hs como o RA obtêm informações da dieta atual. Quando corretamente aplicados e respondidos, proporcionam boa acurácia na avaliação do consumo alimentar ${ }^{86}$. Porém, se aplicados por apenas um dia podem refletir uma dieta atípica; e mesmo poucos dias podem ser insuficientes para a correta estimativa de alguns micronutrientes ${ }^{82,87}$.

Segundo McPherson et al. ${ }^{88}$, especialmente no grupo de crianças e adolescentes, as aplicações repetidas de instrumentos para avaliação do consumo alimentar têm sua utilização limitada devido à tendência ao seu baixo nível de motivação e cooperação. Erros de relato ou omissão de alimentos podem ocorrer, pois é difícil conhecer todos os ingredientes de uma preparação, principalmente quando essa é preparada e consumida fora do lar ${ }^{89}$.

A fim de verificar a validade do RA e do R24hs para a estimativa do consumo energético de crianças e adolescentes, alguns autores utilizam o gasto energético total (GET) estimado por água duplamente marcada como método de referência (ideal quando o indivíduo possui peso estável). Bratteby et al. ${ }^{90}$ e Champagne et al. ${ }^{91}$ avaliaram adolescentes com médias de idade de 11,1 e 15,0 anos, respectivamente, e verificaram que múltiplos RAs subestimaram o consumo energético em 13,0 a 41,3\% do GET. Em contrapartida, Lindquist et al. ${ }^{92}$ concluíram que dois R24hs são válidos para estimar o consumo energético de crianças entre 6 e 11 anos de idade. Além do método e técnica utilizada, a idade, o estado nutricional e os fatores cognitivos, comportamentais e sociais influenciam a acurácia da estimativa do consumo alimentar de crianças e adolescentes ${ }^{93-96}$.

Ao contrário do RA e do R24hs, o QFA avalia a dieta pregressa e considera a exposição por longos períodos aos fatores dietéticos. Apesar de apresentar conceitos gerais, sua construção é específica para a população estudada ${ }^{97}$. O QFA foi o método utilizado no presente estudo para a estimativa do consumo alimentar e tem suas características detalhadas a seguir (seção 3.2.1).

\subsubsection{Questionário de frequência alimentar}


O instrumento precursor dos atuais QFAs foi desenvolvido em 1947 por Bertha Burke no Harvard's Department of Nutrition. A fim de classificar a ingestão dos indivíduos e associála com a ocorrência de doenças, Burke coletou dados dietéticos através de um R24hs, de um RA de três dias e de uma lista de alimentos pré-estabelecidos para a investigação do consumo alimentar dos últimos 28 dias ${ }^{98}$.

Em 1961, um grupo de pesquisadores britânicos concluiu que a frequência exerce mais influência sobre o consumo de nutrientes do que o tamanho da porção, estabelecendo assim uma base teórica consistente para a avaliação dietética através da frequência alimentar ${ }^{99}$.

Segundo Willett ${ }^{97}$, vários pesquisadores desenvolveram e utilizaram QFAs durante as décadas de 1960 e 1970, principalmente para estudos sobre a incidência de câncer. No entanto, foi durante as décadas de 1980 e 1990 que os instrumentos foram aprimorados, com foco em validade e reprodutibilidade, através da comparação com R24hs, medidas bioquímicas e capacidade de predizer a incidência de doenças. Em geral, os novos QFAs obtiveram uma melhora na correlação com os métodos de referência ${ }^{100}$. Desde então, esses instrumentos têm sido intensivamente utilizados em estudos epidemiológicos ${ }^{97}$.

Os QFAs constituem-se, basicamente, em listas estruturadas de alimentos comumente consumidos pela população alvo, organizados em grupos alimentares (tais como carnes, frutas, vegetais etc.), e de uma seção na qual o indivíduo é orientado a responder com que frequência (nunca, uma vez ao mês etc.) consumiu cada item alimentar ao longo de um período préestabelecido (um mês, seis meses, um ano etc.) ${ }^{97,101,102}$.

A composição da lista de alimentos de um QFA varia em função do objetivo da avaliação e pode não avaliar o consumo total ${ }^{103}$. A sua construção pode ser feita a partir de um banco de alimentos proveniente de inquéritos alimentares anteriores ou a partir de tabelas de composição de alimentos ${ }^{104}$. Os alimentos selecionados devem estar de acordo com os hábitos da população, serem consumidos por um número importante de indivíduos e apresentarem consumo variável de pessoa para pessoa, bem como o nutriente de interesse ${ }^{97}$. Se o nutriente estudado estiver relacionado à energia total ou se o objetivo da avaliação for estratificar os indivíduos de acordo com o nível de consumo, a lista de alimentos deve ser ampla ${ }^{104,105}$. Uma lista de alimentos com 50 a 100 itens é considerada adequada para não tornar o procedimento cansativo e, ao mesmo tempo, ser capaz de mensurar o consumo alimentar ${ }^{81}$. QFAs que visam mensurar um nutriente específico ou um grupo de alimentos, tal como vitamina A, ácidos graxos EPA e DHA ou frutas e verduras, podem ser mais curtos. A extensão do QFA também é influenciada por características da população alvo e pelo número de outros questionários que o indivíduo deverá preencher na avaliação ${ }^{101}$. 
A frequência de consumo do QFA é registrada em unidades de tempo: dias, semanas, meses, semestres ou anos, podendo contemplar ou não o fracionamento destas unidades. $\mathrm{O}$ detalhamento das escalas de frequência contribui para a capacidade informativa do instrumento. Um grande número de possibilidades é capaz de distinguir categorias de indivíduos, tais como aqueles que consomem determinado alimento apenas uma vez por semana, mesmo que isso não seja representativo no consumo total de nutrientes ingeridos ${ }^{104}$. As opções de frequência devem ser estabelecidas em um gradiente crescente ou decrescente, variando entre cinco a dez opções ${ }^{97}$.

Em relação ao período de investigação do consumo alimentar, a unidade de tempo mais utilizada é o ano precedente, uma vez que este contém um ciclo completo de estações e as dietas se correlacionam ano a ano. No entanto, os aspectos fisiológicos da doença estudada ou do fator dietético analisado são determinantes para a escolha da unidade de tempo ${ }^{104}$.

Além da lista de alimentos e da frequência de consumo, o QFA poderá conter uma seção referente ao tamanho da porção consumida. No caso dessa seção estar ausente, o QFA é denominado qualitativo, ou seja, visa apenas identificar os tipos de alimentos consumidos e sua frequência. Quando possui porções de referência para a estimativa do consumo de energia e de nutrientes, o QFA é denominado semiquantitativo. Por fim, o QFA é denominado quantitativo quando o tamanho da porção é descrito pelo entrevistado em uma questão aberta ${ }^{106}$.

O tamanho das porções dos alimentos deve refletir o padrão de consumo da população estudada; enquanto o número de opções deve ser em quantidade suficiente para que indivíduos com uma mesma frequência de consumo, mas diferentes tamanhos de porções, possam ser distinguidos adequadamente ${ }^{101,107}$. O uso de porções de referência aplicadas igualmente a todos os indivíduos simplifica o questionário, mas reduz a sensibilidade do instrumento se o tamanho variar na mesma população ${ }^{108}$. Por outro lado, as questões abertas demandam maior tempo para a aplicação do QFA e podem induzir a erros de codificação e transcrição e aumentar o número de questionários rejeitados por questões incompletas ou de difícil interpretação. A decisão por incluir ou não uma porção de referência dependerá da disponibilidade de dados sobre o tamanho médio das porções, da variabilidade do tamanho das porções na população e da capacidade da população para informar com precisão o tamanho das porções consumidas ${ }^{101}$.

O QFA é considerado um método prático e informativo de avaliação do consumo alimentar habitual de indivíduos ou grupos populacionais, pois contém informações globais da ingestão alimentar referente a um amplo período em substituição à avaliação do consumo de alguns dias específicos, podendo assim contemplar variações sazonais (quando aplicado para seis meses ou mais) e intra-semanais ${ }^{97,104,106}$. Além disso, os resultados padronizados são úteis 
para estratificar e ordenar os indivíduos de acordo com o grau de exposição ta um determinado fator dietético, bem como para realizar análises de tendência e de diferença entre níveis extremos de ingestão ${ }^{85,97,109}$. Essas características, associadas à aplicação relativamente rápida em grandes amostras e com baixo custo, tornam o QFA um método apropriado para estudos epidemiológicos que envolvem a avaliação do consumo alimentar ${ }^{81,104}$.

No entanto, o QFA é um método de menor acurácia quando comparado ao RA e $24 \mathrm{hs}$ 85,86. As limitações são resultantes de listas incompletas de alimentos, erros na estimativa dos tamanhos das porções e da frequência de consumo, bem como da memória do entrevistado. Esses fatores podem levar a resultados subestimados ou superestimação do consumo alimentar, o que impede o uso direto da medida dietética em análises de riscos ${ }^{103}$.

Os hábitos alimentares variam enormemente ao longo dos anos e de acordo com etnia, cultura, situação econômica e faixa etária das populações, entre outros fatores. Portanto, cada novo instrumento deve ser validado separadamente na população objeto de estudo, mesmo que esse seja majoritariamente baseado em um questionário anterior, pois informações incorretas podem levar a falsas associações entre fatores dietéticos e marcadores e/ou ocorrência de doenças ${ }^{101,107}$.

\subsection{2 Índices de qualidade da dieta}

Em epidemiologia nutricional, a abordagem dominante no passado, em que se verificava a simples associação entre consumo de nutrientes e prevenção ou risco de doenças, é repleta de vieses devido à complexidade da dieta humana ${ }^{110}$. Os indivíduos não consomem apenas nutrientes isolados, mas uma combinação de alimentos constituídos de nutrientes e outros compostos bioativos com potenciais sinérgicos e antagônicos ${ }^{111}$. Nesse contexto, instrumentos de avaliação global da dieta, tais como os índices dietéticos, têm surgido como uma alternativa para avaliar a associação entre consumo alimentar e desfechos em saúde por considerar simultaneamente um conjunto de características dietéticas ${ }^{5}$.

Índices dietéticos são sistemas de pontuação que sintetizam em apenas uma variável quantitativa as características do consumo alimentar. Os diversos componentes do índice são quantificados e somados a fim de fornecerem uma medida geral da qualidade da dieta de indivíduos ou de populações ${ }^{112}$. 
Ao longo do tempo, diversos índices dietéticos têm sido propostos: índices baseados em nutrientes, índices baseados em alimentos ou grupos de alimentos e índices que combinam nutrientes, alimentos ou grupos de alimentos e variedade da dieta, os quais permitem a avaliação global da alimentação ou de seus itens ${ }^{112}$. Os índices dietéticos atuais são caracterizados pelos atributos de proporcionalidade (porções estipuladas para grupos de alimentos), moderação (limitação da ingestão excessiva de alimentos e nutrientes com potencial efeito prejudicial à saúde) e variedade (exposição a diversos alimentos), tendo em vista a prevenção de doenças crônicas não transmissíveis ${ }^{6}$.

Segundo o estudo de revisão publicado por Kourlaba e Panagiotakos ${ }^{110}$, até 2008 a maioria dos índices dietéticos foi desenvolvida para avaliar a dieta de adultos e construída com base em diretrizes / recomendações dietéticas oficiais ou no padrão alimentar mediterrâneo. Alguns instrumentos foram amplamente utilizados, tais como o Healthy Eating Index (HEI) ${ }^{113}$, o Diet Quality Index (DQI) ${ }^{114}$, o Healthy Diet Indicator (HDI) ${ }^{115}$ e o Mediterranean Diet Scale (MDS) ${ }^{116}$. A partir de adaptações destes índices para a realidade de cada local, diversos outros foram criados ${ }^{110}$.

A fim de avaliar os principais índices dietéticos e suas aplicações, Wirt e Collins ${ }^{117}$ também publicaram um estudo de revisão e, segundo os autores, os principais índices existentes entre 2004 e 2007 eram o HEI ${ }^{113}$, o HDI ${ }^{115}$, o DQI ${ }^{114}$, o MDS ${ }^{116}$, o Healthy Food Index (HFI) ${ }^{118}$, o Recommended Food Score (RFS) ${ }^{119}$ e o Diet Quality Score (DQS) ${ }^{120}$.

Marshall et al. ${ }^{121}$ publicaram uma revisão sistemática com o objetivo de sumarizar os índices dietéticos utilizados ou desenvolvidos especificamente para a população pediátrica até 2013. Identificaram 80 diferentes instrumentos em 119 estudos, sendo que a maioria destes foi publicada a partir de 2005 ( $n=89$ estudos), com 44 estudos publicados a partir de 2010. Entre os 80 instrumentos identificados, 15 foram desenvolvidos na América do Norte, 27 na Europa, 17 na Ásia, 8 na América Latina, 12 na África, e um em local não mencionado. No Brasil, a revisão sistemática identificou o uso do HEI em duas versões com subescalas modificadas para características alimentares locais ${ }^{122,123}$. Além desses estudos nacionais, uma nova busca em bibliotecas eletrônicas identificou o uso do Child Feeding Index (CFI) ${ }^{124}$, do Recommended Food Score (RFS) ${ }^{125}$, do Índice de Qualidade da Dieta para Pré-Escolares ${ }^{126,127}$, do Índice de Alimentação do Escolar (Ales) ${ }^{128,129}$ e do IQD-R ${ }^{8-12}$.

O primeiro índice dietético para a avaliação global da dieta foi desenvolvido por Patterson et al. ${ }^{114}$, em 1994, e denominado Diet Quality Index (DQI). O DQI foi baseado nas recomendações do National Research Council ${ }^{130}$, de 1989, e possui oito componentes, sendo seis relacionados a nutrientes (gordura total, gordura saturada, colesterol, proteína, cálcio e 
sódio) e dois relacionados a grupos de alimentos (frutas e hortaliças e cereais e leguminosas). A pontuação para cada componente varia entre zero (ingestão atinge a recomendação dietética), um (ingestão atinge parcialmente a recomendação dietética) e dois (ingestão muito distante da recomendação dietética). A pontuação final do DQI varia de zero (dieta de excelente qualidade) a 16 pontos (dieta de má qualidade). Apesar de ter sido desenvolvido especificamente para adultos, há relato de seu uso em crianças ${ }^{121}$.

Outro índice dietético que permite a avaliação global da dieta é o Healthy Eating Index (HEI), proposto por Kennedy et al. ${ }^{113}$. O HEI foi desenvolvido com base nas recomendações da pirâmide alimentar ${ }^{131}$ e do guia alimentar ${ }^{132}$ norte-americanos para ser aplicado à população maior de dois anos de idade. A partir de sua publicação, em 1995, o HEI passou a ser utilizado pelo U.S. Department of Agriculture para avaliar e monitorar as modificações da dieta nacional 113 .

Em 2008, o HEI-1995 foi revisado e validado devido às novas recomendações nutricionais para a população norte-americana, originando o HEI-2005 ${ }^{133}$. Mais recentemente, o HEI passou por novo processo de revisão e validação, transformando-se em HEI-2010, para atender as recomendações do Guia Alimentar para Norte-Americanos, de $2010{ }^{134,135}$. Este índice dietético pode ser utilizado para o desenvolvimento e monitoramento de ações de promoção à saúde, atividades de educação nutricional, planejamento e avaliação de intervenções nutricionais e dietéticas, estudos epidemiológicas e avaliação da relação entre custo e qualidade da dieta ${ }^{135}$.

O HEI-2010 possui doze componentes, sendo que nove avaliam a adequação da dieta (frutas totais; frutas inteiras; vegetais totais; vegetais verde-escuros, alaranjados e leguminosas; cereais integrais; leite e derivados; proteínas totais; frutos do mar e proteínas vegetais e ácidos graxos) e três referem-se a itens da dieta que devem ser consumidos com moderação (cereais refinados, sódio e calorias vazias - energia de gorduras sólidas, álcool e açúcar de adição). A pontuação do HEI-2010 varia de zero a 100 pontos, sendo que maiores valores representam melhor qualidade da dieta ${ }^{135}$.

Guenther et al. ${ }^{134}$ além de validarem o HEI-2010 também reavaliaram a validade e confiabilidade do HEI-2005 utilizando os mesmos métodos utilizados para a avaliação do HEI2010. Os autores concluíram que ambos os instrumentos são sensíveis o suficiente para detectar diferenças na qualidade de dieta entre os indivíduos da população, bem como suas modificações ao longo do tempo. Assim, a versão mais recente não invalida a versão anterior, a qual pode ser mais apropriada para determinados tipos de estudos como intervenções nutricionais, pois podem refletir melhor as recomendações dietéticas dadas aos participantes. 


\subsubsection{1 Índice de Qualidade da Dieta Revisado (IQD-R)}

Em 2004, Fisberg et al. ${ }^{136}$, em 2004, adaptaram e validaram o HEI-1995 para a população brasileira, o qual denominaram Índice de Qualidade da Dieta (IQD). Destaca-se que não foi realizada a tradução literal dos termos, a qual seria "Índice de Alimentação Saudável". Portanto, deve-se ter claro que esse instrumento não é uma adaptação do DQI. O IQD avaliou cinco componentes baseados em grupos de alimentos (cereais, pães, tubérculos e raízes; verduras e legumes; frutas; leite e produtos lácteos; carnes e ovos) a partir das recomendações da Pirâmide Alimentar Brasileira e considerou a variedade da dieta baseada em dados coletados pelo próprio estudo. Para a avaliação dos componentes baseados em nutrientes (gordura total, gordura saturada, colesterol e sódio) foram mantidas as referências norte-americanas. A pontuação do IQD varia de zero a 100 pontos, sendo que maiores valores representam melhor qualidade da dieta.

A partir da publicação do Guia Alimentar para a População Brasileira em $2006{ }^{137}$, surgiu a necessidade de atualização do IQD para refletir as novas recomendações nutricionais. Assim, Previdelli et al. ${ }^{7}$, em 2011, considerando como modelo a versão do HEI-2005 e as recomendações do Guia Alimentar para a População Brasileira, da OMS ${ }^{138}$, do Institute of Medicine ${ }^{139}$ e da Sociedade Brasileira de Cardiologia ${ }^{140}$, desenvolveram o IQD-R para a população brasileira.

O IQD-R possui 12 componentes, dentre eles nove são baseados no consumo de grupos de alimentos que caracterizam uma dieta saudável ou de melhor qualidade: (1) Frutas Totais (inclui todos os tipos de frutas e sucos de frutas), (2) Frutas Inteiras (inclui todos os tipos de frutas e exclui os sucos de frutas), (3) Vegetais Totais e Leguminosas (inclui todos os tipos de vegetais e as leguminosas somente depois que a pontuação do grupo carnes e ovos for atingida), (4) Vegetais Verde-Escuros, Alaranjados e Leguminosas (inclui somente os vegetais de cor verde-escuro ou alaranjados e as leguminosas depois que a pontuação do grupo carnes e ovos for atingida); (5) Cereais Totais (representa o grupo dos cereais, raízes e tubérculos), (6) Cereais Integrais (inclui grãos inteiros e preparações à base de farinhas integrais), (7) Leite e Derivados (inclui leite e seus derivados e bebidas à base de soja); (8) Carnes, Ovos e Leguminosas e (9) Óleos (inclui todos os óleos vegetais e gorduras mono e poli-insaturadas de peixes e oleaginosas); dois são baseados no consumo de nutrientes: (10) Gordura Saturada e (11) Sódio; e um é baseado no consumo de nutrientes e itens dietéticos: (12) Gord_AA, que representa as calorias provenientes de gordura sólida, álcool e açúcar de adição; sendo que os componentes 
gordura saturada, sódio e Gord_AA devem ter seu consumo limitado por caracterizarem uma dieta não saudável ou de pior qualidade ${ }^{7}$.

A pontuação do IQD-R varia de zero a 100 pontos. Para todos os componentes baseados em grupos de alimentos a pontuação máxima é atribuída para a ingestão no nível recomendado ou superior e a pontuação mínima representa a ausência de consumo. Os componentes que requerem consumo limitado (gordura saturada, sódio e Gord_AA) são pontuados de maneira inversa, ou seja, atingem a pontuação máxima quando há ausência de consumo ou consumo menor ou igual a recomendação. Dessa forma, tanto para a pontuação total quanto para a pontuação dos componentes, maiores pontuações refletem melhor qualidade da dieta ${ }^{7}$.

O peso da pontuação de um componente determina o quão importante este é em relação aos demais ${ }^{141}$. De maneira geral, os grupos de alimentos do IQD-R são pontuados de zero a dez, o que significa que todos são igualmente importantes. Apesar de frutas, verduras e cereais possuírem dois componentes cada um (total e subgrupo), a cada componente é atribuído o valor máximo de cinco pontos, o que resulta em uma pontuação efetiva de 10 pontos para cada grupo de alimentos. Ao componente Gord_AA é atribuído valor máximo de 20 pontos, como se esse fosse duas vezes mais importante que os demais. De acordo com os idealizadores do instrumento original (HEI-2005), a ênfase se justifica pelo fato de que as gorduras sólidas, as bebidas alcoólicas e o açúcar de adição adicionam energia à dieta sem adição de nutrientes, podem deslocar o consumo de alimentos ricos em nutrientes e atualmente são consumidos em quantidades superiores às recomendações ${ }^{141}$.

O cálculo do IQD-R é realizado com base em densidade energética e avalia a adequação da ingestão considerando o número de porções ou o percentual calórico de um determinado nutriente e/ou item dietético por $1.000 \mathrm{Kcal}^{7}$. Dessa forma, a qualidade da dieta é avaliada independentemente da quantidade de energia ingerida. Por ser um indicador qualitativo, o IQD$\mathrm{R}$ não avalia diretamente a quantidade de energia, mas devido à natureza quantitativa da variável pode ser utilizado para associar a qualidade da dieta a desfechos epidemiológicos relacionados com o consumo energético, tal como o índice de massa corporal (IMC) ${ }^{142}$

O IQD-R pode ser utilizado para avaliar a qualidade da dieta em nível individual ou populacional. Pode ser também aplicado nas diversas fases da vida, excluindo-se lactentes, visto que foi desenvolvido de acordo com as recomendações do Guia Alimentar para a População Brasileira $^{7,137}$.

Em 2013, Andrade et al. ${ }^{142}$ realizaram um estudo metodológico do IQD-R e concluíram que o instrumento é confiável e estruturalmente válido para avaliar e monitorar a qualidade da dieta dos brasileiros de acordo com as principais recomendações do Ministério da Saúde. No 
entanto, os autores apontam como limitação do estudo a não comparação do IQD-R a um instrumento referência que avalie a qualidade da dieta, tal como ocorreu para o HEI-2005 a partir das recomendações oficiais baseadas em cardápios. Assim, sugerem que marcadores bioquímicos podem servir como método referência para alguns componentes baseados em nutrientes.

\subsubsection{Marcadores bioquímicos do consumo alimentar}

Nos últimos anos, a dosagem de marcadores bioquímicos (biomarcadores) no sangue e outros tecidos corporais tem sido comumente utilizada como determinante do estado nutricional geral ${ }^{101}$. No entanto, atualmente cresce o número de estudos que pretendem identificar biomarcadores relacionados ao consumo de nutrientes, alimentos e grupos alimentares.

A principal vantagem do uso de biomarcadores para a avaliação do consumo alimentar é que os erros medidos por esse não têm relação com os erros medidos pelos métodos tradicionais. Por exemplo, os biomarcadores não dependem da memória do indivíduo e de tabelas de composição nutricional ${ }^{4}$. Além disso, muitos biomarcadores fornecem uma medida mais próxima do estado nutricional para alguns nutrientes do que os dados de ingestão dietética, particularmente em estudos cujo desfecho de interesse possa alterar o hábito ou a informação sobre o consumo alimentar ${ }^{14}$.

No entanto, a utilização dos biomarcadores como método referência em estudos de validação de métodos de avaliação do consumo alimentar deve considerar alguns aspectos limitantes, tais como a variação interindividual nos processos de absorção e metabolização para a maioria dos nutrientes, a influência de processos fisiológicos como ciclo circadiano e ciclo menstrual, a flutuação nas concentrações plasmáticas devido à ingestão irregular do nutriente e o erro técnico associado às medições laboratoriais. A consequência de todas essas variações para os estudos de validação é a redução dos coeficientes de correlação entre as medidas de consumo alimentar e os biomarcadores. Ainda assim, a existência de tais correlações oferece evidência quase inquestionável de validação ${ }^{4}$. A concentração de nutrientes em fluidos corporais e tecidos também pode ser influenciada por herança genética, tabagismo, obesidade, atividade física, doenças, entre outros; fatores esses que devem ser controlados sempre que possível ${ }^{143}$. 
Outro aspecto importante a ser considerado em estudos de validação com biomarcadores é a sua relação temporal com o consumo alimentar. Os biomarcadores podem ser categorizados em de curto prazo (refletem a ingestão de horas ou dias), de médio prazo (refletem a ingestão de semanas ou meses) e de longo prazo (refletem a ingestão de meses ou anos); sendo o tipo de amostra coletada a principal determinante da relação temporal com o consumo alimentar. Assim, por exemplo, o plasma e o soro seriam mais adequados para analisar a ingestão recente de nutrientes do que amostras de cabelo e unha ${ }^{14}$.

São três as possíveis abordagens para a medida de biomarcadores: a) medida direta da concentração do nutriente ou seu produto metabólico em tecidos ou fluido; b) análise funcional de atividade de enzimas específicas ou produtos derivados do nutriente relacionado com a ingestão alimentar e c) concentração de nutriente no sangue ou urina pouco antes e em intervalos após administração de uma dose conhecida do nutriente a ser validado ${ }^{144}$.

Concentrações plasmáticas de retinol, $\beta$-caroteno e $\alpha$-tocoferol são sensíveis à ingestão alimentar atual ${ }^{145,146}$ e têm sido sugeridos como biomarcadores da exposição a nutrientes

antioxidantes ${ }^{147-149}$, apresentando boa correlação com o consumo de frutas e vegetais ${ }^{150-154}$. Freisiling et al. ${ }^{155}$ desenvolveram um índice de frequência alimentar a partir de um QFA para o qual verificaram, além de correlações positivas entre a melhor qualidade da dieta e a maior concentração de carotenoides ( $\beta$-caroteno, $\beta$-criptoxantina, zeaxantina, e luteína), uma correlação positiva com a concentração plasmática de 25-hidroxivitamina D.

\subsection{Validação de Métodos de Avaliação do Consumo Alimentar}

O termo validade refere-se ao grau com que um instrumento mede aquilo que se propõe a medir, seja um valor absoluto, índice ou indicador ${ }^{156}$. Diz-se, então, que uma medição é validada quando está livre de erros sistemáticos 4 .

Em estudos de validação, o consumo de alimentos ou de nutrientes estimado pelo método a ser testado é comparado com outro método de avaliação dietética, julgado superior, apesar de sempre imperfeito, e considerado o padrão-ouro ${ }^{4}$. Esse tipo de estudo tem por objetivo quantificar os erros de medição, através de parâmetros estatísticos, em modelos que especificam relações entre a estimativa do consumo e seu valor supostamente verdadeiro ${ }^{13}$. Dessa forma, o processo de validação descreve os erros de medição e não o instrumento do qual 
derivam as medidas. Portanto, a validação considera o contexto no qual o instrumento será utilizado ${ }^{107}$.

Métodos de avaliação do consumo alimentar desenvolvidos para caracterizar a dieta habitual de indivíduos, tais como o QFA, são difíceis de serem validados, pois o consumo verdadeiro nunca é absolutamente conhecido. Devido à ausência de um método referência, a validação do instrumento é considerada relativa ${ }^{4,156}$. Ainda que se busque como método referência o melhor substituto para a ingestão verdadeira, o estudo de validação indica apenas se ambos os instrumentos utilizados fornecem ou não respostas relacionadas. Se há discordância entre os métodos, não é possível identificar qual está correto ${ }^{101}$. Assim, considerando que não existe método perfeito para a avaliação do consumo alimentar, é necessário que se escolha como referência aquele que apresente erros não relacionados ao método a ser testado ${ }^{4,101,157}$.

Entre os métodos mais utilizados como referência para a validação de QFAs estão o RA e o R24hs. Destes, o RA possui a menor quantidade de erros relacionados ao QFA, pois suas questões são abertas em vez de uma lista fixa de alimentos, não depende da memória, permite a estimativa direta do tamanho da porção e minimiza os erros relacionados à interpretação da frequência de consumo ${ }^{4}$. No entanto, o RA pode levar o indivíduo a não relatar todos os alimentos consumidos e/ou a mudar seu consumo consciente ou inconscientemente a partir da conhecimento de que está sendo observado ${ }^{101}$. Esta última consequência, denominada efeito Hawthorne, deve ser amplamente evitada em pesquisa científica pois pode levar a conclusões inesperadas e errôneas ${ }^{158}$. Embora o R24hs exija menos dos entrevistados e seja incapaz de interferir na dieta dos indivíduos, suas fontes de erro tendem a ser mais relacionadas às fontes de erro do QFA (dependência de memória, estimativa do tamanho das porções e distorção da dieta relatada). Porém, em indivíduos com baixa escolaridade e pouca cooperativos o R24hs pode ser mais apropriado que o RA ${ }^{4}$.

Em um estudo de revisão, Cade et al. ${ }^{101}$ observaram que $75 \%$ das validações de QFA utilizaram como referência algum método baseado em relato dos indivíduos. Destes, 51\% utilizaram o RA (25\% RA pesado e $26 \%$ RA estimado) e 22\% utilizaram o R24hs. Apenas 19\% utilizaram biomarcadores como método referência.

A fim de superar as limitações de RA e R24hs como métodos referência, os biomarcadores têm sido cada vez mais utilizados para a validação de QFAs. Até 2009, 26,6\% dos estudos com adultos e $15,2 \%$ dos estudos com crianças e adolescentes que validaram QFAs para a estimativa do consumo de vitaminas e minerais haviam utilizado biomarcadores ${ }^{159,160}$. A principal vantagem dessa abordagem é que os erros medidos pelos biomarcadores não têm relação com os erros medidos pelos métodos baseados em relatos de indivíduos ${ }^{4}$. 
Biomarcadores também têm sido utilizados para a validação da qualidade da dieta total e do consumo de grupos alimentares específicos, tais como frutas e vegetais ${ }^{161,162}$.

No caso da utilização de biomarcadores com método referência, esses devem refletir o consumo usual em um período de tempo determinado para a aplicação do método teste ${ }^{14}$. Caso os métodos comparados se refiram a diferentes períodos de consumo, discrepâncias podem ser esperadas entre os dados ${ }^{105}$. Quando há disponibilidade de mais de uma dosagem do biomarcador para o período de consumo alimentar investigado, Willett e Lenart ${ }^{4}$ sugerem que a correção para a variabilidade intrapessoal pode melhorar os coeficientes de correlação entre os métodos teste e referência.

Em estudos de validação os participantes deverão refletir as características da população para o qual o instrumento a ser validado se destina ${ }^{101}$. No entanto, é necessário certo grau de heterogeneidade na amostra (por exemplo, diferenças de sexo, condição socioeconômica, estado nutricional, tabagismo etc.); caso contrário, o QFA pode ter sua validade externa reduzida ${ }^{163}$.

Para avaliar a eficácia dos métodos de avaliação do consumo alimentar, diversos procedimentos estatísticos têm sido utilizados em estudos de validação. Estudiosos da área sugerem o uso de mais de uma técnica para garantir a robustez do processo de validação, o que proporciona também uma visão global da avaliação ${ }^{101,164}$.

Na validação de métodos de avaliação do consumo alimentar através de biomarcadores, as unidades de medidas comparadas são diferentes. Portanto, para esta situação, a comparação de médias, a análise da diferença entre médias e a plotagem dos dados de acordo com a metodologia Bland e Altman não são procedimentos úteis. Tais análises são restritas aos processos de validação que utilizam como referência outros métodos baseados na estimativa do consumo alimentar.

As correlações ainda são as medidas estatísticas mais utilizadas e devem ser apresentadas, na medida do possível, ajustadas para diferentes variáveis, principalmente energia ingerida, idade e sexo ${ }^{163}$. Na validação com biomarcadores, as correlações com as medidas de consumo alimentar frequentemente são bastante modestas e variam de 0,3 a 0,5 , ainda que as medidas dietéticas sejam altamente acuradas e precisas. Entre os fatores que contribuem para os baixos coeficientes de correlação estão as imperfeições nos instrumentos de avaliação, os erros técnicos na medição dos biomarcadores, as variações diárias ou controle homeostático do biomarcador de acordo com o nível de ingestão e outros determinantes não dietéticos ${ }^{4,165}$. No entanto, estes valores de correlação fornecem evidência útil e objetiva para a validade do consumo avaliado por um instrumento dietético ${ }^{165}$. 
Outro recurso utilizado em estudos de validação de métodos de avaliação do consumo alimentar é a concordância entre categorias (tercis, quartis etc.) de consumo e de biomarcadores. A análise é feita pela porcentagem de indivíduos classificados na mesma categoria, em categorias adjacentes ou categorias opostas (erro bruto) ${ }^{101}$.

De acordo com Block e Hartman ${ }^{166}$, correlações e categorias avaliam de forma eficaz, pois consideram o grau de ingestão individual. 


\section{OBJETIVOS}

\subsection{Objetivo Geral}

Validar, através de biomarcadores, um Questionário Semiquantitativo de Frequência Alimentar e seu respectivo Índice de Qualidade da Dieta Revisado para crianças e adolescentes, de 9 a 13 anos de idade, do município de Ribeirão Preto - SP.

\subsection{Objetivos Específicos}

a) Descrever e associar a estimativa de ingestão de nutrientes de um Questionário Semiquantitativo de Frequência Alimentar a biomarcadores de vitaminas lipossolúveis, vitaminas hidrossolúveis e ácidos graxos.

b) Descrever e associar os componentes do Índice de Qualidade da Dieta Revisado, gerado por um Questionário Semiquantitativo de Frequência Alimentar, a biomarcadores de vitaminas lipossolúveis, vitaminas hidrossolúveis, ácidos graxos e creatina. 


\section{MÉTODOS}

\subsection{Inserção do Estudo}

Esta dissertação está vinculada a uma pesquisa mais abrangente intitulada "Nova Estratégia para Analisar Interação Gene-Nutriente em Crianças e Adolescentes”, cujo nome fantasia é "Brazil Micronutrient Project". A citada pesquisa foi realizada no município de Ribeirão Preto - SP, entre os anos de 2013 e 2014, e trata-se de um estudo do tipo ensaio clínico N-of-1. Neste tipo de ensaio clínico, os sujeitos são submetidos a períodos de intervenção e de washout, sendo, portanto, analisados como seus próprios controles. Para todos os participantes da pesquisa foram avaliados dados dietéticos, antropométricos e metabólicos no momento basal (T1), após seis semanas de suplementação de vitaminas e minerais (T2) e após seis semanas de washout (T3).

A pesquisa foi executada pelo Departamento de Puericultura e Pediatria da Faculdade de Medicina de Ribeirão Preto da Universidade de São Paulo (FMRP-USP), sob coordenação da Professora Jacqueline Pontes Monteiro, e com o apoio científico do Dr. James Kaput e sua equipe (Head of Translational Unit - Nestlé Institute of Health Science, Lausanne, Switzerland). O financiamento foi recebido da Fundação de Amparo à Pesquisa do Estado de São Paulo (FAPESP), através do processo 12/20421-8, e do Nestlé Institute of Health Sciences.

\subsection{Delineamento e População}

O desenho desta dissertação pode ser definido como observacional, transversal e de caráter analítico. Somente os dados coletados no T1 do Brazil Micronutrient Project foram utilizados para as presentes análises.

A população estudada compreende todos os indivíduos incluídos no Brazil Micronutrient Project e foi composta por crianças e adolescentes, de 9 a 13 anos de idade, matriculados em duas escolas públicas (Escola Estadual Professor Rafael Leme Franco e Escola Estadual Professor Walter Ferreira) e uma particular (Colégio Viktor Frankl) da zona oeste do município de Ribeirão Preto - SP. 


\subsection{Amostra e Amostragem}

A técnica de amostragem utilizada foi a não probabilística. Para o recrutamento dos participantes, inicialmente foram contatadas cinco escolas da região, através de seus diretores e coordenadores, porém, somente as três citadas acima concordaram em participar da pesquisa. Após a autorização das escolas, a equipe organizadora da pesquisa realizou atividades de avaliação do estado nutricional das crianças e dos adolescentes e reuniões foram realizadas com os pais dos alunos para fornecer os resultados referentes aos seus filhos. As reuniões incluíram explicações sobre os objetivos, procedimentos e critérios de inclusão da pesquisa e, logo após, foi realizado o convite aos pais para a participação dos alunos. Os interessados deveriam comparecer à FMRP-USP para o T0, em data agendada.

\subsubsection{Critérios de Inclusão e Não-Inclusão}

Foram incluídos na pesquisa somente crianças e adolescentes de 9 a 13 anos, 11 meses e 29 dias de idade, sem diagnóstico prévio de doença, clinicamente estável e que apresentaram consentimento de seus pais ou responsáveis legais. A avaliação clínica foi realizada por pediatra.

Os critérios para não inclusão no estudo foram: estar em uso de suplementação de vitaminas e/ou minerais, estar em seguimento de dieta supervisionada para redução de peso ou qualquer outro tipo de dieta, ter apresentado pelo menos um episódio de temperatura axilar $>37^{\circ} \mathrm{C}$ nos últimos 15 dias e ter apresentado três ou mais episódios de fezes líquidas ou semilíquidas nas últimas 24 horas.

\subsubsection{Tamanho Amostral}

A figura 1 descreve o fluxograma de inclusão dos participantes nas análises desta dissertação. Compareceram ao T0 do Brazil Micronutrient Project 151 indivíduos em 2013 e 149 indivíduos em 2014. Destes, 139 e 141 foram incluídos na pesquisa nos anos de 2013 e 
2014 , respectivamente, totalizando uma amostra de 280 participantes. Todos compareceram ao $\mathrm{T} 1$.

O Brazil Micronutrient Project prevê uma amostra de replicação, ou seja, parte das crianças e adolescentes participantes do estudo em 2013 deveria ser submetida novamente à intervenção e à coleta de dados em 2014. Sendo assim, 70 participantes de 2013 apresentaramse novamente em 2014 para o estudo. Considerando que fatores genéticos podem influenciar as concentrações de biomarcadores, a amostra de replicação foi excluída das análises estatísticas desta dissertação. Dessa forma, evita-se reforçar o efeito genético nas análises de associação entre consumo alimentar e biomarcadores.

Sabe-se que há uma tendência em subestimar e superestimar a ingestão entre participantes de estudos sobre consumo alimentar. Assim, foram considerados outliers relacionados ao sub ou super-relato e excluídos das análises estatísticas os indivíduos que relataram consumo alimentar menor que $0,79 \times$ taxa metabólica basal (TMB) ou maior que 2,4 x TMB, respectivamente ${ }^{151,167}$. A TMB foi estimada de acordo com as equações propostas por Schofield ${ }^{168}$, para idade e sexo. Após a exclusão dos casos de sub e super-relato do consumo alimentar, os dados de 177 participantes foram considerados adequados para as análises estatísticas. No entanto, devido às perdas durante as análises laboratoriais, a amostra final variou de 119 a 172 indivíduos, a depender do biomarcador analisado.

Segundo Serra-Majem et al. ${ }^{163}$, quando os biomarcadores são o método de referência, um tamanho amostral maior que 50 é considerado suficiente para estudos de validação de QFA. Esse número é capaz de determinar se um coeficiente de correlação de 0,39 difere de zero, com nível de significância de 5\% e poder estatístico de $80 \%{ }^{169}$. 


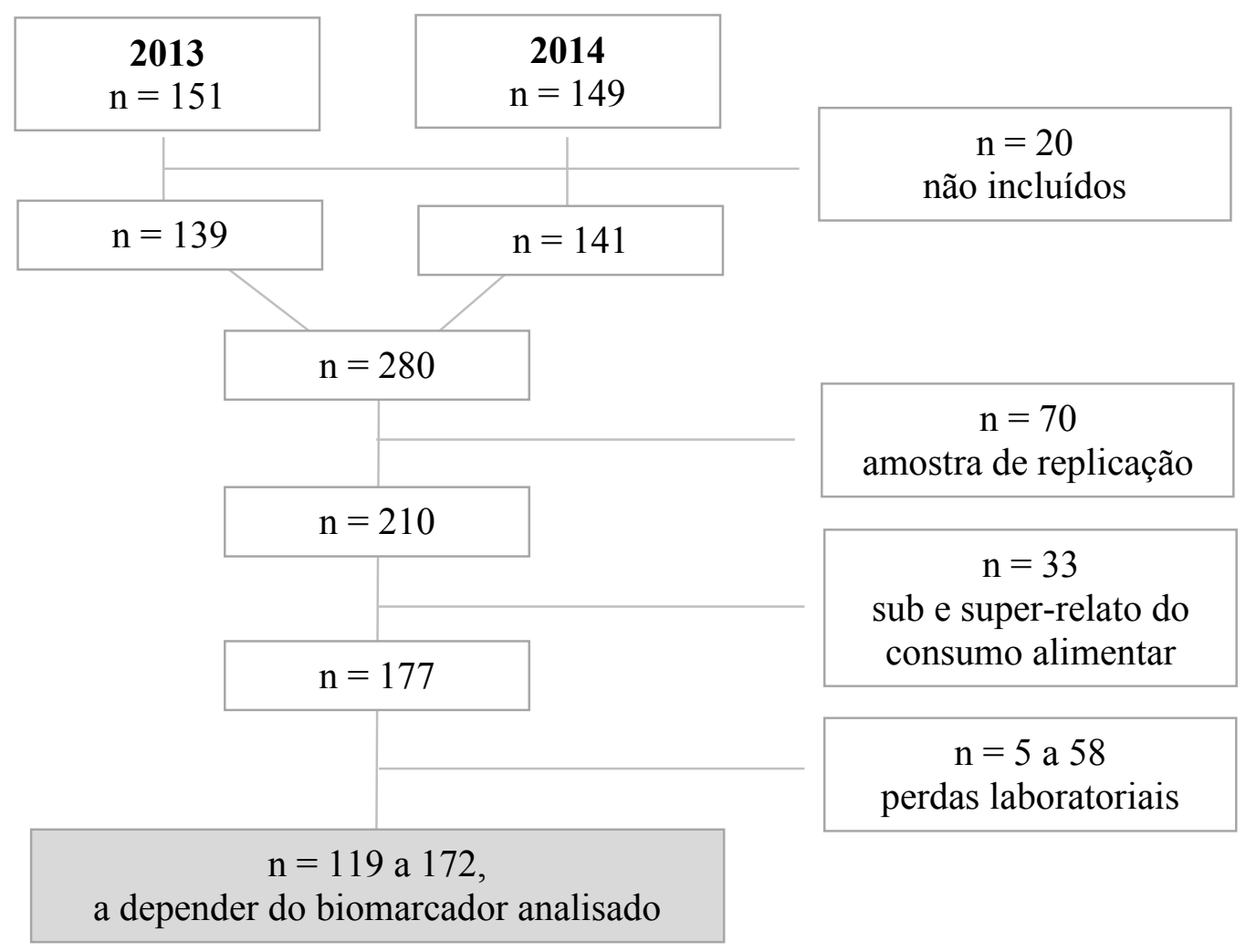

Figura 1 - Fluxograma de inclusão dos participantes no estudo.

\subsection{Instrumentos e Técnicas para Coleta e Análise de Dados}

A coleta dos dados do Brazil Micronutriente Project ocorreu entre março de 2013 e junho de 2014, nas dependências da FMRP-USP, em dois momentos, conforme descritos abaixo:

- T0 - Inclusão dos participantes na pesquisa, preenchimento do questionário auto aplicado intitulado "Critério de Classificação Econômica Brasil”" (ANEXO C) ${ }^{170}$ para avaliação da condição socioeconômica dos participantes e obtenção de assinaturas para os termos de consentimento e assentimento.

- T1 - Encontro realizado quinze dias após o T0 para a realização da avaliação do consumo alimentar, da avaliação antropométrica e da coleta de sangue.

\subsubsection{Consumo Alimentar}




\subsubsection{Ingestão de Energia e Nutrientes}

O consumo alimentar foi aferido por QSFA previamente validado para crianças de 5 a 10 anos de idade (ANEXO B) ${ }^{171}$. A primeira versão do QSFA foi proposta por Ribeiro e Cardoso ${ }^{172}$ e desenvolvida para uma população adulta do estado de São Paulo $(n=212)$ com médias de idade de 45,4 e 43,4 anos para homens e mulheres, respectivamente. A lista de alimentos foi elaborada a partir de um QFA validado para adultos de uma comunidade nipobrasileira, excluindo-se os alimentos de origem japonesa, e avaliada pela contribuição percentual de energia e nutrientes em relação ao consumo total estimado por R24hs ${ }^{173}$. Os tamanhos das porções foram determinados de acordo com a distribuição percentual dos pesos correspondentes às medidas caseiras referidas no R24hs e classificados em pequeno, médio e grande (percentis 25, 50 e 75). Fumagalli et al. ${ }^{171}$ validaram, então, esse mesmo QSFA para crianças de 5 a 10 anos de idade pela aplicação de três R24hs. Após ajuste para energia e variabilidade intrapessoal, os coeficientes de correlação variaram de 0,15 para sódio a 0,81 para cálcio, sendo que $83 \%$ dos nutrientes apresentaram coeficiente de correlação de 0,2 a 0,6.

O QSFA contém 64 itens alimentares; questões sobre a ingestão habitual de gordura visível das carnes, o tipo de gordura utilizada no preparo das refeições, a frequência do consumo de produtos do tipo light e o fracionamento da dieta; e uma questão sobre outros alimentos habitualmente consumidos que não constam na lista pré-definida.

O QSFA foi aplicado na forma de entrevista por alunos de graduação e pós-graduação previamente treinados. A aplicação do inquérito alimentar ocorreu na presença dos pais ou responsáveis legais para que o relato da ingestão alimentar dos participantes fosse feito com maior confiabilidade ${ }^{174}$. Foi solicitado aos participantes que fornecessem as informações referentes ao consumo alimentar do último mês: frequência usual de consumo de cada item alimentar (quantas vezes) com a respectiva unidade de tempo (se diariamente, semanalmente ou mensalmente) e tamanho da porção habitual (pequena, média ou grande). Um álbum fotográfico com as porções dos alimentos do QSFA foi utilizado a fim de minimizar o viés de memória e melhorar a qualidade da informação sobre o tamanho das porções referidas ${ }^{175}$.

Os cálculos para a conversão das frequências de consumo em quantidades diárias foram realizados em planilhas no Microsoft Office Excel ${ }^{\circledR}$, versão 2010. A opção de frequência "uma vez por dia" foi codificada como " 1 " e as demais opções foram proporcionalmente associadas à unidade de tempo. Por exemplo, para os itens que foram consumidos "2 vezes por semana", a frequência diária foi de 0,28 (estimada pela razão $2 / 7$ dias) ${ }^{176}$. Após a determinação desses 
escores, os mesmos foram multiplicados pelo peso da porção alimentar indicada pelo participante para a determinação da quantidade diária ingerida, em gramas. Os alimentos sazonais foram considerados em sua totalidade para a estimativa da quantidade diária ingerida, uma vez que a aplicação do QSFA foi referente apenas ao último mês de consumo e o objetivo do estudo é avaliar a associação entre consumo alimentar e biomarcadores.

A quantidade diária ingerida de cada alimento, em gramas, foi inserida no software Nutrition Data System for Research (NDSR) ${ }^{\circledR}$, versão $2015{ }^{177}$ para a estimativa da ingestão de energia e de nutrientes. O NDSR contém a compilação de dados das tabelas de composição de alimentos do Departamento de Agricultura dos Estados Unidos, de diversas tabelas de composição de alimentos estrangeiras, de publicações científicas e de informações de fabricantes. Quando as preparações não estavam disponíveis no NDSR, as receitas foram padronizadas e cadastradas.

Todos os dados de consumo alimentar inseridos em planilhas do Microsoft Office Excel ( ) e no software NDSR foram duplamente checados a fim de evitar digitação incorreta.

\subsubsection{Qualidade da Dieta}

O IQD-R foi calculado a partir dos dados de consumo alimentar coletados por meio do QSFA. O cálculo foi realizado no software Stata ${ }^{\circledR}$ (versão 13.0) ${ }^{178}$ de acordo com a metodologia proposta pelo Grupo de Pesquisa de Avaliação do Consumo Alimentar e descrita a seguir ${ }^{7,179}$. Para isso, e a partir do relatório de ingredientes gerado pelo NDSR, todos os alimentos e ingredientes de preparações do QSFA foram classificados em seu grupo alimentar correspondente (APÊNDICE A).

Para o cálculo dos componentes baseados no consumo de grupos de alimentos (Frutas Totais; Frutas Inteiras; Vegetais Totais e Leguminosas; Vegetais Verdes-Escuros e Alaranjados e Leguminosas (Veveal); Cereais Totais; Cereais Integrais; Leite e Derivados e Carnes, Ovos e Leguminosas), o número de porções diárias recomendadas de cada componente por 1.000 kcal foi definido mantendo-se a correspondência com a preconização do Guia Alimentar para a População Brasileira ${ }^{137}$. Para isso, foi aplicada a seguinte equação: [(valor total de kcal do componente x 1.000) / valor energético total (VET)] / Kcal de uma porção no guia alimentar. A pontuação máxima (cinco ou 10 pontos) foi atribuída para a ingestão maior ou igual às porções recomendadas dos componentes por $1.000 \mathrm{kcal}$ e a pontuação mínima (zero pontos) foi 
atribuída para a ausência de ingestão. Os valores intermediários foram calculados proporcionalmente à quantidade consumida. O quadro 1 resume os critérios da pontuação total e por componentes do IQD-R ${ }^{7}$.

Uma vez que os componentes Frutas Inteiras, Veveal e Cereais Integrais não possuem recomendações específicas no guia alimentar, esses foram calculados proporcionalmente aos componentes Frutas Totais, Vegetais Totais e Leguminosas e Cereais Totais, respectivamente. Por exemplo, o valor energético de uma porção de frutas e sucos de frutas no Guia Alimentar para a População Brasileira é $70 \mathrm{Kcal}$ e recomenda-se o consumo de 1,5 porções por 1.000 Kcal. Assim, determinou-se como consumo ideal a ingestão de 1,0 (70 kcal) e 0,5 (35 Kcal) porções de Frutas Totais e Frutas Inteiras, respectivamente, para cada 1.000 kcal ingeridas. $\mathrm{O}$ valor energético correspondente aos componentes Frutas Inteiras, Veveal e Cereais Integrais também são computados no cálculo dos seus respectivos grupos totais ${ }^{7}$.

A pontuação do componente Carnes, Ovos e Leguminosas foi calculada pela soma do valor energético de carnes e ovos com o valor energético de leguminosas até completar a pontuação máxima $(190 \mathrm{kcal}=1$ porção $=10$ pontos $)$. Valores energéticos excedentes de leguminosas no grupo de Carnes, Ovos e Leguminosas foram computados simultaneamente nos grupos Vegetais Totais e Leguminosas e Veveal. Assim, caso o valor energético de carnes e ovos fosse o suficiente para ultrapassar $190 \mathrm{Kcal}$ (1 porção), o valor energético das leguminosas era integralmente computado nos grupos Vegetais Totais e Leguminosas e Veveal ${ }^{7}$.

Conforme mencionado, o IQD-R pressupõe que o valor energético proveniente de leguminosas e que esteja excedente no grupo Carnes, Ovos e Leguminosas seja incluído simultaneamente nos grupos Vegetais Totais e Leguminosas e Veveal. No entanto, considerando que um dos objetivos do presente estudo é correlacionar a dosagem de biomarcadores específicos às pontuações dos componentes do IQD-R, optou-se por apresentar também as pontuações dos componentes de vegetais sem a inclusão do excedente de leguminosas. Esses componentes modificados foram denominados Vegetais Totais sem Leguminosas e Veveal sem Leguminosas.

Os componentes baseados no consumo de nutrientes incluem o sódio e a gordura saturada. A pontuação do componente Sódio foi calculada com base na recomendação do Institute of Medicine ${ }^{139}$, o qual propõe uma Ingestão Adequada (AI) de 1,5 g de sódio, e com base em uma dieta de 2.000 kcal proposta pelo Guia Alimentar para a População Brasileira ${ }^{137}$. Assim, a pontuação máxima (10 pontos) foi conferida ao consumo de $0,75 \mathrm{~g} / 1.000 \mathrm{Kcal}$, a pontuação intermediária ( 8 pontos) ao consumo de 1.0 g/ 1000 Kcal (valor máximo de consumo 
estipulado pelo guia alimentar) e a pontuação mínima (zero pontos) ao consumo de $2,0 \mathrm{~g} / 1.000$ Kcal (dobro do valor máximo de consumo estipulado pelo guia alimentar) ${ }^{7}$.

O cálculo do componente Gordura Saturada foi realizado a partir da contribuição em gramas de gordura saturada, transformada em Kcal e em percentual de contribuição no VET, de acordo com a seguinte equação: [(gordura saturada $(\mathrm{g})$ x 9) / VET] x 100. A pontuação máxima (10 pontos), baseada nas Diretrizes sobre Dislipidemia e Prevenção de Aterosclerose da Sociedade Brasileira de Cardiologia ${ }^{140}$, foi conferida ao consumo $\leq 7 \%$ do VET. A pontuação intermediária ( 8 pontos), baseada nas recomendações da OMS ${ }^{138}$, foi conferida ao consumo que representasse $10 \%$ do VET. E, por fim, a pontuação mínima (zero pontos) foi conferida ao consumo $\geq 15 \%$ do $\operatorname{VET}^{7}$.

Os componentes baseados no consumo de nutrientes e itens dietéticos incluem os óleos, oleaginosas, gordura de peixe e as calorias provenientes da gordura sólida, álcool e açúcar de adição (Gord_AA). O cálculo do componente Óleos foi realizado com base na porção recomendada dos grupos Óleos, Gorduras e Sementes do Guia Alimentar para a População Brasileira ${ }^{137}$. Atribuiu-se pontuação máxima (10 pontos) para o consumo de 0,5 porções / 1.000 $\mathrm{Kcal}^{7}$.

Considerando-se que não há recomendações específicas para a ingestão do componente Gord_AA no Guia Alimentar para a População Brasileira, os valores de consumo correspondentes aos percentis 16 e 85 da população avaliada para o desenvolvimento do método foram considerados para o estabelecimento das pontuações mínima e máxima, respectivamente ${ }^{7}$. Para tanto, foram necessárias as conversões descritas a seguir:

- Gorduras $(\mathrm{Kcal})=[$ gordura saturada $(\mathrm{g})+$ gordura trans $(\mathrm{g})]$ x 9 Kcal

- Etanol $($ Kcal $)=$ álcool $(\mathrm{g}) \times 7$ Kcal

- Açúcar / carboidratos de bebidas alcóolicas $(\mathrm{Kcal})=$ carboidrato $(\mathrm{g})$ x $4 \mathrm{Kcal}$

- Açúcar de adição (kcal) = açúcar adicionado (g) x 4 Kcal

A soma das calorias provenientes de todos os nutrientes e itens dietéticos do componente Gord_AA foi convertida em percentual calórico do VET. A pontuação máxima (20 pontos) foi atribuída a um valor $\leq 10 \%$ do VET e a pontuação mínima (zero pontos) a um valor $\geq 35 \%$ do $\operatorname{VET}^{7}$.

A pontuação total do IQD-R foi obtida pela soma de todos os componentes originais do método. Os componentes Vegetais Totais sem Leguminosas e Veveal sem Leguminosas não foram incluídos na pontuação final, pois tratam-se de versões modificadas dos componentes do instrumento original. $\mathrm{O}$ valor mínimo de zero pontos representa a dieta de pior qualidade e valor máximo de 100 pontos representa a dieta de melhor qualidade ${ }^{7}$. 
Quadro 1 - Critérios de pontuação total e por componentes do Índice de Qualidade da Dieta Revisado.

\begin{tabular}{|c|c|c|c|c|}
\hline \multirow{2}{*}{ Componente } & \multicolumn{3}{|c|}{ Pontuação } & \multirow{2}{*}{ Critérios de pontuação } \\
\hline & Mínima & Intermediária & Máxima & \\
\hline Frutas totais $^{\text {a }}$ & 0 & - & 5 & $\begin{array}{l}\text { 0: não consumo } \\
\text { 5: } 1,0 \text { porção / } 1.000 \mathrm{Kcal}\end{array}$ \\
\hline Frutas inteiras ${ }^{b}$ & 0 & - & 5 & $\begin{array}{l}\text { 0: não consumo } \\
\text { 5: } 0,5 \text { porção / } 1.000 \mathrm{Kcal}\end{array}$ \\
\hline $\begin{array}{l}\text { Vegetais totais e } \\
\text { leguminosas }\end{array}$ & 0 & - & 5 & $\begin{array}{l}\text { 0: não consumo } \\
\text { 5: } 1,0 \text { porção / } 1.000 \mathrm{Kcal}\end{array}$ \\
\hline Veveal $^{\mathrm{d}}$ & 0 & - & 5 & $\begin{array}{l}\text { 0: não consumo } \\
\text { 5: } 0,5 \text { porção / } 1.000 \mathrm{Kcal}\end{array}$ \\
\hline Cereais totais ${ }^{\mathrm{e}}$ & 0 & - & 5 & $\begin{array}{l}\text { 0: não consumo } \\
5: 2,0 \text { porção / } 1.000 \mathrm{Kcal}\end{array}$ \\
\hline Cereais integrais ${ }^{f}$ & 0 & - & 5 & $\begin{array}{l}\text { 0: não consumo } \\
5: 1,0 \text { porção / } 1.000 \mathrm{Kcal}\end{array}$ \\
\hline Leite e derivados $\mathrm{g}$ & 0 & - & 10 & $\begin{array}{l}0: \text { não consumo } \\
10: 1,5 \text { porção / } 1.000 \mathrm{Kcal}\end{array}$ \\
\hline $\begin{array}{l}\text { Carnes, ovos e } \\
\text { leguminosas }\end{array}$ & 0 & - & 10 & $\begin{array}{l}\text { 0: não consumo } \\
\text { 10: } 1,0 \text { porção / } 1.000 \mathrm{Kcal}\end{array}$ \\
\hline Gordura saturada & 0 & 8 & 10 & $\begin{array}{l}0: \geq 15 \% \text { do VET } \\
8:=10 \% \text { do VET } \\
10: \leq 7 \% \text { do VET }\end{array}$ \\
\hline Sódio & 0 & 8 & 10 & $\begin{array}{l}0: \geq 2,0 \mathrm{~g} / 1.000 \mathrm{Kcal} \\
8:=1,0 \mathrm{~g} / 1.000 \mathrm{Kcal} \\
10: \leq 0,75 \mathrm{~g} / 1.000 \mathrm{Kcal}\end{array}$ \\
\hline Óleos ${ }^{\mathrm{h}}$ & 0 & - & 10 & $\begin{array}{l}0: \text { não consumo } \\
\text { 10: } 0,5 \text { porção / } 1.000 \mathrm{Kcal}\end{array}$ \\
\hline Gord_AA & 0 & - & 20 & $\begin{array}{l}0: \geq 35 \% \text { do VET } \\
20: \leq 10 \% \text { do VET }\end{array}$ \\
\hline Pontuação total & 0 & - & 100 & $\begin{array}{l}\text { 0: pior qualidade de dieta } \\
\text { 100: melhor qualidade de dieta }\end{array}$ \\
\hline
\end{tabular}

Gord_AA: calorias provenientes de gordura sólida, álcool e açúcar de adição; VET: valor energético total; Veveal: vegetais verde-escuros, alaranjados e leguminosas.

a inclui frutas e sucos de frutas naturais; ${ }^{b}$ exclui sucos de frutas naturais; ${ }^{c, d}$ inclui apenas o excedente de leguminosas depois que a pontuação máxima de carnes, ovos e leguminosas for atingida; ${ }^{\mathrm{e}}$ representa o grupo dos cereais, raízes e tubérculos; ${ }^{\mathrm{f}}$ inclui grãos inteiros e preparações à base de farinhas integrais, ${ }^{\mathrm{g}}$ inclui leite e derivados e bebidas à base de soja; ${ }^{\mathrm{h}}$ : inclui gordura total dos óleos vegetais e gorduras mono e poli-insaturadas de peixes e oleaginosas.

Fonte: Elaborado pela autora (2017). Adaptado de Previdelli et al. ${ }^{7}$. 


\subsubsection{Variáveis Antropométricas}

A aferição da massa corporal $(\mathrm{Kg})$ e da estatura $(\mathrm{m})$ foi realizada por estudantes de graduação em Nutrição e de pós-graduação, devidamente treinados, para o cálculo do IMC $\left(\mathrm{Kg} / \mathrm{m}^{2}\right)$. Todas as medidas foram aferidas após 12 horas de jejum e de acordo com os procedimentos detalhados por Jellife ${ }^{180}$ e pela OMS ${ }^{181}$. O IMC foi utilizado para a classificação do estado nutricional conforme as curvas de crescimento da OMS, a qual determina valores de percentis e escores-z (desvio padrão) para indivíduos de cinco a 19 anos. Com relação à classificação do IMC, as crianças e adolescentes foram considerados com magreza grave se índice de massa corporal para idade $(\mathrm{IMC} / \mathrm{I})<$ escore-z -3 , magreza se escore-z $-3 \leq \mathrm{IMC} / \mathrm{I}<$ escore-z -2 , eutrofia se escore- $z-2 \leq \mathrm{IMC} / \mathrm{I} \leq$ escore- $\mathrm{z}+1$, sobrepeso se escore- $\mathrm{z}+1<\mathrm{IMC} / \mathrm{I} \leq$ escore- $\mathrm{z}+2$, obesidade se escore- $\mathrm{z}+2<\mathrm{IMC} / \mathrm{I} \leq$ escore- $\mathrm{z}+3$ e obesidade grave se $\mathrm{IMC} / \mathrm{I}>$ escore- $Z+3^{182,183}$.

\subsubsection{Coleta de Sangue}

A coleta de sangue foi realizada por flebotomistas treinados na "Sala de Coleta de Sangue" do HCFMRP-USP, local com infraestrutura e segurança necessárias aos procedimentos efetuados. Tal procedimento oferece risco mínimo (Categoria 2; 45 CFR 46.110) e é rotineiramente realizado nesta instituição.

Para a coleta de sangue os participantes estavam em jejum de 12 horas. Foram coletados $4 \mathrm{~mL}$ em tubos com EDTA para a análise dos vitaminas e ácidos graxos, sendo as amostras protegidas da luz. Para a análise de metabolômica com ressonância magnética nuclear, uma amostra de $4 \mathrm{~mL}$ foi coletada em tubos com heparina. No local da coleta de sangue, as amostras foram centrifugadas para a separação do plasma, o qual foi congelado a $-80^{\circ} \mathrm{C}$. Em um prazo de 48 horas todas as amostras foram enviadas através do World Courier (World Courier do Brasil Transportes Internacionais Ltda, São Paulo, SP, Brasil) para o laboratório do Nestlé Institute of Health Sciences, Lausanne, Suíça, para a análise dos metabólitos.

A fim de garantir a correta identificação das amostras, todas foram codificadas no momento da coleta por um código de barras correspondente a cada participante. 


\subsubsection{Dosagem dos metabólitos}

$\beta$-caroteno, retinol e $\alpha$-tocoferol: Para a extração foi utilizado tubo Pyrex de $8 \mathrm{~mL}$ contendo $250 \mu \mathrm{L}$ de etanol com padrões internos (rac-tocol and trans- $\beta$-apo- 8 '-Carotenal); $200 \mu \mathrm{L}$ de plasma foram adicionados e então a mistura foi centrifugada. Após a adição de 250 $\mu 1$ de butanol : acetate etílico (1:1) e a sonicação, as amostras foram extraídas duas vezes com 2,5 $\mathrm{mL}$ de n-hexano com antioxidantes e posteriormente centrifugadas (2500 x g, $4 \mathrm{~min}$ ). As fases orgânicas foram combinadas, secas com nitrogênio e reconstituídas em $100 \mu 1$ de isooctane antes das análises. Para a análise cromatográfica, caroteno, retinol e $\alpha$-tocopherol foram separados pela injeção de $5 \mu 1$ de extrato em uma coluna Thermo Hypersil GOLD Silica, $1.9 \mu \mathrm{m}, 200$ x $2.1 \mathrm{~mm}$ à $35^{\circ} \mathrm{C}$ utilizando-se um gradiente lento de $\mathrm{n}$-hexano : dioxano. A série analítica durou 22 minutos, com registros de sinais fluorescentes a $\lambda_{E x}=325 \mathrm{~nm}$ e $\lambda_{\mathrm{Em}}=458 \mathrm{~nm}$ para retinol, $\lambda_{\mathrm{Ex}}=296 \mathrm{~nm}$ e $\lambda_{\mathrm{Em}}=330 \mathrm{~nm}$ para tocoferóis e absorbância visível de $\lambda_{\mathrm{abs}}=452 \mathrm{~nm}$ para $\beta$-caroteno.

Vitamina D: a dosagem de $25(\mathrm{OH}) \mathrm{D}_{3}$ foi realizada pela Vitas Analytical Services ${ }^{\circledR}$ (Oslo, Noruega). O ensaio foi baseado em cromatografia líquida de alta eficiência acoplada a espectrômetro de massas e interface de ionização química a pressão atmosférica. O limite de detecção é 1-4 nmol/L. Os coeficientes de variação inter-ensaio são 7.6\% para a concentração de $47,8 \mathrm{nmol} / \mathrm{L}$ de $25(\mathrm{OH}) \mathrm{D}_{3}$ e $6.9 \%$ para $83,0 \mathrm{nmol} / \mathrm{L}$.

Vitaminas B1, B2, B3, B5, B6 e derivados: tiamina, riboflavina, niacina, ácido pantotênico, piridoxina e seus derivados foram analisados utilizando-se método publicado ${ }^{184}$. Brevemente, uma alíquota de $100 \mu \mathrm{L}$ de plasma foi transferida para um frasco de vidro ambarizado ou Eppenddorf para extração. Após adição de isótopos padronizados, as proteínas foram precipitadas com metanol acidificado. Após a centrifugação o sobrenadante foi coletado e evaporado sob uma corrente de azoto. As amostras foram então reconstituídas em soluções apropriadas para análises cromatográficas. Todas as vitaminas foram analisadas por cromatografia líquida de alta eficiência em fase reversa (RP-UHPLC) com espectrometria de massa (MS) operando em Positive Electrospray Ionization (ESI+), à resolução unitária.

5 metil-tetrahidrofolato (5 Me-THF): a dosagem de 5 Me-THF foi realizada conforme método publicado ${ }^{184}$. Para a extração, uma alíquota de $200 \mu \mathrm{L}$ alíquota de plasma foi transferida 
para uma placa Waters $\mathrm{OSTRO}^{\mathrm{TM}}$. Após adição de isótopos padronizados, as proteínas foram precipitadas com metanol acidificado e as amostras foram filtradas na placa para a remoção de proteínas fosfolipídios. O filtrado foi recolhido em uma placa de 96 poços e evaporado sob corrente de azoto. As amostras foram então reconstituídas em soluções apropriadas para análises cromatográficas. 5 Me-THF foi analisado por cromatografia líquida de alta eficiência em fase reversa (RP-UHPLC) com espectrometria de massa (MS) operando em Positive Electrospray Ionization (ESI+), à resolução unitária. A faixa analítica foi 0,5-150 nmol/L, com erros de calibração inferiores a 5\%. A precisão foi igual a 100\% $\pm 10 \%$ em três níveis da faixa analítica. As variações foram inferiores a 10\% para nível de $5 \mathrm{nMol} / \mathrm{L}$ e inferiores a $5 \%$ para níveis de $40 \mathrm{nmol} / \mathrm{L}$ e $100 \mathrm{nmol} / \mathrm{L}$.

Vitamina B12 (cobalamina total) e folato (folato total) por ELISA: a análise foi realizada pela Vitas Analytical Services ${ }^{\circledR}$ (Oslo, Noruega). (vitas.no) utilizando-se AM-396 e MonoBind ELISA (Folate/Vitamin B12 Anemia Panel VAST test system, Monobind, Lake Forest, CA 92630, USA). Uma alíquota de $50 \mu \mathrm{L}$ de Folate Enzyme Reagent foi adicionada e a placa foi agitada suavemente por 20-30 segundos. Uma alíquota de $100 \mu \mathrm{L}$ de soro/plasma humano foi pré-tratada com um agente de extração para liberar os derivados de folato das proteínas ligadoras de folato e, então, $50 \mu \mathrm{L}$ foram pipetados em uma placa revestida com estreptavidina.

Para o folato, $50 \mu \mathrm{L}$ de Folate Enzyme Reagent foram adicionados e a placa foi agitada suavemente por 20-30 segundos. Uma alíquota de $50 \mu \mathrm{L}$ de Folate Biotin Reagent foi então adicionada a todos os poços, a placa foi agitada suavemente por 20-30 segundos e, então, incubada por 45 minutos em temperatura ambiente. Uma reação de competição ocorre entre uma proteína de ligação específica, um conjugado enzima-antígeno e um antígeno nativo. Após a lavagem, $100 \mu \mathrm{L}$ de substrato reagente foram adicionados a todos os poços e a placa foi incubada à temperatura ambiente por 20 minutos, antes de $50 \mu \mathrm{L}$ de uma solução para parar a reação ser adicionada. Posteriormente, a placa foi suavemente agitada e lida a 450nm.

Para a vitamina B12, $50 \mu \mathrm{L}$ de Vitamin B12 Biotin Reagent foram adicionados, a placa foi agitada suavemente por 20-30 segundos e, então foi incubada por 45 minutos a temperatura ambiente. Após a incubação, uma alíquota de $50 \mu \mathrm{L}$ de Vitamin B12 Enzyme Reagent foi adicionada, a placa foi agitada suavemente por 20-30 segundos e, então, incubada por 30 minutos em temperatura ambiente. Uma reação de competição ocorre entre um anticorpo, um conjugado enzima-antígeno e um antígeno nativo. Após a lavagem, $100 \mu \mathrm{L}$ de substrato reagente foram adicionados a todos os poços e a placa foi incubada à temperatura ambiente por 
20 minutos, antes de $50 \mu \mathrm{L}$ de uma solução para parar a reação ser adicionada. Posteriormente, a placa foi suavemente agitada e lida a $450 \mathrm{~nm}$.

Creatina: a análise foi realizada em espectrômetro Bruker Avance III $600 \mathrm{MHz}$ com um CPTCI de 5mm a $300 \mathrm{~K}$ (Bruker Biospin, Rheinstetten, Alemanha). A atribuição de picos a metabólitos específicos foi realizada utilizando uma biblioteca de compostos na literatura e confirmada por ressonância magnética nuclear (NMR) padrão bidimensional (JRES, TOCSY, HSQC, HMBC) em amostras selecionadas. Para as análises estatísticas, foram convertidos todos os espectros NMR em pontos de dados $12 \mathrm{~K}$ na faixa de $\delta 0,4$ - 10,0 e então importados para o software MATLAB versão 7.14.0 (R2012a; The MathWorks Inc., Natick, MA), excluindo o resíduo de água (água $\delta=4,67-4,97$ ).

Ácidos graxos eritrocitários: $200 \mathrm{ul}$ de eritrócitos peletizados foram adicionados a 200 ul de tampão de lise, misturados dez vezes e então congelados a $-80^{\circ} \mathrm{C}$. O tampão de lise era (NH4Cl 1,5 M, 120 mM NaHCO3 10 mM EDTA 292,2 mg / mL). As amostras descongeladas foram processadas de acordo com o protocolo descrito por Massod et al. ${ }^{185}$. Os ácidos graxos derivados de éster metílico foram analisados por cromatografia gás-líquido (GLC) conforme previamente descrito ${ }^{186}$.

\subsection{Análise Estatística}

Inicialmente, o teste de Kolmogorov-Smirnov e a representação gráfica foram utilizados para avaliar a normalidade dos dados, os quais são descritos por medidas de tendência central, dispersão e frequências relativas e absolutas.

A diferença de médias de VET e IQD-R total entre os sexos foi analisada por teste tStudent, enquanto que essas mesmas diferenças entre as categorias socioeconômicas e de estado nutricional foram analisadas por ANOVA. A correlação de Pearson foi utilizada para avaliar a correlação entre escore-z de IMC/I e VET.

As associações entre os biomarcadores e a estimativa da ingestão de nutrientes ou os componentes do IQD-R foram avaliadas por correlação de Spearman, e posteriormente ajustadas para idade, gênero e escore-z de IMC/I. Todos os indivíduos foram classificados em quartis de acordo com a estimativa da ingestão de nutrientes, as pontuações dos componentes 
do IQD-R e os biomarcadores. A concordância entre quartis foi avaliada pela classificação dos indivíduos nos mesmos quartis, em quartis adjacentes e em quartis opostos. A média da ingestão verdadeira (considerada neste estudo a dosagem de biomarcadores) foi calculada para cada quartil do QSFA ou IQD-R e a tendência entre os valores médios da ingestão verdadeira foi avaliada por modelos lineares generalizados, considerando o valor do biomarcador como variável independente e o número do quartil do QSFA ou IQD-R como variável dependente e contínua, sendo o modelo ajustado para idade, sexo e IMC/I. A significância estatística da diferença entre os valores médios dos quartis de menor e maior valor foi avaliada por teste $U$ de Mann-Whitney.

Todas as análises estatísticas foram realizadas no software Statistical Package for the Social Sciences (SPSS), versão 20.0, com significância de 5\%.

\subsection{Aspectos Éticos da Pesquisa}

Este estudo foi aprovado pelo Comitê de Ética em Pesquisa do HCFMRP-USP (processo HCRP n ${ }^{\circ}$ 14255/2010) (ANEXO C) e pela Comissão Nacional de Ética em Pesquisa - CONEP (Processo CAAE $n^{\circ} 00969412.6 .0000 .5440, \mathrm{n}^{\circ}$ parecer 1.185.875) (ANEXO D) como parte do projeto de pesquisa intitulado Nova Estratégia para Analisar Interação Gene Nutriente em Crianças e Adolescentes. Todos os participantes assinaram o Termo de Assentimento Livre e Esclarecido (ANEXO E) e seus responsáveis legais assinaram o Termo de Consentimento Livre e Esclarecido (ANEXO F), que explicam os objetivos, os procedimentos nas coletas de dados e a utilização dos dados da pesquisa. 


\section{RESULTADOS}

Participaram deste estudo 177 crianças e adolescentes cujo consumo alimentar estimado pelo QSFA foi considerado adequado para as análises estatísticas (indivíduos sem sub e superrelato). O valor médio de idade dos participantes foi 11,5 anos (DP 1,1 anos), sendo 48,0\% (n $=85)$ do sexo masculino.

O VET médio ingerido estimado pelo QSFA foi de $2107 \mathrm{Kcal}$ (DP $609 \mathrm{Kcal}$ ) entre os meninos e de $1936 \mathrm{Kcal}$ (DP $548 \mathrm{Kcal}$ ) entre as meninas ( $\mathrm{p}$ =0,002). A pontuação total do IQD$\mathrm{R}$ foi 60,3 (DP 9,2) para a amostra total, sem diferença entre os sexos (IQD-R total para meninos $=60,2 ; \mathrm{DP}=8,0 ;$ IQD-R total para meninas $=60,3 ; \mathrm{DP}=9,5)(\mathrm{p}=0,909)$.

A tabela 1 apresenta o estado nutricional dos participantes do estudo, de acordo com a classificação do escore-z de IMC/I. O valor médio do escore-z de IMC/I foi 0,59 (DP 1,46 escore-z), sendo a maioria da amostra classificada como eutrófica (56,5\%); no entanto, 37,9\% foi classificada em excesso de peso e 15,3\% com obesidade. Houve diferença de VET de acordo com o estado nutricional $(p=0,004)$, com uma correlação positiva fraca entre escore-z de IMC/I e VET $(r=0,206, p=0,006)$. Não houve diferença do valor médio de IQD-R total entre os grupos classificados pelo estado nutricional $(\mathrm{p}=0,267)$.

Tabela 1 - Estado nutricional das crianças e adolescentes participantes do estudo.

\begin{tabular}{ccc}
\hline Estado nutricional & $\mathbf{n}$ & $\mathbf{\%}$ \\
\hline Magreza grave & 0 & 0 \\
Magreza & 4 & 2,3 \\
Eutrofia & 100 & 56,5 \\
Sobrepeso & 46 & 26,0 \\
Obesidade & 21 & 11,9 \\
Obesidade grave & 6 & 3,4 \\
Total & 177 & 100 \\
\hline
\end{tabular}

Quanto à classificação socioeconômica (tabela 2), verificou-se que a maioria dos indivíduos se encontravam nas categorias B2 (36,2\%), com renda familiar mensal média de R\$ 2565,00, e C1 (29,9\%), com renda familiar mensal média de R \$ 1541,00. Não houve diferença entre as médias de VET ( $p=0,223)$, do IQD-R total $(\mathrm{p}=0,215)$, e dos componentes do IQD-R (dados não apresentados) de acordo com as classes socioeconômicas. 
Tabela 2 - Distribuição da classificação socioeconômica das famílias das crianças e adolescentes participantes do estudo.

\begin{tabular}{cccc}
\hline Classe & $\mathbf{n}$ & $\mathbf{\%}$ & $\begin{array}{c}\text { Renda mensal familiar média } \\
\text { (Valor bruto em R\$) }\end{array}$ \\
\hline A1 & 0 & 0 & 12.926 \\
A2 & 10 & 5,6 & 8.418 \\
B1 & 20 & 11,3 & 4.418 \\
B2 & 64 & 36,2 & 2.565 \\
C1 & 53 & 29,9 & 1.541 \\
C2 & 24 & 13,6 & 1.024 \\
D & 6 & 3,4 & 714 \\
E & 0 & 0 & 477 \\
Total & 177 & 100 & - \\
\hline
\end{tabular}

As tabelas 3, 4 e 5 apresentam os valores de mediana e de percentil 25 e 75 da estimativa da ingestão de nutrientes pelo QSFA, das pontuações dos componentes do IQD-R e das concentrações plasmáticas de biomarcadores, respectivamente. 
Tabela 3 - Valores de mediana e de percentis da estimativa de ingestão de nutrientes pelo Questionário Semiquantitativo de Frequência Alimentar $(n=177)$.

\begin{tabular}{|c|c|c|}
\hline Nutrientes & Mediana & $(\mathrm{p} 25-\mathrm{p} 75)$ \\
\hline$\beta$-caroteno, mcg & 1226,4 & $614,4-2355,9$ \\
\hline Retinol, mcg & 290,0 & $201,4-399,6$ \\
\hline$\alpha$-tocoferol, mg & 5,4 & $4,1-6,6$ \\
\hline Vitamina D, mcg & 3,9 & $2,8-6,1$ \\
\hline $\mathrm{C} 14: 0, \mathrm{~g}$ & 1,8 & $1,3-2,4$ \\
\hline C16:0, g & 12,3 & $9,8-15,2$ \\
\hline $\mathrm{C} 17: 0, \mathrm{~g}$ & 0,0064 & $0,046-0,090$ \\
\hline C18:0, g & 5,6 & $4,5-7,1$ \\
\hline ALA, $g$ & 1,9 & $1,5-2,5$ \\
\hline EPA, g & 0,008 & $0,004-0,014$ \\
\hline DHA, g & 0,023 & $0,011-0,045$ \\
\hline Vitamina B1, mg & 1,6 & $1,3-2,0$ \\
\hline Vitamina B2, mg & 1,5 & $1,3-1,9$ \\
\hline Vitamina B3, mg & 21,9 & $17,6-27,0$ \\
\hline Vitamina B5, mg & 4,3 & $3,4-5,2$ \\
\hline Vitamina B6, mg & 1,8 & $1,4-2,2$ \\
\hline Folato, mcg & 453,7 & $356,0-572,9$ \\
\hline Vitamina B12, mcg & 3,7 & $2,8-5,0$ \\
\hline
\end{tabular}

C14:0: ácido mirístico; C16:0: ácido palmítico; C17:0: ácido margárico; C18:0: ácido esteárico; ALA: ácido $\alpha$-linolênico; DHA: ácido docosahexaenóico; EPA: ácido eicosapentaenoico. 
Tabela 4 - Valores de mediana e de percentis das pontuações dos componentes do Índice de Qualidade da Dieta Revisado $(\mathrm{n}=177)$.

\begin{tabular}{lcc}
\hline Componentes IQD-R & Mediana & (p25- p75) \\
\hline Fruta total & 3,1 & $1,0-5,0$ \\
Fruta inteira & 3,1 & $1,0-5,0$ \\
Vegetal total e leguminosas & 3,6 & $2,3-5,0$ \\
Vegetal total SL & 2,7 & $1,6-4,0$ \\
Veveal & 2,6 & $0,3-5,0$ \\
Veveal SL & 1,0 & $0,8-1,3$ \\
Cereal total & 5,0 & $4,9-5,0$ \\
Cereal integral & 0 & $0-0,4$ \\
Leite e derivados & 5,4 & $3,3-7,7$ \\
Carnes, ovos e leguminosas & 10,0 & $7,5-10$ \\
Óleo & 10,0 & $10-10$ \\
Gordura saturada & 8,0 & $5,8-9,0$ \\
Sódio & 4,3 & $3,7-5,4$ \\
Gord_AA & 7,7 & $3,7-10,5$ \\
IQD-R total & 61,0 & $53,9-66,9$ \\
\hline
\end{tabular}

Gord_AA: calorias provenientes de gorduras sólidas, álcool e açúcar de adição; IQD-R: Índice de Qualidade da Dieta Revisado; Vegetal total SL: vegetal total sem leguminosas; Veveal SL: vegetais verdes-escuros e alaranjados sem leguminosas; Veveal: vegetais verdes-escuros e alaranjados e leguminosas. 
Tabela 5 - Valores de mediana e de percentis das concentrações de biomarcadores.

\begin{tabular}{|c|c|c|c|}
\hline Biomarcadores & $\mathbf{n}$ & Mediana & $(p 25-p 75)$ \\
\hline$\beta$-caroteno, $\mathrm{mg} / \mathrm{L}$ & 166 & 0,20 & $0,13-0,28$ \\
\hline$\beta$-caroteno/colesterol $\left[\times 10^{-3}\right]$ & 166 & 1,2 & $0,8-1,7$ \\
\hline Retinol, mg/mL & 168 & 0,34 & $0,29-0,41$ \\
\hline$\alpha$-tocoferol, mg/L & 169 & 5,9 & $5,1-7,0$ \\
\hline$\alpha$-tocoferol/colesterol $\left[\times 10^{-2}\right]$ & 169 & 3,8 & $3,2-4,2$ \\
\hline $25(\mathrm{OH}) \mathrm{D}_{3}, \mathrm{nmol} / \mathrm{L}$ & 166 & 65,4 & $54,4-80,9$ \\
\hline $\mathrm{C} 14: 0, \mathrm{mg} / \mathrm{dL}$ & 172 & 0,43 & $0,36-0,51$ \\
\hline $\mathrm{C} 15: 0, \mathrm{mg} / \mathrm{dL}$ & 172 & 0,20 & $0,17-0,21$ \\
\hline $\mathrm{C} 16: 0, \mathrm{mg} / \mathrm{dL}$ & 172 & 31,8 & $30,4-33,3$ \\
\hline $\mathrm{C} 17: 0, \mathrm{mg} / \mathrm{dL}$ & 172 & 0,51 & $0,45-0,57$ \\
\hline $\mathrm{C} 18: 0, \mathrm{mg} / \mathrm{dL}$ & 172 & 25,7 & $24,5-26,9$ \\
\hline $\mathrm{ALA}, \mathrm{mg} / \mathrm{dL}$ & 172 & 0,23 & $0,18-0,29$ \\
\hline $\mathrm{EPA}, \mathrm{mg} / \mathrm{dL}$ & 172 & 0,45 & $0,31-0,56$ \\
\hline $\mathrm{DHA}, \mathrm{mg} / \mathrm{dL}$ & 172 & 4,7 & $2,8-6,2$ \\
\hline Creatina, $\mathrm{mg} / \mathrm{dL}$ & 119 & 314,2 & $260,2-353,5$ \\
\hline Tiamina, ng/mL & 123 & 3,3 & $2,5-4,3$ \\
\hline Riboflavina, nmol/L & 156 & 11,8 & $7,9-17,2$ \\
\hline Nicotinamida, ng/mL & 170 & 403,5 & $327,5-489,5$ \\
\hline Nudifloramida, nmol/L & 170 & 938,5 & $675,5-1377,8$ \\
\hline Ácido pantotênico $(\mu \mathrm{M}$ & 153 & 1,7 & $1,1-2,3$ \\
\hline Piridoxamina, nmol/L & 170 & 207,0 & $177,0-259,3$ \\
\hline Piridoxal 5-fosfato, nmol/L & 166 & 7,8 & $6,1-10,0$ \\
\hline $\mathrm{PLP}, \mathrm{nmol} / \mathrm{L}$ & 123 & 32,7 & $22,9-44,8$ \\
\hline 5-Me THF, mg/dL & 119 & 20,4 & $12,3-28,5$ \\
\hline Folato, ng/mL & 163 & 4,6 & $3,2-6,3$ \\
\hline Vitamina B12, pg/mL & 164 & 394,0 & $306,3-520,0$ \\
\hline
\end{tabular}

25(OH)D $\mathrm{D}_{3}: 25$ hidroxivitamina $\mathrm{D}_{3}$; 5-Me THF: 5-metil tetrahidrofolato; C14:0: ácido mirístico; C15:0: ácido pentadecanóico; C16:0: ácido palmítico; C17:0: ácido margárico; C18:0: ácido esteárico; ALA: ácido $\alpha$-linolênico; DHA: ácido docosahexaenóico; EPA: ácido eicosapentaenoico; PLP: piridoxal 5-fosfato; PLP: piridoxal 5-fosfato. 


\subsection{Validação do Questionário Semiquantitativo de Frequência Alimentar utilizando Biomarcadores}

A tabela 6 apresenta os coeficientes de correlação brutos e ajustados entre a estimativa da ingestão de nutrientes pelo QSFA e as concentrações de biomarcadores. São apresentados somente os resultados com significância estatística na análise bruta ou ajustada. Os biomarcadores $\beta$-caroteno, $\beta$-caroteno/colesterol, $25(\mathrm{OH}) \mathrm{D}_{3}, \mathrm{C} 14: 0$ (ácido graxo mirístico), EPA e DHA apresentaram correlações significativas e positivas com suas respectivas ingestões. Os coeficientes de correlação brutos variaram de 0,164 a 0,316 e após o ajuste variaram de 0,166 a 0,211, sendo que apenas o DHA deixou de apresentar correlação significativa após o ajuste. $\mathrm{O}$ consumo de $\alpha$-tocoferol apresentou correlação inversa e significativa com a dosagem direta de $\alpha$-tocoferol plasmático $(r=-0,185)$.

A habilidade do QSFA em estimar a "ingestão verdadeira" (nesse estudo considerada a dosagem do biomarcador) foi avaliada pela média da concentração do biomarcador em cada quartil de estimativa do QSFA (tabela 7). Assim, um valor médio significativamente menor do biomarcador foi verificado no quartil 1 comparado ao quartil 4 para $\beta$-caroteno, $\beta$ caroteno/colesterol, 25(OH)D 3 , C14:0, EPA e DHA.

Quando calculada a média dos biomarcadores em cada quartil de consumo de acordo com o QSFA, verificou-se a tendência de aumento do valor médio do biomarcador com o aumento do quartil para $\beta$-caroteno, $\beta$-caroteno/colesterol, $25(\mathrm{OH}) \mathrm{D}_{3}, \mathrm{C} 14: 0, \mathrm{EPA}$ e DHA. Para o $\alpha$-tocoferol, houve tendência de redução do valor médio do biomarcador com o aumento do quartil.

A classificação simultânea da estimativa da ingestão de nutrientes pelo QSFA e da concentração dos biomarcadores em quartis é apresentada na tabela 8. Uma elevada proporção de participantes $(>70 \%)$ foi classificada nos mesmos quartis e quartis adjacentes para $\beta$ caroteno, $\beta$-caroteno/colesterol, 25(OH)D 3 , C14:0, EPA e DHA. A proporção de participantes classificados em quartis opostos foi menor ou igual a $10 \%$ para $\beta$-caroteno, $\beta$ caroteno/colesterol, C14:0, EPA e DHA.

Não foram encontradas correlações significativas entre as concentrações dos biomarcadores de vitaminas hidrossolúveis (tiamina, riboflavina, nicotinamida, nudifloramida, ácido pantotênico, piridoxamina, piridoxal 5-fosfato (PLP), 5-Me THF, folato e vitamina B12), retinol, C16:0 (ácido graxo palmítico), C18:0 (ácido graxo esteárico) e ALA com o consumo dos respectivos nutrientes estimados pelo QSFA. 
Tabela 6 - Coeficientes de correlação de Spearman e de correlações ajustadas entre a estimativa de ingestão de nutrientes por Questionário Semiquantitativo de Frequência Alimentar e as concentrações de biomarcadores.

\begin{tabular}{llcccc}
\hline \multirow{2}{*}{ Biomarcador } & \multirow{2}{*}{ Nutriente } & \multicolumn{2}{c}{ Correlação bruta } & \multicolumn{2}{c}{ Correlação ajustada* } \\
\cline { 3 - 6 } & & $\mathbf{r}$ & $\mathbf{p}$ & $\mathbf{r}$ & $\mathbf{p}$ \\
\hline$\beta$-caroteno & $\beta$-caroteno & 0,316 & $<0,001$ & 0,168 & 0,032 \\
$\beta$-caroteno / CT & $\beta$-caroteno & 0,302 & $<0,001$ & 0,171 & 0,045 \\
$\alpha$-tocoferol & $\alpha$-tocoferol & $-0,167$ & 0,030 & $-0,185$ & 0,017 \\
$\alpha$-tocoferol / CT & $\alpha$-tocoferol & $-0,043$ & 0,579 & $-0,070$ & 0,370 \\
$25(\mathrm{OH}) \mathrm{D}_{3}$ & Vitamina D & 0,174 & 0,025 & 0,209 & 0,008 \\
C14:0 & C14:0 & 0,214 & 0,005 & 0,211 & 0,006 \\
EPA & EPA & 0,241 & 0,001 & 0,166 & 0,031 \\
DHA & DHA & 0,226 & 0,003 & 0,087 & 0,258 \\
\hline C14:0: acis
\end{tabular}

C14:0: ácido graxo mirístico; CT: colesterol total; EPA: ácido eicosapentaenoico; DHA: docosahexaenóico; $25(\mathrm{OH}) \mathrm{D}_{3}: 25$ hidroxivitamina $\mathrm{D}_{3}$. ${ }^{*}$ Correlação ajustada para idade, gênero e índice de massa corporal. 
Tabela 7 - Distribuição das concentrações de biomarcadores em quartis definidos pela estimativa de consumo de nutrientes através de Questionário Semiquantitativo de Frequência Alimentar.

\begin{tabular}{|c|c|c|c|c|c|c|c|c|}
\hline & \multirow[t]{2}{*}{ Biomarcador } & \multirow[t]{2}{*}{ Nutriente } & \multicolumn{4}{|c|}{$\begin{array}{c}\text { Distribuição de biomarcadores por quartil de ingestão de } \\
\text { nutriente }\end{array}$} & \multirow{2}{*}{$\begin{array}{l}\text { Q1 vs. } \\
\text { Q4* }\end{array}$} & \multirow[t]{2}{*}{$\mathbf{p}^{\dagger}$} \\
\hline & & & Q1 & $\mathbf{Q 2}$ & Q3 & Q4 & & \\
\hline \multirow{8}{*}{ 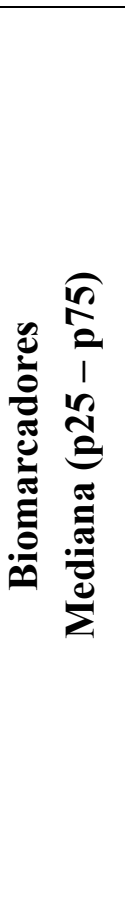 } & $\beta$-caroteno & $\beta$-caroteno & $\begin{array}{c}0,15 \\
(0,11-0,22)\end{array}$ & $\begin{array}{c}0,18 \\
(0,12-0,25)\end{array}$ & $\begin{array}{c}0,22 \\
(0,14-0,29)\end{array}$ & $\begin{array}{c}0,24 \\
(0,16-0,31)\end{array}$ & 0,015 & 0,005 \\
\hline & $\beta$-caroteno / CT $\left[\times 10^{-3}\right]$ & $\beta$-caroteno & $\begin{array}{c}0,88 \\
(0,64-1,30)\end{array}$ & $\begin{array}{c}1,14 \\
(0,84-1,40)\end{array}$ & $\begin{array}{c}1,38 \\
(0,89-1,92)\end{array}$ & $\begin{array}{c}1,43 \\
(1,09-1,83)\end{array}$ & 0,018 & 0,004 \\
\hline & $\alpha$-tocoferol & $\alpha$-tocoferol & $\begin{array}{c}6,23 \\
(5,39-7,24)\end{array}$ & $\begin{array}{c}6,10 \\
(5,12-6,64)\end{array}$ & $\begin{array}{c}5,92 \\
(5,05-7,12)\end{array}$ & $\begin{array}{c}5,57 \\
(4,11-6,46)\end{array}$ & 0,011 & 0,007 \\
\hline & $\alpha$-tocoferol / CT $\left[\times 10^{-2}\right]$ & $\alpha$-tocoferol & $\begin{array}{c}3,76 \\
(3,41-4,29)\end{array}$ & $\begin{array}{c}3,68 \\
(3,13-4,16)\end{array}$ & $\begin{array}{c}3,90 \\
(3,34-4,20)\end{array}$ & $\begin{array}{c}3,62 \\
(3,14-4,10)\end{array}$ & 0,293 & 0,491 \\
\hline & $25(\mathrm{OH}) \mathrm{D}_{3}$ & Vitamina D & $\begin{array}{c}63,3 \\
(56,8-71,5)\end{array}$ & $\begin{array}{c}63,5 \\
(51,9-80,2)\end{array}$ & $\begin{array}{c}66,4 \\
(55,6-81,8)\end{array}$ & $\begin{array}{c}72,2 \\
(56,2-84,8)\end{array}$ & 0,015 & 0,030 \\
\hline & $\mathrm{C} 14: 0$ & C14:0 & $\begin{array}{c}0,41 \\
(0,34-0,50)\end{array}$ & $\begin{array}{c}0,39 \\
(0,32-0,48)\end{array}$ & $\begin{array}{c}0,44 \\
(0,39-0,51)\end{array}$ & $\begin{array}{c}0,48 \\
(0,40-0,57)\end{array}$ & 0,016 & 0,013 \\
\hline & EPA & EPA & $\begin{array}{c}0,38 \\
(0,26-0,52)\end{array}$ & $\begin{array}{c}0,46 \\
(0,31-0,54)\end{array}$ & $\begin{array}{c}0,45 \\
(0,30-0,54)\end{array}$ & $\begin{array}{c}0,53 \\
(0,38-0,64)\end{array}$ & 0,002 & 0,024 \\
\hline & DHA & DHA & $\begin{array}{c}4,26 \\
(2,10-5,76)\end{array}$ & $\begin{array}{c}4,47 \\
(1,90-5,90)\end{array}$ & $\begin{array}{c}5,32 \\
(3,65-6,60)\end{array}$ & $\begin{array}{c}4,95 \\
(3,84-6,38)\end{array}$ & 0,048 & 0,019 \\
\hline
\end{tabular}

25(OH) $\mathrm{D}_{3}$ : 25 hidroxivitamina $\mathrm{D}_{3}$; CT: colesterol total; C 14:0: ácido graxo mirístico; DHA: docosahexaenóico; EPA: ácido eicosapentaenoico; QSFA: questionário semiquantitativo de frequência alimentar. ${ }^{*}$ Teste de Mann-Whitney para médias das concentrações de biomarcadores nos quartis 1 e 4. ${ }^{\dagger}$ Análise de tendência entre os valores médios das concentrações de biomarcadores em cada quartil e os quartis do questionário semiquantitativo de frequência alimentar, realizada por modelo linear generalizado ajustado para idade, sexo e índice de massa corporal para a idade. 
Tabela 8 - Porcentagem de concordância entre quartis de estimativa da ingestão de nutrientes por Questionário Semiquantitativo de Frequência Alimentar e de concentrações de biomarcadores.

\begin{tabular}{llccc}
\hline Biomarcador & Nutriente & $\begin{array}{c}\text { Mesmo } \\
\text { quartil }\end{array}$ & $\begin{array}{c}\text { Mesmo } \\
\text { quartil }+ \\
\text { adjacentes }\end{array}$ & $\begin{array}{c}\text { Quartis } \\
\text { opostos }\end{array}$ \\
\hline$\beta$-caroteno & $\beta$-caroteno & 36,9 & 71,1 & 6,0 \\
$\beta$ caroteno / CT & $\beta$-caroteno & 39,3 & 71,7 & 5,4 \\
$\alpha$-tocoferol & $\alpha$-tocoferol & 19,8 & 55,0 & 15,8 \\
$\alpha$-tocoferol / CT & $\alpha$-tocoferol & 24,3 & 62,1 & 14,2 \\
$25(\mathrm{OH}) \mathrm{D}_{3}$ & Vitamina D & 33,3 & 70,3 & 11,5 \\
C14:0 & C14:0 & 33,0 & 72,1 & 7,5 \\
EPA & EPA & 32,4 & 71,2 & 9,9 \\
DHA & DHA & 31,7 & 70,6 & 9,9 \\
\hline $25(\mathrm{OH}) \mathrm{D}_{3: 25}$ hidroxivitamina $\mathrm{D}_{3}$; C14:0: ácido graxo mirístico; CT: colesterol total; DHA: \\
docosahexaenóico; 25(OH) $\mathrm{D}_{3}$ : EPA: ácido eicosapentaenoico. & &
\end{tabular}




\subsection{Validação do Índice de Qualidade da Dieta Revisado gerado por questionário semiquantitativo de frequência alimentar utilizando biomarcadores}

A tabela 9 apresenta os coeficientes de correlação brutos e ajustados entre as pontuações dos componentes do IQD-R e as concentrações de biomarcadores. São apresentados somente os resultados com significância estatística na análise bruta ou ajustada. $\mathrm{Na}$ análise ajustada, as correlações dos componentes de vegetais com biomarcadores foram semelhantes entre $\beta$ caroteno e $\beta$-caroteno/colesterol, porém as correlações foram maiores para os componentes sem leguminosas (Vegetal total SL e Veveal SL) do que para os componentes originais. O componente Vegetal Total SL apresentou correlação positiva com riboflavina, 5-Me THF e vitamina B12; e o componente Veveal SL apresentou correlação positiva com 5-Me THF. O componente Leite e Derivados apresentou correlação positiva com os biomarcadores ácido pantotênico, PLP, vitamina B12 e C14:0. Correlações inversas e significativas foram verificadas entre os biomarcadores 5-Me THF e folato e o componente Carnes, Ovos e Leguminosas; entre os biomarcadores nudifloramida, ácido pantotênico, piridoxal e vitamina B12 e o componente Gordura Saturada; e entre os biomarcadores piridoxal, PLP e vitamina B12 e o componente Cereal Total.

A grande proporção de indivíduos com pontuação máxima nos componentes Vegetal Total, Veveal, Cereal Total e Carne, Ovos e Leguminosas impossibilitou a criação de quartis proporcionais aos biomarcadores. Assim, as análises de concordância, diferença e tendência entre quartis desses componentes do IQD-R e de biomarcadores não foram possíveis de serem realizadas. A dosagem do biomarcador em cada quartil de acordo com os demais componentes do IQD-R é apresentada na tabela 10. Com exceção dos pares riboflavina vs. Vegetal Total SL e piridoxal vs. Gordura Saturada, todos os demais apresentaram valores significativamente diferentes entre o quartil 1 e o quartil 4. A tendência em aumentar ou diminuir a média do biomarcador entre os quartis de acordo com a correlação apresentada (positiva ou negativa) foi apresentada entre todos os pares, com exceção de riboflavina $v s$. Vegetal Total SL e de C15:0 e C17:0 vs. Leite e Derivados.

A classificação simultânea pelos componentes do IQD-R e as concentrações de biomarcadores em quartis é apresentada na tabela 11. Para os pares com correlações positivas, a proporção de indivíduos classificados no mesmo quartil variou de 66,6 a 77,0\%, enquanto a proporção de participantes classificados em quartis opostos variou de 2,4 a 10,2\%.

Não foram encontradas correlações significativas dos biomarcadores tiamina, nicotinamida, piridoxamina, retinol, 25(OH) $\mathrm{D}_{3}, \mathrm{C} 14: 0, \mathrm{C16}: 0, \mathrm{C18}$ :0, EPA, DHA e ALA com 
as pontuações de qualquer um dos componentes do IQD-R. O pontuação total do IQD-R também não apresentou correlação significativa com qualquer um dos biomarcadores avaliados. 
Tabela 9 - Coeficientes de correlação de Spearman e de correlação ajustada entre os componentes do Índice de Qualidade da Dieta Revisado e as concentrações de biomarcadores.

\begin{tabular}{llrrrr}
\hline Biomarcador & Componente do IQD-R & \multicolumn{2}{c}{$\begin{array}{c}\text { Correlação } \\
\text { bruta }\end{array}$} & \multicolumn{2}{c}{$\begin{array}{c}\text { Correlação } \\
\text { ajustada* }\end{array}$} \\
\cline { 3 - 6 } & & \multicolumn{1}{c}{$\mathbf{r}$} & $\mathbf{p}$ & $\mathbf{r}$ & $\mathbf{p}$ \\
\hline$\beta$-caroteno & Vegetal total & 0,244 & 0,004 & 0,234 & 0,003 \\
$\beta$-caroteno & Vegetal total SL & 0,422 & $<0,001$ & 0,340 & $<0,001$ \\
$\beta$-caroteno & Veveal & 0,154 & 0,047 & 0,120 & 0,127 \\
$\beta$-caroteno & Veveal SL & 0,388 & $<0,001$ & 0,291 & $<0,001$ \\
$\beta$-caroteno/ CT & Vegetal total & 0,255 & 0,002 & 0,230 & 0,003 \\
$\beta$-caroteno/ CT & Vegetal total SL & 0,428 & $<0,001$ & 0,313 & $<0,001$ \\
$\beta$-caroteno/ CT & Veveal & 0,181 & 0,020 & 0,133 & 0,092 \\
$\beta$-caroteno/ CT & Veveal SL & 0,433 & $<0,001$ & 0,269 & 0,001 \\
& & & & & \\
Creatina & Vegetal total & 0,279 & 0,002 & 0,278 & 0,003 \\
Creatina & Veveal & 0,365 & $<0,001$ & 0,327 & $<0,001$ \\
Creatina & Carne, ovos e leguminosas & 0,271 & 0,003 & 0,205 & 0,027
\end{tabular}

Vitamina B2

Riboflavina

Vegetal total

0,158

0,048

0,108

0,183

Riboflavina

Vegetal total SL

0,142

0,078

0,175

0,031

Vitamina B3

Nudifloramida Vegetal total

Nudifloramida Veveal

Gordura saturada

$\mathrm{t}$

$\begin{array}{rrrr}0,152 & 0,048 & 0,139 & 0,073 \\ 0,191 & 0,013 & 0,128 & 0,100 \\ -0,134 & 0,082 & -0,190 & 0,014\end{array}$

Vitamina B5

Ácido pantotênico Cereal total

$\begin{array}{llll}-0,141 & 0,067 & -0,241 & 0,002\end{array}$

Ácido pantotênico Leite e derivados

$0,233 \quad 0,002 \quad 0,233 \quad 0,004$

Ácido pantotênico Gordura saturada

$\begin{array}{llll}-0,199 & 0,009 & -0,201 & 0,009\end{array}$ 
continuação

Tabela 9 - Coeficientes de correlação de Spearman e de correlação ajustada entre os componentes do Índice de Qualidade da Dieta Revisado e as concentrações de biomarcadores.

\begin{tabular}{|c|c|c|c|c|c|}
\hline \multirow[t]{2}{*}{ Biomarcador } & \multirow[t]{2}{*}{ Componente do IQD-R } & \multicolumn{2}{|c|}{$\begin{array}{c}\text { Correlação } \\
\text { bruta }\end{array}$} & \multicolumn{2}{|c|}{$\begin{array}{c}\text { Correlação } \\
\text { ajustada* }^{*}\end{array}$} \\
\hline & & $\mathbf{r}$ & $\mathbf{p}$ & $\mathbf{r}$ & $\mathbf{p}$ \\
\hline \multicolumn{6}{|l|}{ Vitamina B6 } \\
\hline Piridoxal & Cereal total & $-0,172$ & 0,027 & $-0,282$ & $<0,001$ \\
\hline Piridoxal & Gordura saturada & $-0,163$ & 0,036 & $-0,169$ & 0,031 \\
\hline PLP & Cereal total & $-0,279$ & 0,002 & $-0,223$ & 0,014 \\
\hline PLP & Leite e derivados & 0,270 & 0,003 & 0,283 & 0,002 \\
\hline \multicolumn{6}{|l|}{ Vitamina B9 } \\
\hline 5-Me THF & Vegetal total SL & 0,200 & 0,030 & 0,195 & 0,036 \\
\hline 5-Me THF & Veveal SL & 0,179 & 0,052 & 0,201 & 0,030 \\
\hline 5-Me THF & Carne, ovos e leguminosas & $-0,239$ & 0,009 & $-0,216$ & 0,020 \\
\hline Folato & Carne, ovos e leguminosas & $-0,137$ & 0,081 & $-0,178$ & 0,024 \\
\hline Vitamina B12 & Vegetal total SL & 0,254 & 0,001 & 0,194 & 0,014 \\
\hline Vitamina B12 & Cereal total & $-0,210$ & 0,007 & $-0,192$ & 0,014 \\
\hline Vitamina B12 & Leite e derivados & 0,233 & 0,003 & 0,265 & 0,010 \\
\hline Vitamina B12 & Gordura saturada & $-0,206$ & 0,008 & $-0,233$ & 0,003 \\
\hline $\mathrm{C} 14: 0$ & Leite e derivados & 0,203 & 0,007 & 0,169 & 0,028 \\
\hline C15:0 & Leite e derivados & 0,319 & $<0,001$ & 0,136 & 0,077 \\
\hline $\mathrm{C} 17: 0$ & Leite e derivados & 0,211 & 0,005 & $-0,014$ & 0,861 \\
\hline
\end{tabular}

5-Me THF: 5-metil tetrahidrofolato; C14:0: ácido mirístico; C15:0: ácido pentadecanóico; C17:0: ácido margárico; IQD-R: Índice de Qualidade da Dieta Revisado; PLP: piridoxal 5fosfato; Vegetal total SL: vegetal total sem leguminosas; Veveal SL: vegetais verdes-escuros e alaranjados sem leguminosas; Veveal: vegetais verdes-escuros e alaranjados e leguminosas. * Correlação ajustada para idade, gênero e índice de massa corporal. 
Tabela 10 - Distribuição das concentrações de biomarcadores em quartis definidos pelos componentes do Índice de Qualidade da Dieta Revisado.

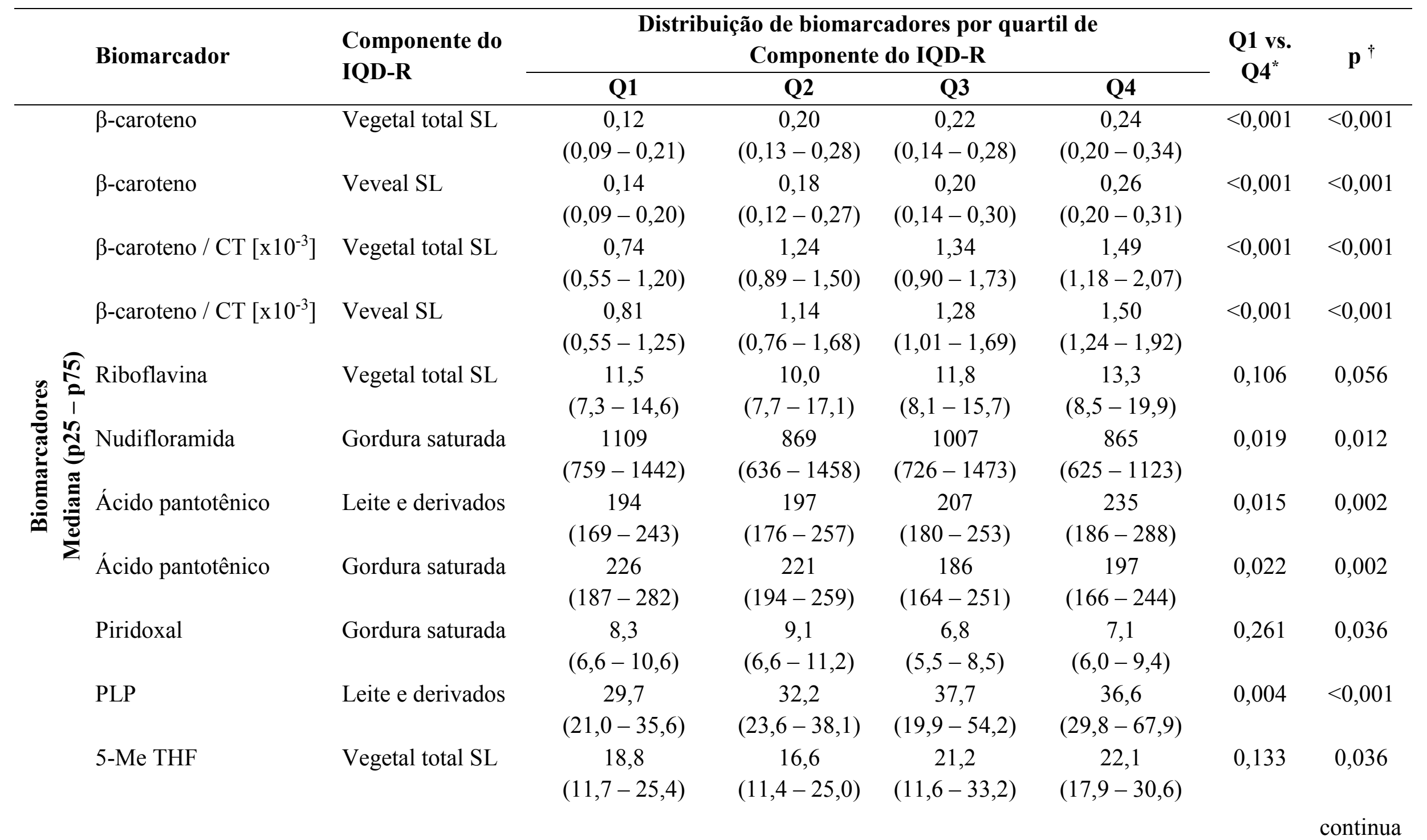


Tabela 10 - Distribuição das concentrações de biomarcadores em quartis definidos pelos componentes do Índice de Qualidade da Dieta Revisado.

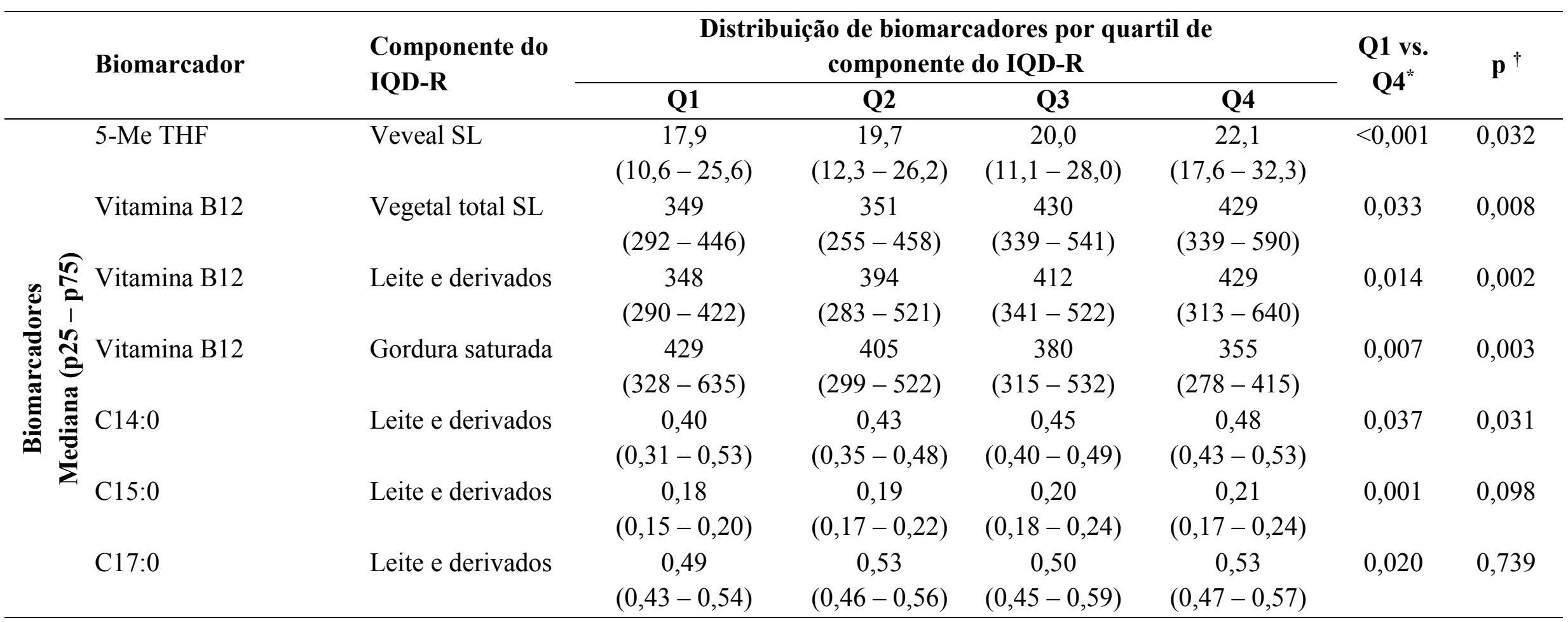

5-Me THF: 5-metil tetrahidrofolato; C14:0: ácido mirístico; C15:0: ácido pentadecanóico; C17:0: ácido margárico; CT: colesterol total; IQD-R: Índice de Qualidade da Dieta Revisado; PLP: piridoxal 5-fosfato; Vegetal total SL: vegetal total sem leguminosas; Veveal SL: vegetais verdesescuros e alaranjados sem leguminosas; Veveal: vegetais verdes-escuros e alaranjados e leguminosas. ${ }^{*}$ Teste de Mann-Whitney para médias das concentrações de biomarcadores nos quartis 1 e $4 .{ }^{\dagger}$ Análise de tendência entre os valores médios das concentrações de biomarcadores em cada quartil e os quartis dos componentes do IQD-R, realizada por modelo linear generalizado ajustado para idade, sexo e índice de massa corporal para a idade. 
Tabela 11 - Porcentagem de concordância entre quartis de componentes do Índice de Qualidade da Dieta Revisado e de concentrações de biomarcadores.

\begin{tabular}{|c|c|c|c|c|}
\hline Biomarcador & $\begin{array}{l}\text { Componente do } \\
\text { IQD-R }\end{array}$ & $\begin{array}{l}\text { Mesmo } \\
\text { quartil }\end{array}$ & $\begin{array}{c}\text { Mesmo } \\
\text { quartil + } \\
\text { adjacentes }\end{array}$ & $\begin{array}{l}\text { Quartis } \\
\text { opostos }\end{array}$ \\
\hline$\beta$-caroteno & Vegetal total SL & 37,9 & 76,5 & 2,4 \\
\hline$\beta$-caroteno & Veveal SL & 31,3 & 76,5 & 3,0 \\
\hline$\beta$-caroteno / CT & Vegetal total SL & 35,5 & 77,0 & 3,0 \\
\hline$\beta$-caroteno / CT & Veveal SL & 38,0 & 76,5 & 2,4 \\
\hline Riboflavina & Vegetal total SL & 30,1 & 66,6 & 10,2 \\
\hline Nudifloramida & Gordura saturada & 20,6 & 56,5 & 15,9 \\
\hline Ácido pantotênico & Leite e derivados & 32,4 & 70,6 & 9,4 \\
\hline Ácido pantotênico & Gordura saturada & 18,2 & 52,9 & 17,6 \\
\hline Piridoxal & Gordura saturada & 20,5 & 56,0 & 13,2 \\
\hline PLP & Leite e derivados & 33,3 & 74,8 & 6,5 \\
\hline 5-Me THF & Vegetal total SL & 26,9 & 68,7 & 5,9 \\
\hline 5-Me THF & Veveal SL & 35,3 & 71,3 & 6,7 \\
\hline Vitamina B12 & Vegetal total SL & 31,7 & 73,2 & 7,9 \\
\hline Vitamina B12 & Leite e derivados & 33,5 & 72,0 & 9,7 \\
\hline Vitamina B12 & Gordura saturada & 17,7 & 58,0 & 17,7 \\
\hline C14:0 & Leite e derivados & 30,2 & 72,7 & 11,0 \\
\hline C15:0t & Leite e derivados & 34,3 & 76,1 & 10,4 \\
\hline $\mathrm{C} 17: 0$ & Leite e derivados & 25,0 & 70,3 & 8,1 \\
\hline
\end{tabular}

5-Me THF: 5-metil tetrahidrofolato; C14:0: ácido mirístico; C15:0: ácido pentadecanóico; C17:0: ácido margárico; CT: colesterol total; IQD-R: Índice de Qualidade da Dieta Revisado; PLP: piridoxal 5-fosfato; Vegetal total SL: vegetal total sem leguminosas; Veveal SL: vegetais verdes-escuros e alaranjados sem Leguminosas; Veveal: vegetais verdes-escuros e alaranjados e leguminosas. 


\section{DISCUSSÃO}

Este estudo determinou a validade relativa do QSFA utilizado no Brazil Micronutrient Project, em crianças e adolescentes de 9 a 13 anos de idade, clinicamente estáveis, pela comparação da estimativa de ingestão de nutrientes e dos componentes do IQD-R com biomarcadores plasmáticos.

Os valores médios de energia total encontrados com o QSFA foram de $2.107 \mathrm{kcal} \mathrm{e}$ $1.936 \mathrm{kcal}$ para meninos e meninas, respectivamente, sendo esses semelhantes aos relatados por Veiga et al. ${ }^{187}$, com o uso de dois RAs, entre os adolescentes de 10 e 13 anos de idade avaliados no Inquérito Nacional de Alimentação 2008-2009 (meninos $=1.952 \mathrm{kcal}$ e meninas $=1.896$ Kcal). A diferença entre sexos é esperada uma vez meninos necessitam de ingestão energética superior à das meninas.

A pontuação média total do IQD-R foi de 60,3 pontos para toda a amostra estudada, sem diferença entre os sexos. Este resultado é próximo aos obtidos por outros estudos nacionais e internacionais. Andrade et al. ${ }^{10}$ utilizaram o IQD-R para avaliar a qualidade da dieta de adolescentes de 12 a 19 anos de idade da Grande São Paulo e encontraram uma pontuação média de 50,3 pontos. Na mesma região, Prado et al. ${ }^{9}$, em estudo com crianças de 7 a 10 anos de idade, encontraram uma pontuação media do IQD-R total que variou entre 62,4 e 65,5, a depender do padrão de realização das refeições diárias. Em João Pessoa, o IQD-R total de adolescentes de 10 a 16 anos de idade foi de 52,3 pontos ${ }^{12}$. Em Pelotas, aos 18 anos de idade uma coorte de adolescentes apresentou IQD-R total de 62,4 pontos ${ }^{188}$. Em Niterói, adolescentes de 12 a 19 anos de idade apresentaram IQD-R total de 71,8 pontos ${ }^{189}$. Estudos internacionais que utilizaram o HEI-2005, método a partir do qual o IQD-R foi derivado, encontraram pontuação total média para adolescentes americanos ${ }^{190}$, turcos ${ }^{191}$, gregos ${ }^{192}$ e porto-riquenhos 193 de 55,9; 51,5; 60,5 e 40,9, respectivamente. Assim, de maneira geral, todos esses valores indicam que os hábitos alimentares de crianças e adolescentes precisam ser melhorados.

$\mathrm{Na}$ amostra estudada, a prevalência de déficit de peso $(2,8 \%)$ foi semelhante aos dados nacionais da Pesquisa de Orçamentos Familiares (POF) 2008-2009 em que crianças e adolescentes de 9 a 13 anos apresentaram prevalência de déficit de peso de 3,7\% a 4,1\%, a depender da idade. No entanto, as prevalências de excesso de peso $(37,9 \%)$ e de obesidade $(15,3 \%)$ foram pouco superiores aos dados nacionais, sendo que esses variaram de $25,5 \%$ a $35,6 \%$ e de $5,7 \%$ a $12,2 \%$, respectivamente ${ }^{18}$. 
Conforme o esperado, o consumo energético estimado pelo QSFA associou-se positivamente ao escore-z de IMC/I. No entanto, assim como os estudos de Ramos ${ }^{189}$ e de Andrade et al. ${ }^{10}$, os quais avaliaram a qualidade da dieta de adolescentes nos estados do Rio de Janeiro e de São Paulo, respectivamente, o presente estudo não encontrou diferença de IQD-R total entre os indivíduos eutróficos e com excesso de peso. Possivelmente essa ausência de associação se deve ao fato de que o IQD-R não considera o consumo energético total. Porém, o desenho transversal do estudo não permite a comprovação de temporalidade relativa entre as variáveis estudadas, o que impede inferir de forma segura sobre relações de causalidade. Isto é, talvez a falta de associação se deva a mudanças no comportamento alimentar dos adolescentes estudados. Não obstante, outros estudos têm encontrado resultados diversos. Wendpap et al. ${ }^{194}$ demonstraram associação positiva entre o IQD-R total e o excesso de peso, enquanto Pinheiro e Atalah ${ }^{195}$, com adaptação do HEI para adolescentes chilenos, verificaram que os menores escores de qualidade da dieta estavam associados ao sobrepeso.

O consumo alimentar e a qualidade da dieta de crianças e adolescentes podem ser influenciados por sua condição socioeconômica, ou seja, o maior ou menor poder aquisitivo podem estar relacionados à aquisição de certos tipos de alimentos. No presente estudo, a maioria dos indivíduos analisados pertencia às classes B2 (36,2\%) e C1 (29,9\%), as quais possuem renda familiar mensal média de $\mathrm{R} \$ 1541,00$ e $\mathrm{R} \$ 2565,00$, respectivamente. Não foram encontradas diferenças de VET e de pontuação total do IQD-R entre os participantes classificados nas diversas classes socioeconômicas. Segundo a POF 2008-2009, existe uma associação positiva entre classes de renda e frequências de consumo de verduras, frutas e leite derivados. Por outro lado, alguns marcadores negativos da qualidade da dieta, como o consumo de doces, refrigerantes, pizzas e salgados fritos e assados, são menos frequentes na categoria de menor renda; na classe de menor renda também são consumidos com maior frequência feijão e preparações à base de feijão. Apesar dessas diferenças, o consumo excessivo de açúcar e insuficiente de frutas, verduras e legumes foi identificado em todo o país e em todas as classes de renda ${ }^{196}$. Diversos estudos internacionais com índices de qualidade da dieta observaram associação inversa entre qualidade da dieta e renda, em crianças, adolescentes e adultos ${ }^{114,197-}$ 200. No Brasil, outros estudos que utilizaram o IQD-R em diferentes faixas etárias, gerado a partir de R24hs ${ }^{10}$ ou QFA ${ }^{194}$, também não observaram diferença da qualidade da dieta entre as classes de renda. 


\subsection{Questionário semiquantitativo de frequência alimentar}

O QSFA apresentou bom desempenho para a avaliação da ingestão de $\beta$-caroteno, vitamina D, C14:0 e EPA, de acordo com a validação por biomarcadores.

As maiores correlações foram obtidas entre a estimativa da ingestão de $\beta$-caroteno e os biomarcadores $\beta$-caroteno ou $\beta$-caroteno/colesterol. Apesar de serem correlações modestas $(\leq 0,32)$, essas são comparáveis à estudos prévios, para os quais as correlações brutas variaram de 0,2 a $0,5^{148,149,152-154,201-203}$. Em estudos de coorte prospectivo ${ }^{204}$ e de intervenção ${ }^{205}$, a relação de dose-resposta entre a ingestão e a concentração plasmática de carotenoides foi demonstrada, o que corrobora seu uso como um biomarcador confiável da ingestão alimentar.

Neste estudo, as correlações obtidas ( $\mathrm{r}$ bruto $=0,17$ e $\mathrm{r}$ ajustado $=0,21$ ) entre a estimativa da ingestão de vitamina $\mathrm{D}$ e a concentração plasmática de $25(\mathrm{OH}) \mathrm{D}_{3}$ foram um pouco inferiores às demonstradas por outros estudos $(0,26$ a 0,55$)$, que utilizaram o QFA para a avaliação geral da alimentação ${ }^{152,206,207}$ ou especificamente para a estimativa da ingestão de vitamina $\mathrm{D}^{208,209}$, e refletem somente a ingestão por alimentos. No entanto, tais estudos foram realizados em países de alta latitude nos quais há reduzida incidência de radiação solar, principalmente no inverno. Ao contrário, Ribeirão Preto está localizada em região tropical com elevada incidência de radiação solar durante todo o ano e, assim, a dosagem obtida pode ser influenciada pela síntese endógena. Apesar disso, diversos estudos têm demonstrado elevada prevalência de hipovitaminose $\mathrm{D}$ em populações que vivem em regiões ensolaradas ${ }^{52}$. Entre os fatores associados a essa situação podem ser citados o menor tempo de exposição solar por mudanças no estilo de vida, a utilização de filtro solar e o aumento do nível de poluição ${ }^{53}$. Portanto, mesmo em regiões de baixa latitude, a ingestão de vitamina D pode ter sua representatividade aumentada na concentração plasmática total. Uma vez que o QSFA não possui alimentos considerados grandes fontes de vitamina $\mathrm{D}$, é provável que a correlação observada resulte do consumo de outros alimentos que acompanhem aqueles considerados fontes.

Dentre os ácidos graxos poli-insaturados (PUFA) avaliados, foram observadas correlações positivas do biomarcador com a estimativa da ingestão de EPA ( $\mathrm{r}$ bruto $=0,24$ e $\mathrm{r}$ ajustado $=0,17)$; enquanto a correlação de DHA $(r$ bruto $=0,23)$ deixou de ser significante após ajuste para idade, sexo e IMC ( $\mathrm{r}$ ajustado $=0,09$ ). Metherel et al. ${ }^{210}$, em estudo com suplementação de óleo de peixe, verificaram que as concentrações eritrocitárias de EPA e DHA refletiram rapidamente o aumento e a redução da ingestão, indicando que esses são bons 
biomarcadores de sua ingestão recente. Além disso, os autores demonstraram que as correlações da estimativa da ingestão de ácido graxos poli-insaturados (PUFA) com as dosagens em diversas frações do sangue (plasma, eritrócito, sangue total e sangue capilar) são maiores quando são utilizadas as porcentagens de EPA e DHA em relação ao total de PUFA do que quando são utilizados seus valores absolutos. O presente estudo não dosou a concentração total de PUFA nos eritrócitos e, portanto, não dispõe das porcentagens de EPA e DHA. Assim, as menores correlações encontradas em comparação a outros estudos que validaram a estimativa da ingestão de PUFA ${ }^{148,211-213}$ pode ser, em parte, atribuída a utilização das concentrações absolutas de EPA e DHA.

Em análises complementares, foi verificada a correlação significativa entre a estimativa da ingestão da DHA e seu biomarcador no sexo feminino ( $\mathrm{r}$ bruto $=0,313 \mathrm{e} \mathrm{p}=0,002$; $\mathrm{r}$ ajustado $=0,28$ e $p=0,048)$, mas não no masculino ( $r$ bruto $=0,088$ e $p=0,443 ; r$ ajustado $=-0,023$ e $p$ $=0,840$ ). Maiores concentrações teciduais ${ }^{214}$, plasmáticas ${ }^{215}$ e eritrocitárias ${ }^{210}$ de DHA em mulheres tem sido observada quando comparadas às concentrações em homens. Essa diferença tem sido atribuída ao efeito positivo do estrogênio na conversão de ALA e EPA em DHA. Estudos com isótopos estáveis de ALA identificaram elevada incorporação em moléculas de DHA de mulheres férteis ${ }^{216,217}$, enquanto estudos com reposição hormonal em mulheres na menopausa ${ }^{218}$ e em transexuais ${ }^{219}$ demonstraram aumento das concentrações de DHA após o início da terapia. No entanto, a diferença de síntese e de concentração de DHA entre os sexos é observada apenas quando há baixa disponibilidade do ácido graxo ${ }^{217}$, sendo esse o caso da amostra estudada. Dessa forma, a análise estratificada por sexos é justificada e, ainda que as concentrações de DHA não reflitam apenas o consumo alimentar em mulheres, o QSFA mostrou-se válido para ranquear os indivíduos do sexo feminino de acordo com as concentrações de DHA.

O C14:0 foi o único ácido graxo saturado a apresentar correlação com seu biomarcador ( $\mathrm{r}$ bruto e ajustado $=0,21$ ). Estudos de validação com biomarcadores para o consumo de ácidos graxos saturados específicos são escassos, porém, a estimativa de ingestão do C14:0 tem sido validada tanto em comparação aos ácidos graxos teciduais ${ }^{149}$ quanto eritrocitários ${ }^{220}$. O C14:0 é abundante em produtos lácteos e alguns estudos o classificam como um biomarcador para a gordura do leite, apesar dessa associação ser suscetível à influência da produção endógena 221,222. No fígado, o C14:0 se alonga e é rapidamente incorporado aos triglicerídeos celulares, o que o torna um importante ácido graxo na elevação da colesterolemia ${ }^{223}$. Apesar desse efeito, revisões e meta-análises não têm encontrado relação entre o consumo de leite e derivados com maior risco de doenças cardiovasculares, doença coronariana, acidente vascular encefálico ${ }^{224}$ 
e síndrome metabólica ${ }^{225}$; enquanto foi demonstrada relação inversa com o risco de diabetes 226 .

Além do uso de correlações brutas e ajustadas, a validade do QSFA foi avaliada por diversos outros testes estatísticas, p. ex. comparação do valor médio do biomarcador entre primeiro e último quartil, tendência entre os valores médios dos biomarcadores em cada quartil e percentual de classificação correta dos indivíduos em quartis. Uma vez que os biomarcadores não são medidas da ingestão absoluta, a habilidade para ranquear os indivíduos de acordo com o consumo é mais importante ${ }^{4}$. O QSFA foi capaz de diferenciar os valores médios dos biomarcadores $\beta$-caroteno, $\beta$-caroteno/colesterol, $25(\mathrm{OH}) \mathrm{D}_{3}, \mathrm{C} 14: 0$ e EPA entre o primeiro e o último quartil de consumo, bem como identificar tendência entre os valores médios desses biomarcadores em cada quartil. Na análise de concordância o QSFA obteve bom desempenho ( $>70 \%$ no mesmo quartil e quartis adjacentes) para classificar os indivíduos de acordo com a ingestão de $\beta$-caroteno, vitamina D, EPA e C14:0.

\section{2 Índice de Qualidade da Dieta Revisado gerado por questionário semiquantitativo de frequência alimentar}

As associações verificadas entre os componentes do IQD-R e os biomarcadores podem ser classificadas em dois grupos: 1 - associações diretas da estimativa de ingestão de nutrientes com grupos de alimentos (componentes de vegetais vs. $\beta$-caroteno, $\beta$-caroteno/colesterol e 5 Me-THF; leite vs. C14:0, ácido pantotênico, PLP e vitamina B12) e 2 - associações que, através de correlações inversas, refletem uma dieta menos saudável (Gordura saturada vs. nudifloramida, ácido pantotênico, piridoxal e vitamina B12; Cereal total vs. ácido pantotênico, piridoxal, PLP e vitamina B12; Carnes, ovos e leguminosas vs. folato). Além disso, todos os componentes ricos em proteína vegetal (leguminosas) e animal (carnes e ovos) foram correlacionados com creatina.

Assim, como no QSFA, as maiores correlações com os componentes do IQD-R foram verificadas a partir do biomarcador de $\beta$-caroteno. Os componentes Vegetal total SL e Veveal SL apresentaram correlações mais fortes do que os componentes originais, sendo que o Veveal deixou de ser significante com a correlação ajustada. Essa diferença pode ser explicada pelo elevado consumo de leguminosas apresentado pelos participantes desse estudo, pois $82,5 \%$ deles relataram consumir feijão pelo menos uma vez ao dia (dados não apresentados), sendo 
que esse alimento não é uma fonte de carotenoides. As correlações encontradas entre os componentes de vegetais com leguminosas e creatina reforçam essa explicação. A creatina tem sido proposta como um biomarcador de alimentos proteicos. No entanto, ela é influenciada por diversos fatores, tal como massa muscular, e sua confiabilidade como biomarcador precisa ser mais bem determinada ${ }^{227}$. Os componentes Vegetal total SL e Veveal SL apresentaram ainda correlações positivas com o 5 Me-THF, a principal forma ativa de ácido fólico em nível celular 228. Mesmo em populações suplementadas com ácido fólico, como o caso da população brasileira, a concentração plasmática de folato tem sido indicada como um biomarcador útil do consumo de vegetais e, ainda que as correlações possam ser atenuadas em populações suplementadas, seu valor continua a ser preditivo ${ }^{229}$. Por fim, o componente Vegetal total SL apresentou correlação positiva com riboflavina. Outros relatos dessa associação não foram encontrados na literatura. Carnes e vegetais são consideradas boas fontes de riboflavina, porém o longo aquecimento necessário para o cozimento das carnes pode reduzir a disponibilidade da vitamina ${ }^{230}$. A riboflavina pode ser sintetizada por bactérias intestinais e uma maior produção foi verificada após a ingestão de uma dieta baseada em vegetais se comparada a uma dieta baseada em carnes ${ }^{231}$.

O componente Leite e derivados apresentou correlação com o C14:0 e, conforme mencionado anteriormente, esse ácido graxo tem sido classificado como um biomarcador para a gordura do leite ${ }^{221,222}$. Além da correlação verificada com vitamina B12, a qual já foi descrita em diversos estudos ${ }^{232-234}$, o componente Leite e derivados também apresentou correlação com PLP e ácido pantotênico. Outros estudos que avaliaram a concentração plasmática de PLP de acordo com grupos de alimentos encontraram associação com leite e derivados ${ }^{232,235}$. Stelutti et al. ${ }^{236}$, ao estudar o consumo alimentar de adolescentes brasileiros, verificaram que o leite integral e as bebidas lácteas estão entre os cinco alimentos que mais contribuem para a ingestão de vitamina B6. Apesar desses alimentos não apresentarem elevada concentração de vitamina B6, eles possuem importante papel como fonte alimentar devido à maior quantidade consumida se comparada aos demais. O ácido pantotênico é amplamente distribuído nos alimentos vegetais e animais, e são necessários mais estudos para comprovar se a associação ao componente Leite e derivados é efeito direto do consumo de leite e derivados ou de padrões alimentares.

De fato, as concentrações plasmáticas de vitaminas do complexo B não são relacionadas apenas ao consumo dos alimentos fontes, mas também aos padrões alimentares ${ }^{237,238}$. Além das correlações positivas encontradas entre componentes do IQD-R considerados fontes de vitaminas do complexo B e seus biomarcadores, correlações negativas foram encontradas entre esses e os componentes Carne, ovos e leguminosas, Gordura saturada e Cereal total. Apesar do 
componente Cereal total ser idealizado para relacionar-se à melhor qualidade da dieta, esse grupo foi constituído majoritariamente por carboidratos refinados. Iglesia et al. ${ }^{232}$ observaram que o consumo de produtos de confeitaria, chocolates, bolos, e lanches salgados foi associado à menor concentração plasmática de vitaminas B6, folato e B12; e concluíram que o consumo de tais alimentos pode comprometer a ingestão e o status de vitaminas pela substituição dos alimentos com maior densidade de vitaminas do complexo B. O maior consumo de carnes relacionado à redução das concentrações plasmáticas de folato está de acordo com os resultados de diversos estudos ${ }^{239-241}$, os quais sugerem uma associação positiva entre o status de folato e um padrão alimentar caracterizado pelo elevado consumo de frutas, legumes e verduras e pelo baixo consumo de carnes.

O presente estudo apresenta como limitação o fato de que o consumo alimentar investigado com o QSFA, a partir do qual foi gerado o IQD-R, foi referente ao mês anterior, enquanto alguns biomarcadores utilizados representam a ingestão mais recente de alimentos.

Entre os pontos fortes a serem destacados neste estudo está a sua classificação como de boa qualidade de acordo com o sistema de avaliação de estudos de validação da ingestão alimentar, desenvolvido pelo EURopean micronutrient RECommendations Aligned Network of Excellence (EURRECA) ${ }^{163}$. Alguns dos fatores que contribuíram para a boa qualidade foram a heterogeneidade da amostra em relação ao sexo, estado nutricional e condição socioeconômica; o tamanho amostral superior à quantidade mínima recomendada de 50 indivíduos em todas as análises e a diversidade de análises estatísticas realizadas. Ainda que a maioria dos coeficientes de correlação encontrados tenham sido modestos $(r<0,3)$, a existência de correlação entre a estimativa da ingestão de alimentos e os biomarcadores fornece evidência quase inquestionável de validação ${ }^{4}$. Baixos coeficientes de correlação são comuns em estudos de validação com biomarcadores mesmo que as medições da ingestão de alimentos sejam altamente precisas e são influenciados pelo uso de ferramentas de avaliação imprecisas, por erros técnicos na medição de biomarcadores, pela variabilidade diária de biomarcadores ou controle homeostático e por herança genética ${ }^{4,165}$. Os resultados das análises de diferença de médias e de tendência entre quartis corroboram todas as correlações verificadas com o QSFA e a maioria das correlações encontradas entre os componentes do IQD-R e os biomarcadores, exceto para riboflavina e 5 Me-THF $v s$. Vegetal total SL e para piridoxal vs. Gordura saturada. Além disso, para a maioria das correlações positivas a concordância no mesmo quartil e em quartis adjacentes foi maior que 70\%, com exceção de riboflavina e 5 Me-THF vs. Vegetal total 
SL. Conforme o esperado, as concordâncias entre os quartis de Gordura saturada e nudifloramida, ácido pantotênico e vitamina B12 foram menores, uma vez que apresentaram correlações negativas. 


\section{CONCLUSÕES}

Esse estudo mostrou, pela comparação com marcadores bioquímicos do consumo alimentar, que o QSFA é um instrumento válido para ranquear as crianças e adolescentes, de ambos os sexos, de acordo com a estimativa de ingestão de $\beta$-caroteno, vitamina D, C14:0 e EPA. A estimativa da ingestão de DHA é válida ranquear apenas as crianças e adolescentes do sexo feminino.

Quanto ao IQD-R gerado a partir do QSFA, o componente original Vegetal total e as versões modificadas Vegetal total SL e Veveal SL foram diretamente associados à concentração plasmática de $\beta$-caroteno, enquanto que os componentes modificados Vegetal total SL e Veveal SL foram diretamente associados às concentrações plasmáticas de vitamina B12 e de 5-Me THF, respectivamente. Todos os componentes ricos em proteínas de origem vegetal (leguminosas) e animal (carnes e ovos) foram associados à creatina plasmática $\mathrm{O}$ componente Leite e derivados mostrou-se diretamente associado aos biomarcadores C14:0, vitamina B12, PLP e ácido pantotênico. Além disso, o IQD-R demonstrou que concentrações plasmáticas de vitaminas do complexo B foram inversamente associadas aos componentes Cereais totais (vitaminas B5, B6 e B12) e Gordura saturada (vitaminas B3, B5 e B6).

Diante do exposto, o QSFA e seu IQD-R podem ser utilizados em estudos clínicos e epidemiológicos, com crianças e adolescentes de 9 a 13 anos de idade e na Região de Ribeirão Preto, que investiguem a associação entre desfechos em saúde e consumo alimentar dos nutrientes e componentes descritos acima. 


\section{REFERÊNCIAS}

1. Lucas B. Nutrição na infância. In: Mahan LK, Escott-Stump S, editors. Krause Alimentos, Nutrição e Dietoterapia. 12a ed. Rio de Janeiro: Elsevier; 2010. p. 222-45.

2. Monteiro CA, Mondini L, Souza ALM, Popkin BM. Da desnutrição para a obesidade: a transição nutricional no Brasil. In: Monteiro CA, editor. Velhos e novos males da saúde no Brasil: a evolução do país e de suas doenças. 2a ed. São Paulo: Hucitec; 2000. p. 247-55.

3. Souza AM, Barufaldi LA, Abreu GA, Giannini DT, Oliveira CL, Santos MM, et al. ERICA: Intake of macro and micronutrients of Brazilian adolescents. Rev Saude Publica. 2016;50(supl 1):1s-15s.

4. Willett W, Lenart E. Reproducibility and Validity of Food Frequency Questionnaires. In: Willett WC, editor. Nutritional Epidemiology. $3^{\mathrm{a}}$ ed. New York: Oxford University Press; 2013. p. 96-141.

5. Kant AK. Indexes of overall diet quality: a review. J Am Diet Assoc. 1996;96(8):78591.

6. Cervato AM, Vieira VL. Índices dietéticos na avaliação da qualidade global da dieta. Rev Nutr. 2003;16(3):347-55.

7. Previdelli ÁN, Andrade SC, Pires MM, Ferreira SRG, Fisberg RM, Marchioni DM. Índice de Qualidade da Dieta Revisado para população brasileira. Rev Saúde Pública. 2011;45(4):794-8.

8. Tanaka LF, Latorre MRDO, Medeiros AM, Konstantyner TCRO, Mendes EC, Marques HHS. Poor diet quality among Brazilian adolescents with HIV/AIDS. J Pediatr (Rio J). 2015;91(2):152-9.

9. Prado BG, Hinning PF, Tanaka LF, Latorre MRDO. Qualidade da dieta de escolares de 7 a 10 anos do município de São Paulo: associação com o número e os locais de refeições. Rev Nutr Campinas. 2015;28(6):607-18.

10. Andrade SC, Previdelli ÁN, Cesar CLG, Marchioni DML, Fisberg RM. Trends in diet quality among adolescents, adults and older adults: A population-based study. Prev Med Reports. 2016;4:391-6. 
11. Rodrigues PRM, Luiz RR, Monteiro LS, Ferreira MG, Gonçalves-Silva RMV, Pereira RA. Adolescents' unhealthy eating habits are associated with meals skipping. Nutrition. 2017 Mar 27; [Epub ahead of print]. Disponível em: http://www.nutritionjrnl.com/article/S0899-9007(17)30065-5/pdf

12. Coutinho ISL, Arruda ACP, Costa MJC, Ferreira FELL. Diet Quality and Risk Factors for Cardiovascular Diseases Among Adolescents from the Public Schools in a City in the Northeast Region of Brazil. Int Arch Med. 2016;9(187):1-11.

13. Kaaks R, Riboli E, Estève J, Kappel AL Van, Staveren WA Van. Estimating the accuracy of dietary questionnaire assessments: Validation in terms of structural equation models. Stat Med. 1994;13(2):127-42.

14. Potischman N. Biologic and Methodologic Issues for Nutritional Biomarkers. J Nutr. 2003;133(Suppl 3):875S-880S.

15. International Food Policy Research Institute. Global Nutrition Report 2016: From Promise to Impact: Ending Malnutrition by 2030. Washington, DC: International Food Policy Research Institute; 2016. 157 p.

16. Batista Filho M, Rissin A. A transição nutricional no Brasil: tendências regionais e temporais. Cad Saude Publica. 2003;19(suppl 1):S181-91.

17. Ng M, Fleming T, Robinson M, Thomson B, Graetz N, Margono C, et al. Global, regional, and national prevalence of overweight and obesity in children and adults during 1980-2013: A systematic analysis for the Global Burden of Disease Study 2013. Lancet. 2014;384(9945):766-81.

18. Instituto Brasileiro de Geografia e Estatística. Pesquisa de Orçamentos Familiares 2008-2009: Antropometria e estado nutricional de crianças, adolescentes e adultos no Brasil/ IBGE, Coordenação de Trabalho e Rendimento. Rio de Janeiro: IBGE, 2010. $130 \mathrm{p}$.

19. Pulgarón ER. Childhood Obesity: A Review of Increased Risk for Physical and Psychological Comorbidities. Clin Ther. 2013;35(1):A18-32.

20. Wang Y, Lobstein T. Worldwide trends in childhood overweight and obesity. Int J Pediatr Obes. 2006;1(1):11-25. 
21. Reilly JJ, Kelly J. Long-term impact of overweight and obesity in childhood and adolescence on morbidity and premature mortality in adulthood: systematic review. Int J Obes. 2011;35(7):891-8.

22. Marins VMR, Almeida RM V, Pereira RA, Barros MB. Factors associated with overweight and central body fat in the city of Rio de Janeiro: results of a two-stage random sampling survey. Public Health. 2001;115(3):236-42.

23. Rinaldi AEM, Pereira AF, Macedo CS, Mota JF, Burini RC. Contribuições das práticas alimentares e inatividade física para o excesso de peso infantil. Rev Paul Pediatr. 2008;26(3):271-7.

24. Villar BS. Epidemiologia Nutricional - Uma Nova Disciplina. In: Dutra-de-Oliveira JE, Marchini JS, editors. Ciências Nutricionais - Aprendendo a Aprender. $2^{\mathrm{a}}$ ed. São Paulo: Sarvier; 2008. p. 601-11.

25. World Health Organization [homepage]. Geneva: World Health Organization; 2017. Micronutrient deficiencies. Vitamin A deficiency [citado 15 mai. 2017]. Disponível em: http://www.who.int/nutrition/topics/vad/en/

26. Brasil. Ministério da Saúde. Pesquisa Nacional de Demografia e Saúde da Criança e da Mulher - PNDS 2006 : dimensões do processo reprodutivo e da saúde da criança / Ministério da Saúde, Centro Brasileiro de Análise e Planejamento. Brasília: Ministério da Saúde; 2009. 300 p. (Série G. Estatística e Informação em Saúde)

27. Ribeiro-Silva RC, Nunes IL, Assis AMO. Prevalence and factors associated with vitamin A deficiency in children and adolescents. J Pediatr (Rio J). 2014;90(5):48692.

28. Liu S, Lee IM, Ajani U, Cole SR, Buring JE, Manson JE. Intake of vegetables rich in carotenoids and risk of coronary heart disease in men: The Physicians' Health Study. Int J Epidemiol. 2001;30(1):130-5.

29. D'Odorico A, Martines D, Kiechl S, Egger G, Oberhollenzer F, Bonvicini P, et al. High plasma levels of alpha- and beta-carotene are associated with a lower risk of atherosclerosis: results from the Bruneck study. Atherosclerosis. 2000;153(1):231-9. 
30. Hozawa A, Jacobs DR, Steffes MW, Gross MD, Steffen LM, Lee D-H. Relationships of Circulating Carotenoid Concentrations with Several Markers of Inflammation, Oxidative Stress, and Endothelial Dysfunction: The Coronary Artery Risk Development in Young Adults (CARDIA)/Young Adult Longitudinal Trends in Antioxidants (YALTA) Study. Clin Chem. 2007;53(3):447-455.

31. Bjelakovic G, Nikolova D, Gluud LL, Simonetti RG, Gluud C. Antioxidant supplements for prevention of mortality in healthy participants and patients with various diseases. Cochrane Database Syst Rev. 2012;14(3):CD007176.

32. Silva LSV, Veiga GV, Ramalho RA. Association of serum concentrations of retinol and carotenoids with overweight in children and adolescents. Nutrition.

2007;23(5):392-7.

33. Center for Disease Control [homepage]. Atlanta, GA: CDC; 2012. Second National Report on Biochemical Indicators of Diet and Nutrition in the U. S. Population [citado 04 fev. 2017]. Disponível em:

https://www.cdc.gov/nutritionreport/pdf/Nutrition_Book_complete508_final.pdf

34. Vardia M, Blumc S, Levy AP. Haptoglobin genotype and cardiovascular outcomes in diabetes mellitus - natural history of the disease and the effect of vitamin E treatment. Meta-analysis of the medical literature. Eur J Intern Med. 2012;23(7):628-632.

35. Levy AP, Friedenberg P, Lotan R, Ouyang P, Tripputi M, Higginson L, et al. The Effect of Vitamin Therapy on the Progression of Corona Artery Atherosclerosis Varies by Haptoglobin Type in Postmenopausal Women. Diabetes Care. 2004;27(4):925-30.

36. Pae M, Meydani SN, Wu D. The role of nutrition in enhancing immunity in aging. Aging Dis. 2012;3(1):91-129.

37. Han SN, Meydani SN. Impact of vitamin E on immune function and its clinical implications. Expert Rev Clin Immunol. 2006;2(4):561-567.

38. Wright ME, Lawson KA, Weinstein SJ, Pietinen P, Taylor PR, Virtamo J, et al. Higher baseline serum concentrations of vitamin $\mathrm{E}$ are associated with lower total and cause-specific mortality in the Alpha-Tocopherol, Beta-Carotene Cancer Prevention Study. Am J Clin Nutr. 2006;84(5):1200-7. 
39. McBurney MI, Yu EA, Ciappio ED, Bird JK, Eggersdorfer M, Mehta S. Suboptimal serum Alpha-tocopherol concentrations observed among younger adults and those depending exclusively upon food sources, NHANES 2003-2006. PLoS One. 2015;10(8):1-13.

40. Kim YN, Lora KR, Giraud DW, Driskell JA. Nonsupplemented children of latino immigrants have low vitamin $\mathrm{E}$ intakes and plasma concentrations and normal vitamin $\mathrm{C}$, selenium, and carotenoid intakes and plasma concentrations. J Am Diet Assoc. 2006;106(3):385-91.

41. Allen LH, Rosado JL, Casterline JE, López P, Muñoz E, Garcia OP, et al. Lack of hemoglobin response to iron supplementation in anemic Mexican preschoolers with multiple micronutrient deficiencies. Am J Clin Nutr. 2000;71(6):1485-94.

42. Misra M, Pacaud D, Petryk A, Collett-Solberg PF, Kappy M. Vitamin D Deficiency in Children and Its Management: Review of Current Knowledge and Recommendations. Pediatrics. 2008;122(2):398-417.

43. Wang TJ, Pencina MJ, Booth SL, Jacques PF, Ingelsson E, Lanier K, et al. Vitamin D deficiency and risk of cardiovascular disease. Circulation. 2008;117(4):503-11.

44. Reis JP, von Mühlen D, Miller ER, Michos ED, Appel LJ. Vitamin D status and cardiometabolic risk factors in the United States adolescent population. Pediatrics. 2009;124(3):e371-379.

45. Hyppönen E, Läärä E, Reunanen A, Järvelin MR, Virtanen SM. Intake of vitamin D and risk of type 1 diabetes: A birth-cohort study. Lancet. 2001;358(9292):1500-3.

46. Chiu KC, Chu A, Go VLW, Saad MF. Hypovitaminosis D is associated with insulin resistance and $\beta$ cell dysfunction. Am J Clin Nutr. 2004;79(5):820-5.

47. Mitri J, Muraru MD, Pittas AG. Vitamin D and type 2 diabetes: a systematic review. Eur J Clin Nutr Clin Nutr. 2011;65(9):1005-15.

48. Trump DL, Deeb K, Johnson CS. Vitamin D: Considerations in the Continued Development as an Agent for Cancer Prevention and Therapy. Cancer. 2010;16(1):19.

49. Suaini NHA, Zhang Y, Vuillermin PJ, Allen KJ, Harrison LC. Immune modulation by vitamin D and its relevance to food allergy. Nutrients. 2015;7(8):6088-108. 
50. Holick M. Vitamin D deficiency. N Engl J Med. 2007;357(3):266-81.

51. Norris JM. Can the sunshine vitamin shed light on type 1 diabetes ? Lancet. 2001;358(9292):1476-8.

52. Palacios $\mathrm{C}$, Gonzalez L. Is vitamin D deficiency a major global public health problem? J Steroid Biochem Mol Biol. 2014;144(Pt A):138-45.

53. Greer FR. Defining Vitamin D Deficiency in Children: Beyond 25-OH Vitamin D Serum Concentrations. Pediatrics. 2009;124(5):1471-3.

54. Lourenço BH, Qi L, Willett WC, Cardoso MA. FTO genotype, vitamin D status, and weight gain during childhood. Diabetes. 2014;63(2):808-14.

55. Santos BR, Mascarenhas LPG, Satler F, Boguszewski MCS, Spritzer P. Vitamin D deficiency in girls from South Brazil: a cross-sectional study on prevalence and association with vitamin D receptor gene variants. BMC Pediatr. 2012;12(1):62.

56. Gallagher ML. Os nutrientes e seu metabolismo. In: Mahan LK, Escott-Stump S, editors. Krause Alimentos, Nutrição e Dietoterapia. 12ª ed. Rio de Janeiro: Elsevier; 2010. p. 39-143.

57. Powers HJ. Riboflavin (vitamin B-2) and health. Am J Clin Nutr. 2003;77(6):135260.

58. Kirkland JB. Niacin requirements for genomic stability. Mutat Res - Fundam Mol Mech Mutagen. 2012;733(1-2):14-20.

59. McNulty H, Scott JM. Intake and status of folate and related B-vitamins: considerations and challenges in achieving optimal status. Br J Nutr. 2008;99(Suppl 3):S48-54.

60. Institute of Medicine. Standing Committee on the Scientific Evaluation of Dietary Reference Intakes and its Panel on Folate, Other B Vitamins, and Choline. Dietary Reference Intakes for Thiamin, Riboflavin, Niacin, Vitamin B6, Folate, Vitamin B12, Pantothenic Acid, Biotin, and Choline. Washington, DC: National Academies Press; $1998.592 \mathrm{p}$. 
61. Kerr MA, Livingstone B, Bates CJ, Bradbury I, Scott JM, Ward M, et al. Folate, Related B Vitamins, and Homocysteine in Childhood and Adolescence: Potential Implications for Disease Risk in Later Life. Pediatrics. 2009;123(2):627-35.

62. Barnabé A, Aléssio ACM, Bittar LF, de Moraes Mazetto B, Bicudo AM, de Paula E $\mathrm{V}$, et al. Folate, vitamin B12 and Homocysteine status in the post-folic acid fortification era in different subgroups of the Brazilian population attended to at a public health care center. Nutr J. 2015;14(1):19.

63. González-Gross M, Benser J, Breidenassel C, Albers U, Huybrechts I, Valtueña J, et al. Gender and age influence blood folate, vitamin B12, vitamin B6, and homocysteine levels in European adolescents: The Helena Study. Nutr Res. 2012;32(11):817-26.

64. Morris MS, Picciano MF, Jacques PF, Selhub J. Plasma pyridoxal 5'-phosphate in the US population: the National Health and Nutrition Examination Survey, 2003-2004. Am J Clin Nutr. 2008;87(5):1446-54.

65. Bang HO, Dyerberg J, Sinclair HM. The composition of the Eskimo food in north western Greenland. Am J Clin Nutr. 1998;33(12):2657-61.

66. Block RC, Harris WS, Reid KJ, Sands SA, Spertus JA. EPA and DHA in blood cell membranes from acute coronary syndrome patients and controls. Atherosclerosis. 2008;197(2):821-8.

67. Marchioli R, Schweiger C, Tavazzi L, Valagussa F. Efficacy of n-3 polyunsaturated fatty acids after myocardial infarction: Results of GISSI-Prevenzione trial. Lipids. 2001;36(Suppl):S119-126.

68. Simopoulos A. Omega-3 fatty acids in inflammation and autoimmune diseases. J Am Coll Nutr. 2002;21(6):495-505.

69. Das UN. Estrogen, statins, and polyunsaturated fatty acids: Similarities in their actions and benefits - Is there a common link? Nutrition. 2002;18(2):178-88.

70. Fleming JA, Kris-etherton PM. The Evidence for Alpha-Linolenic Acid and Cardiovascular Disease Benefits: Comparisons with Eicosapentaenoic Acid and Docosahexaenoic Acid. Adv Nutr. 2014;5:863S-876S.

71. Zelman K. The Great Fat Debate: A Closer Look at the Controversy-Questioning the Validity of Age-Old Dietary Guidance. J Am Diet Assoc. 2011;111(5):655-8. 
72. Chowdhury R, Warnakula S, Kunutsor S, Crowe F, Ward HA, Johnson L, et al. Association of dietary, circulating, and supplement fatty acids with coronary risk: a systematic review and meta-analysis. Ann Intern Med. 2014;160(6):398-406.

73. Hooper L, Martin N, Abdelhamid A, G DS. Reduction in saturated fat intake for cardiovascular disease. Cochrane Database Syst Rev. 2015;10(6):CD011737.

74. Souza RJ, Mente A, Maroleanu A, Cozma AI, Ha V, Kishibe T, et al. Intake of saturated and trans unsaturated fatty acids and risk of all cause mortality, cardiovascular disease, and type 2 diabetes: systematic review and meta-analysis of observational studies. BMJ. 2015;351:h3978.

75. Siri-Tarino PW, Sun Q, Hu FB, Krauss RM. Meta-analysis of prospective cohort studies evaluating the association of saturated fat with cardiovascular disease. Am J Clin Nutr. 2010;91(3):535-46.

76. Schwab U, Lauritzen L, Tholstrup T, Haldorssoni T, Riserus U, Uusitupa M, et al. Effect of the amount and type of dietary fat on cardiometabolic risk factors and risk of developing type 2 diabetes, cardiovascular diseases, and cancer: a systematic review. Food Nutr Res. 2014;58(25145):1-26.

77. Swanson D, Block R, Mousa SA. Omega-3 fatty acids EPA and DHA: health benefits throughout life. Adv Nutr. 2012;3(1):1-7.

78. Orchard TS, Pan X, Cheek F, Ing SW, Jackson RD. A systematic review of omega-3 fatty acids and osteoporosis. Br J Nutr. 2012;107(2):S253-60.

79. Fabian CJ, Kimler BF, Hursting SD. Omega-3 fatty acids for breast cancer prevention and survivorship. Breast Cancer Res. 2015;17(62):1-11.

80. Kantor ED, Lampe JW, Peters U, Vaughan TL, White E. Long-chain omega-3 polyunsaturated fatty acid intake and risk of colorectal cancer. Nutr Cancer. 2014;66(4):716-27.

81. Fisberg R, Martini LA, Slater B. Métodos de Inquéritos Dietéticos. In: Fisberg R, Slater B, Marchioni DML, Martini LA, editors. Inquéritos Alimentares - Métodos e Bases Científicos. Barueri: Manole; 2005. p. 1-31.

82. Thompson FE, Byers T. Dietary Assessment Resource Manual. J Nutr. 1994;124(suppl 11):2245S-2317S. 
83. Vasconcelos FAG. Indicadores do consumo alimentar. In: Vasconcelos FAG, editor. Avaliação Nutricional de Coletividades. 4ª ed. Florianópolis: Editora da UFSC; 2007. p. 109-24.

84. Fisberg RM, Marchioni DML, Colucci ACA. Assessment of food consumption and nutrient intake in clinical practice Regina. Arq Bras Endocrinol Metabol. 2009;53(5):617-24.

85. Cintra IP, Heyde MED, Schmitz BA, Franceschini SC, Taddei JAAC, Sigulem DM. Métodos de Inquéritos Dietéticos. Cad Nutr. 1997;13(2):11-23.

86. Thompson FE, Subar AF. Dietary Assessment Methodology. In: Coulston AM, Boushey CJ, Ferruzzi MG, editors. Nutrition in the Prevention and Treatment of Disease. $3^{\mathrm{a}}$ ed. Londres: Academic Press; 2013. p. 5-46.

87. Pereira RA, Araujo MC, Lopes TDS, Yokoo EM. How many 24-hour recalls or food records are required to estimate usual energy and nutrient intake? Cad Saude Publica. 2010;26(11):2101-11.

88. McPherson RS, Hoelscher DM, Alexander M, Scanlon KS, Serdula MK. Dietary Assessment Methods among School-Aged Children: Validity and Reliability. Prev Med (Baltim). 2000;31(suppl):S11-33.

89. Cavalcante AAM, Priore SE, Franceschini SCC. Food consumption studies: general methodological aspects and its use in the evaluation of children and adolescents aged. Rev Bras Saude Mater Infant. 2004;4(3):229-40.

90. Bratteby L, Sandhagen B, Fan H, Enghardt H, Samuelson G. Total energy expenditure and physical activity as assessed by the doubly labeled water method in Swedish adolescents in whom energy intake was underestimated by 7 -d diet records. Am J Clin Nutr. 1998;67(5):905-11.

91. Champagne CM, Delany JP, Harsha DW, Bray GA. Underreporting of energy intake in biracial children is verified by doubly labeled water. J Am Diet Assoc. 1996;96(7):707-9.

92. Lindquist $\mathrm{CH}$, Cummings T, Goran MI. Use of tape-recorded food records in assessing children's dietary intake. Obes Res. 2000;8(1):2-11. 
93. Baxter SD, Hardin JW, Royer JA, Guinn CH, Smith AF. Children's recalls from five dietary-reporting validation studies. Intrusions in correctly reported and misreported options in school breakfast reports. Appetite. 2008;51(3):489-500.

94. Baxter SD. Cognitive processes in children's dietary recalls: insight from methodological studies. Eur J Clin Nutr. 2009;63(suppl 1):S19-32.

95. Börnhorst C, Huybrechts I, Ahrens W, Eiben G, Michels N, Pala V, et al. Prevalence and determinants of misreporting among European children in proxy-reported $24 \mathrm{~h}$ dietary recalls. Br J Nutr. 2013;109(7):1257-65.

96. Moore GF, Tapper K, Moore L, Murphy S. Cognitive, Behavioral, and Social Factors Are Associated with Bias in Dietary Questionnaire Self-Reports by Schoolchildren Aged 9 to 11 Years. J Am Diet Assoc. 2008;108(11):1865-73.

97. Willett WC. Food-frequency method. In: Willett WC, editor. Nutritional Epidemiology. $2^{\mathrm{a}}$ ed. Oxford: Oxford University Press; 1998. p. 74-94.

98. Burke BS. The dietary history as a tool in research. J Am Diet Assoc. 1947;23:1041-6.

99. Heady JA. Diets of Bank Clerks Development of a Method of Classifying the Diets of Individuals for Use in Epidemiological Studies. J R Stat Soc. 1961;124(3):336-71.

100. Willett WC. Future directions in the development of food-frequency questionnaires. Am J Clin Nutr. 1994;59(1):171S-174S.

101. Cade J, Thompson R, Burley V, Warm D. Development, validation and utilisation of food-frequency questionnaires - a review. Public Health Nutr. 2002;5(4):567-87.

102. Slater B, Marchioni DL, Fisberg RM. Estimating prevalence of inadequate nutrient intake. Rev Saude Publica. 2004;38(4):599-605.

103. Carroll RJ, Pee D, Freedman LS, Brown CC. Statistical design of calibration studies. Am J Clin Nutr. 1997;65(suppl 4):1187S-1189S.

104. Slater B, Philippi ST, Marchioni DML, Fisberg RM. Validation of Food Frequency Questionnaires - FFQ: methodological considerations. Rev Bras Epidemiol. 2003;6(3):200-8. 
105. Zulkifli SN, Yu SM. The food frequency method for dietary assessment. J Am Diet Assoc. 1992;92(6):681-5.

106. Gibson RS. Measuring food consumption of individuals. In: Gibson RS, editor. The Principles of Nutritional Assessment. $2^{\mathrm{a}}$ ed. Oxford: Oxford University Press; 2005. p. $41-64$.

107. Nelson M. The validation of dietary questionnaires. In: Margetts BM, Nelson M, editors. Design concepts in nutritional epidemiology. $2^{\mathrm{a}}$ ed. Oxford: Oxford University Press; 1997. p. 266-95.

108. Cummings SR, Block G, McHenry K, Baron RB. Evaluation of two food frequency methods of measuring dietary calcium intake. Am J Epidemiol. 1987;126(5):796-802.

109. Drewnowski A. Diet image: a new perspective on the food-frequency questionnaire. Nutr Rev. 2001;59(11):370-2.

110. Kourlaba G, Panagiotakos DB. Dietary quality indices and human health: A review. Maturitas. 2009;62(1):1-8.

111. Mertz W. Foods and nutrients. J Am Diet Assoc. 1984;84(7):769-70.

112. Waijers PMCM, Feskens EJM, Ocké MC. A critical review of predefined diet quality scores. Br J Nutr. 2007;97(2):219-31.

113. Kennedy ET, Ohls J, Carlson S, Fleming K. The Healthy Eating Index: Design and Applications. J Am Diet Assoc. 1995;95(10):1103-8.

114. Patterson RE, Haines PS, Popkin BM. Diet quality index: Capturing a multidimensional behavior. J Am Diet Assoc. 1994;94(1):57-64.

115. Huijbregts P, Feskens E, Räsänen L, Fidanza F, Nissinen A, Menotti A, et al. Dietary pattern and 20 year mortality in elderly men in Finland, Italy, and The Netherlands: longitudinal cohort study. Br J Nutr. 1997;315(7099):13-7.

116. Trichopoulou A, Kouris-Blazos A, Wahlqvist ML, Gnardellis C, Lagiou P, Polychronopoulos E, et al. Diet and overall survival in elderly people. Br Med J. 1995;311(7018):1457-60. 
117. Wirt A, Collins CE. Diet quality - what is it and does it matter? Public Health Nutr. 2009;12(12):2473-92.

118. Osler M, Heitmann BL, Gerdes LU, Jørgensen LM, Schroll M. Dietary patterns and mortality in Danish men and women: a prospective observational study. Br J Nutr. 2001;85(2):219-25.

119. Kant A, Schatzkin A, Graubard BI, Schairer C. A Prospective Study of Diet Quality and Mortality in Women. JAMA. 2000;283(16):2109-15.

120. Fitzgerald AL, Dewar RA, Veugelers PJ. Diet Quality and Cancer Incidence in Nova Scotia, Canada. Nutr Cancer. 2002;43(2):127-32.

121. Marshall S, Burrows T, Collins CE. Systematic review of diet quality indices and their associations with health-related outcomes in children and adolescents. J Hum Nutr Diet. 2014;27(6):577-98.

122. Andrade SC, Azevedo Barros MB, Carandina L, Goldbaum M, Cesar CL, Fisberg RM. Dietary quality index and associated factors among adolescents of the state of Sao Paulo, Brazil. J Pediatr. 2010;156(3):456-60.

123. Vitolo MR, Rauber F, Campagnolo PDB, Feldens CA, Hoffman DJ. Maternal dietary counseling in the first year of life is associated with a higher healthy eating index in childhood. J Nutr. 2010;140(11):2002-7.

124. Bortolini GA, Vitolo MR, Gubert MB, Santos LMP. Iniquidades sociais influenciam a qualidade e a diversidade da dieta de crianças brasileiras de 6 a 36 meses. Cad Saude Publica. 2015;31(11):2413-24.

125. Coelho LG, Cândido APC, Machado-Coelho GLL, Freitas SN. Association between nutritional status, food habits and physical activity level in schoolchildren. J Pediatr (Rio J). 2012;88(5):406-12.

126. Leal KK, Schneider BC, França GVA, Gigante DP, Santos I, Assunção MCF. Diet quality of preschool children aged 2 to 5 years living in the urban area of Pelotas, Brazil. Rev Paul Pediatr. 2015;33(3):310-7.

127. Domene SMÁ, Jackix EA, Raposo HFo. Adaptação das diretrizes alimentares para a população brasileira e o estabelecimento do índice de alimentação saudável para préescolares de 2 a 6 anos. Nutrire. 2006;31(2):75-90. 
128. Kneipp C, Habitzreuter F, Mezadri T, Höfelmann DA. Excesso de peso e variáveis associadas em escolares de Itajaí, Santa Catarina, Brasil. Cien Saude Colet. 2015;20(8):2411-22.

129. Molina MCB, Lopéz PM, Faria CP, Cade NV, Zandonade E. Socioeconomic predictors of child diet quality. Rev Saude Publica. 2010;44(5):785-92.

130. National Research Council. Committee on Diet and Health. Diet and health: implications for reducing chronic disease risk / Committee on Diet and Health, Food and Nutrition Board, Commission on Life Sciences, National Research Council. Washington, DC: National Academies Press; 1989. 768 p.

131. U.S. Department of Agriculture. Center for Nutrition Policy and Promotion. The Food Guide Pyramid. Washington, DC: U.S. Department of Agriculture; 1992. (Home and Garden Bulletin Number 252)

132. U.S. Department of Agriculture. U.S. Department of Health and Human Services. Nutrition and Your Health: Dietary Guidelines for Americans. Washington, DC: U.S. Department of Agriculture; 1990. (Home and Garden Bulletin Number 232)

133. Guenther PM, Reedy J, Krebs-Smith SM, Reeve BB. Evaluation of the Healthy Eating Index-2005. J Am Diet Assoc. 2008;108(11):1854-64.

134. Guenther PM, Kirkpatrick SI, Reedy J, Krebs-Smith SM, Buckman DW, Dodd KW, et al. The Healthy Eating Index-2010 is a valid and reliable measure of diet quality according to the 2010 Dietary Guidelines for Americans. J Nutr. 2014;144(3):399407.

135. Guenther PM, Casavale KO, Reedy J, Kirkpatrick SI, Hiza HAB, Kuczynski KJ, et al. Update of the Healthy Eating Index: HEI-2010. J Acad Nutr Diet. 2013;113(4):56980 .

136. Fisberg RM, Slater B, Barros RR, De Lima FD, Cesar CLG, Carandina L, et al. Índice de Qualidade da Dieta: avaliação da adaptação e e aplicabilidade. Rev Nutr. 2004;17(3):301-8.

137. Brasil. Ministério da Saúde. Secretaria de Atenção à Saúde. Guia alimentar para a população brasileira : promovendo a alimentação saudável / Ministério da Saúde, Secretaria de Atenção à Saúde. Brasília: Ministério da Saúde; 2008. 210 p. (Série A. Normas e Manuais Técnicos) 
138. Waxman A, World Health Assembly. WHO global strategy on diet, physical activity and health. Food Nutr Bull. 2004;25(3):292-302.

139. Institute of Medicine. Panel on Dietary Reference Intakes for Electrolytes and Water. Dietary Reference Intakes for water, potassium, sodium, chloride and sulfate. Washington, DC: National Academies Press; 2005. 617 p.

140. Sposito AC, Caramelli B, Fonseca FAH, Bertolami MC. IV Diretriz Brasileira Sobre Dislipidemias e Prevenção da Aterosclerose. Arq Bras Cardiol. 2007;88(suppl 1):8824.

141. Guenther PM, Reedy J, Krebs-Smith SM, Reeve BB, Basiotis PP. Development and evaluation of the healthy eating index-2005: Technical Report. Center for Nutrition Policy and Promotion, U.S. Department of Agriculture; 2007. Disponível em: https://www.cnpp.usda.gov/sites/default/files/healthy_eating_index/HEI2005TechnicalReport.pdf

142. Andrade SC, Previdelli ÁN, Marchioni DML, Fisberg RM. Avaliação da confiabilidade e validade do Índice de Qualidade da Dieta Revisado. Rev Saude Publica. 2013;47(4):675-83.

143. Gibson R. Validity in dietary assessment methods. In: Gibson R, editor. The Principles of Nutritional Assessment. 2a ed. Oxford: University Press; 2005. p. 146-96.

144. Hunter D. Biochemical Indicators of Dietary Intake. In: Willett WC, editor. Nutritional Epidemiology. 2a ed. New York: Oxford University Press; 1998. p. 174243.

145. Tangney CC, Shekelle RB, Raynor W, Gale M, Betz EP. Intra- and interindividual variation in measurements of beta-carotene, retinol, and tocopherols in diet and plasma. Am J Clin Nutr. 1987;45(4):764-9.

146. Stähelin HB, Gey KF, Eichholzer M, Lüdin E. Beta-carotene and cancer prevention: the Basel Study. Am J Clin Nutr. 1991;53(Suppl 1):265S-269S.

147. Mayne ST. Antioxidant nutrients and chronic disease: Use of biomarkers of exposure and oxidative stress status in epidemiologic research. J Nutr. 2003;133(3 Suppl):933S940S. 
148. Brunner E, Stallone D, Juneja M, Bingham S, Marmot M. Dietary assessment in Whitehall II: comparison of $7 \mathrm{~d}$ diet diary and food-frequency questionnaire and validity against biomarkers. Br J Nutr. 2001;86(3):405.

149. Fraser GE, Jaceldo-Siegl K, Henning SM, Fan J, Knutsen SF, Haddad EH, et al. Biomarkers of Dietary Intake Are Correlated with Corresponding Measures from Repeated Dietary Recalls and Food-Frequency Questionnaires in the Adventist Health Study. J Nutr. 2016;146(3):586-94.

150. Block G, Norkus E, Hudes M, Mandel S, Helzlsouer K. Which plasma antioxidants are most related to fruit and vegetable consumption? Am J Epidemiol.

2001;154(12):1113-8.

151. Black AE, Bingham SA, Johansson G, Coward WA. Validation of dietary intakes of protein and energy against 24 hour urinary $\mathrm{N}$ and DLW energy expenditure in middleaged women, retired men and post-obese subjects: comparisons with validation against presumed energy requirements. Eur J Clin Nutr. 1997;51(6):405-13.

152. Sauvageot N, Alkerwi A, Albert A, Guillaume M. Use of food frequency questionnaire to assess relationships between dietary habits and cardiovascular risk factors in NESCAV study: validation with biomarkers. Nutr J. 2013;12(1):143.

153. Lai JS, Attia J, McEvoy M, Hure AJ. Biochemical validation of the older Australian's food frequency questionnaire using carotenoids and Vitamin E. Nutrients. 2014;6(11):4906-17.

154. Burrows T, Hutchesson M, Rollo M, Boggess M, Guest M, Collins C. Fruit and Vegetable Intake Assessed by Food Frequency Questionnaire and Plasma Carotenoids: A Validation Study in Adults. Nutrients. 2015;7(5):3240-51.

155. Freisling H, Elmadfa I, Schuh W, Wagner KH. Development and validation of a food frequency index using nutritional biomarkers in a sample of middle-aged and older adults. J Hum Nutr Diet. 2009;22(1):29-39.

156. Block G. A review of validations of dietary assessment methods. Am J Epidemiol. 1982;115(4):492-505.

157. Kipnis V, Midthune D, Freedman L, Bingham S, Day NE, Riboli E, et al. Bias in dietary-report instruments and its implications for nutritional epidemiology. Public Health Nutr. 2002;5(6A):915-23. 
158. McCambridge J, Witton J, Elbourne DR. Systematic review of the Hawthorne effect: New concepts are needed to study research participation effects. J Clin Epidemiol. 2014;67(3):267-77.

159. Henríquez-Sánchez $P$, Sánchez-Villegas A, Doreste-Alonso J, Ortiz-Andrellucchi A, Pfrimer K, Serra-Majem L. Dietary assessment methods for micronutrient intake: a systematic review on vitamins. Br J Nutr. 2009;102 Suppl(2009):S10-37.

160. Ortiz-Andrellucchi A, Henríquez-Sánchez P, Sánchez-Villegas A, Peña-Quintana L, Mendez M, Serra-Majem L. Dietary assessment methods for micronutrient intake in infants, children and adolescents: a systematic review. Br J Nutr. 2009;102(Suppl 1):S87-117.

161. Neuhouser ML, Patterson RE, King IB, Horner NK, Lampe JW. Selected nutritional biomarkers predict diet quality. Public Health Nutr. 2003;6(7):703-9.

162. Vyncke K, Cruz Fernandez E, Fajó-Pascual M, Cuenca-García M, De Keyzer W, Gonzalez-Gross M, et al. Validation of the Diet Quality Index for Adolescents by comparison with biomarkers, nutrient and food intakes: the HELENA study. Br J Nutr. 2013;109(11):2067-78.

163. Serra-Majem L, Frost Andersen L, Henríque-Sánchez P, Doreste-Alonso J, SánchezVillegas A, Ortiz-Andrelluchi A, et al. Evaluating the quality of dietary intake validation studies. Br J Nutr. 2009;102 Suppl(2009):S3-9.

164. Ambrosini GLA, Klerk NH, Musk AW, Mackerras D. Agreement between a brief food frequency questionnaire and diet records using two statistical methods. Public Health Nutr. 2001;4(2):255-64.

165. Hu FB. Dietary Assessment Methods. In: Hu FB, editor. Obesity Epidemiology. $1^{\mathrm{a}}$ ed. New York: Oxford University Press; 2008. p. 84-118.

166. Block G, Hartman AM. Issues in reproducibility and validity of dietary studies. Am J Clin Nutr. 1989;50(5 Suppl):1133-8.

167. Goldberg GR, Black AE, Jebb SA, Cole TJ, Murgatroyd PR, Coward WA, et al. Critical evaluation of energy intake data using fundamental principles of energy physiology: 1. Derivation of cut-off limits to identify under-recording. Eur J Clin Nutr. 1991;45(12):569-81. 
168. Schofield W. Predicting basal metabolic rate, new standards and review of previous work. Hum Nutr Clin Nutr. 1985;39(Suppl 1):5-41.

169. Snedecor GW, Cochran W. Statistical Methods. Ames: Iowa State University Press; 1971.

170. Associação Brasileira de Empresas de Pesquisa. Critério de Classificação Econômica Brasil. São Paulo: ABEP; 2012.

171. Fumagalli F, Pontes Monteiro J, Sartorelli DS, Vieira MNCM, Bianchi MLP. Validation of a food frequency questionnaire for assessing dietary nutrients in Brazilian children 5 to 10 years of age. Nutrition. 2008;24(5):427-32.

172. Ribeiro AB, Cardoso MA. Construção de um questionário de freqüência alimentar como subsídio para programas de prevenção de doenças crônicas não transmissíveis. Rev Nutr. 2002;15(2):239-45.

173. Cardoso MA, Kida AA, Tomita LY, Stocco PR. Reproducibility and validity of a food frequency questionnaire among women of Japanese ancestry living in brazil. Nutr Res. 2001;21(5):725-33.

174. Livingstone MB, Robson PJ. Measurement of dietary intake in children. Proc Nutr Soc. 2000;59(2):279-93.

175. Monteiro JP. Consumo Alimentar - Visualizando Porções. Rio de Janeiro: Guanabara Koogan; 2007. 80 p.

176. Araujo MC, Yokoo EM, Pereira RA. Validation and Calibration of a Semiquantitative Food Frequency Questionnaire Designed for Adolescents. J Am Diet Assoc. 2010;110(8):1170-7.

177. Nutrition Coordinating Center, University of Minnesota. Nutrition Data System for Research. Minneapolis, MN: NCC; 2015.

178. StataCorp. Stata Statistical Software. College Station, TX: StataCorp LP; 2013. 
179. Grupo de Pesquisa de Avaliação do Consumo Alimentar [homepage]. Comandos para cálculo do IQD-R - Stata versão 10; 2012 [citado 4 jan. 2016]. Disponível em: http://www.gac-usp.com.br/resources/Calculo\%20do\%20IQDRevisado\%20e\%20seus\%20componentes_2012.pdf

180. Jellife DB. Evaluacion del estado de nutricion de la comunidad: serie de monografias $\mathrm{n}^{\mathrm{o}}$ 53. Geneva: World Health Organization; 1968. 291 p.

181. World Health Organization. Physical status: the use and interpretation of anthropometry. World Health Organ Tech Rep Ser. 1995;854:1-452.

182. Onis M, Onyango A, Borghi E, Siyam A, Nishida C, Siekmann J. Development of a WHO growth reference for school-aged children and adolescents. Bull World Heal Organ. 2007;85(9):660-7.

183. World Health Organization [homepage]. Growth reference data for 5- 19 years; 2007 [citado 20 mai. 2016]. Disponível em: http://www.who.int/growthref/en/

184. Meisser Redeuil K, Longet K, Bénet S, Munari C, Campos-Giménez E. Simultaneous quantification of 21 water soluble vitamin circulating forms in human plasma by liquid chromatography-mass spectrometry. J Chromatogr A. 2015;1422:89-98.

185. Masood A, Stark KD, Salem N. A simplified and efficient method for the analysis of fatty acid methyl esters suitable for large clinical studies. J Lipid Res. 2005;46(10):2299-305.

186. Destaillats F, Cruz-Hernandez C. Fast analysis by gas - liquid chromatography: Perspective on the resolution of complex fatty acid compositions. J Chromatogr A. 2007;1169(1-2):175-8.

187. Veiga, Gloria ValeriaCosta RS, Araújo MC, Souza AM, Bezerra IN, Barbosa FS, Sichier R, et al. Inadequate nutrient intake in Brazilian adolescents. Rev Saude Publica. 2013;47(1 Supl):212-21.

188. Castilhos CB, Schneider BC, Muniz LC, Assunção MCF. Qualidade da dieta de jovens aos 18 anos de idade, pertencentes à coorte de nascimentos de 1993 da cidade de Pelotas (RS), Brasil. Cien Saude Colet. 2015;20(11):3309-18. 
189. Ramos JM. Índice de Qualidade da Dieta e Indicadores do Estado Nutricional de Adolescentes Assistidos no Programa Médico de Família em Niterói-RJ: Projeto CAMELIA [dissertação na internet]. Rio de Janeiro (Brasil): Universidade Federal Fluminense, Instituto de Saúde da Comunidade; 2010 [citado 10 mai. 2017]. 101 p. Disponível em:

http://www.uff.br/saudecoletiva/images/Documentos/dissertacoes/defesa $\% 202010 /$ Tes e\%20final\%20-\%20Juliana\%20Montesso\%20(2).pdf

190. Fungwe T, Guenther PM, Juan W, Hiza H, Lino M. The Quality of Children's Diets in 2003-04 as Measured by the Healthy Eating Index-2005. Nutrition Insight 43. Washington, DC; 2009.

191. Tek NA, Yildiran H, Akbulut G, Bilici S, Koksal E, Karadag MG, et al. Evaluation of dietary quality of adolescents using Healthy Eating Index. Nutr Res Pr. 2011;5(4):322-8.

192. Angelopoulos P, Kourlaba G, Kondaki K, Fragiadakis GA, Manios Y. Assessing children's diet quality in Crete based on Healthy Eating Index: the Children Study. Eur J Clin Nutr. 2009;63(8):964-9.

193. Torres R, Santos E, Orraca L, Elias A, Palacios C. Diet quality, social determinants and weight status in 12-year-old Puerto Rican children. J Acad Nutr Diet. 2015;114(8):1230-5.

194. Wendpap LL, Ferreira MG, Rodrigues PRM, Pereira RA, Loureiro AS, GoncalvesSilva RMV. Adolescents' diet quality and associated factors. Cad Saúde Pública. 2014;30(1):97-106.

195. Pinheiro AC, Atalah E. Propuesta de una metodología de análisis de la calidad global de la alimentación. Rev Med Chil. 2005;133(2):175-82.

196. Instituto Brasileiro de Geografia e Estatística. Pesquisa de orçamentos familiares 2008-2009 : análise do consumo alimentar pessoal no Brasil / IBGE, Coordenação de Trabalho e Rendimento. Rio de Janeiro: IBGE, 2011. 150 p.

197. Hann CS, Rock CL, King I, Drewnowski A. Validation of the Healthy Eating Index with use of plasma biomarkers in a clinical sample of women. Am J Clin Nutr. 2001;74(4):479-86. 
198. Golley RK, Hendrie GA, Mcnaughton SA. Scores on the Dietary Guideline Index for Children and Adolescents Are Associated with Nutrient Intake and Socio-Economic Position but Not Adiposity. J Nutr. 2011;141(7):1340-7.

199. Backholer K, Spencer E, Gearon E, Magliano DJ, McNaughton SA, Shaw JE, et al. The association between socio-economic position and diet quality in Australian adults. Public Health Nutr. 2016;19(3):477-85.

200. McCabe-Sellers BJ, Bowman S, Stuff JE, Champagne CM, Simpson PM, Bogle ML. Assessment of the diet quality of US adults in the Lower Mississippi Delta. Am J Clin Nutr. 2007;86(3):697-706.

201. Enger SM, Longnecker MP, Chen MJ, Harper JM, Haile RW, Shikany JM, et al. Questionnaire Assessment of Intake of Specific Carotenoids. Cancer Epidemiol Biomarkers Prev. 1995;4(3):201-5.

202. Bingham SA, Gill C, Welch A, Cassidy A, Runswick SA, Oakes S, et al. Validation of dietary assessment methods in the UK arm of EPIC using weighed records, and 24hour urinary nitrogen and potassium and serum vitamin $\mathrm{C}$ and carotenoids as biomarkers. Int J Epidemiol. 1997;26(Suppl 1):S137-51.

203. Schröder H, Covas MI, Marrugat J, Vila J, Pena A, Alcántara M, et al. Use of a threeday estimated food record, a 72-hour recall and a food-frequency questionnaire for dietary assessment in a Mediterranean Spanish population. Clin Nutr. 2001;20(5):42937.

204. Al-Delaimy WK, Ferrari P, Slimani N, Pala V, Johansson I, Nilsson S, et al. Plasma carotenoids as biomarkers of intake of fruits and vegetables: individual-level correlations in the European Prospective Investigation into Cancer and Nutrition (EPIC). Eur J Clin Nutr. 2005;59(12):1387-96.

205. Souverein OW, Vries JHM, Freese R, Watzl B, Bub A, Miller ER, et al. Prediction of fruit and vegetable intake from biomarkers using individual participant data of dietcontrolled intervention studies. Br J Nutr. 2015;113(9):1396-409.

206. Jacques F, Sadowski A. Comparison questionnaire micronutrient of micronutrient and biochemical intake measured indicators of by a dietary. Am J Clin Nutr. 1993;57(2):182-9. 
207. Jwa SC, Ogawa K, Kobayashi M, Morisaki N, Sago H, Fujiwara T. Validation of a food-frequency questionnaire for assessing vitamin intake of Japanese women in early and late pregnancy with and without nausea and vomiting. J Nutr Sci. 2016;5(9):1-9.

208. Weir RR, Carson EL, Mulhern MS, Laird E, Healy M, Pourshahidi LK. Validation of a food frequency questionnaire to determine vitamin $D$ intakes using the method of triads. J Hum Nutr Diet. 2016;29(2):255-61.

209. Wu H, Gozdzik A, Barta JL, Wagner D, Cole DE, Vieth R, et al. The development and evaluation of a food frequency questionnaire used in assessing vitamin $\mathrm{D}$ intake in a sample of healthy young Canadian adults of diverse ancestry. Nutr Res.

2009;29(4):255-61.

210. Metherel AH, Armstrong JM, Patterson AC, Stark KD. Assessment of blood measures of n-3 polyunsaturated fatty acids with acute fish oil supplementation and washout in men and women. Prostaglandins Leukot Essent Fat Acids. 2009;81(1):23-9.

211. De Vriese SR, Matthys C, De Henauw S, De Backer G, Dhont M, Christophe AB. Maternal and umbilical fatty acid status in relation to maternal diet. Prostaglandins Leukot Essent Fatty Acids. 2002;67(6):389-96.

212. Sullivan BL, Williams PG, Meyer BJ. Biomarker validation of a long-chain omega-3 polyunsaturated fatty acid food frequency questionnaire. Lipids. 2006;41(9):845-50.

213. Patterson AC, Hogg RC, Kishi DM, Stark KD. Biomarker and Dietary Validation of a Canadian Food Frequency Questionnaire to Measure Eicosapentaenoic and Docosahexaenoic Acid Intakes from Whole Food, Functional Food, and Nutraceutical Sources. J Acad Nutr Diet. 2012;112(7):1005-14.

214. Tavendale R, Lee AJ, Smith WC, Tunstall-Pedoe H. Adipose tissue fatty acids in Scottish men and women: results from the Scottish Heart Health Study.

Atherosclerosis. 1992;94(Issues 2-3):161-9.

215. Crowe FL, Murray Skeaff C, Green TJ, Gray AR. Serum n-3 long-chain PUFA differ by sex and age in a population-based survey of New Zealand adolescents and adults. Br J Nutr. 2008;99(1):168-74.

216. Pawlosky R, Hibbeln J, Lin Y, Salem N. N-3 Fatty Acid Metabolism in Women. Br J Nutr. 2003;90(5):993-5. 
217. Pawlosky RJ, Hibbeln JR, Lin YH, Goodson S, Riggs P, Sebring N, et al. Effects of beef-and fish-based diets on the kinetics of n-3 fatty acid metabolism in human subjects. Am J Clin Nutr. 2003;77(3):565-72.

218. Stark KD, Park EJ, Holub BJ. Fatty acid composition of serum phospholipid of premenopausal women and postmenopausal women receiving and not receiving hormone replacement therapy. Menopause. 2003;10(5):448-55.

219. Giltay EJ, Gooren LJG, Toorians AWFT, Katan MB, Zock PL. Docosahexaenoic acid concentrations are higher in women than in men because of estrogenic effects. Am J Clin Nutr. 2004;80(5):1167-74.

220. Wennberg M, Vessby B, Johansson I. Evaluation of relative intake of fatty acids according to the Northern Sweden FFQ with fatty acid levels in erythrocyte membranes as biomarkers. Public Heal Nutr Nutr. 2009;12(9):1477-84.

221. Wolk A, Furuheim M, Vessby B. Nutritional Methodology Fatty Acid Composition of Adipose Tissue and Serum Lipids Are Valid Biological Markers Of Dairy Fat Intake in Men. J Nutr. 2001;131(3):828-33.

222. Smedman AE, Gustafsson IB, Berglund LG, Vessby BO. Pentadecanoic acid in serum as a marker for intake of milk fat: relations between intake of milk fat and metabolic risk factors. Am J Clin Nutr Clin Nutr. 1999;69(1):22-9.

223. Ohlsson L. Dairy products and plasma cholesterol levels. Food Nutr Res. 2010;54(1):5124.

224. Huth PJ, Park KM. Influence of Dairy Product and Milk Fat Consumption on Cardiovascular Disease Risk : A Review of the Evidence. Adv Nutr. 2012;3:266-85.

225. Chen G-C, Szeto IMY, Chen L-H, Han S-F, Li Y-J, van Hekezen R, et al. Dairy products consumption and metabolic syndrome in adults: systematic review and metaanalysis of observational studies. Sci Rep. 2015;5(1):14606.

226. Aune D, Norat T, Romundstad P, Vatten LJ. Dairy products and the risk of type 2 diabetes : a systematic review and dose-response meta-analysis of cohort studies. Am $\mathrm{J}$ Clin Nutr. 2013;98:1066-83.

227. O'Gorman A, Gibbons H, Brennan L. Metabolomics in the Identification of Biomarkers of Dietary Intake. Comput Struct Biotechnol J. 2013;4(5):1-7. 
228. Bailey LB, Stover PJ, Mcnulty H, Fenech MF, Iii JFG, Mills JL, et al. Biomarkers of Nutrition for Development - Folate Review. J Nutr. 2015;145(7):1-45.

229. Brevik A, Vollset SE, Tell GS, Refsum H, Ueland PM, Loeken EB, et al. Plasma concentration of folate as a biomarker for the intake of fruit and vegetables: The Hordaland Homocysteine Study. Am J Clin Nutr. 2005;81(2):434-9.

230. Pinto JT, Zempleni J. Riboflavin. Adv Nutr. 2016;7:973-5.

231. Iinuma S. Synthesis of riboflavin by intestinal bacteria. J Vitaminol. 1955;1(2):6-13.

232. Iglesia I, Mouratidou T, González-Gross M, Huybrechts I, Breidenassel C, Santabárbara J, et al. Foods contributing to vitamin B6, folate, and vitamin B12 intakes and biomarkers status in European adolescents: The HELENA study. Eur J Nutr. 2016 May 25; [Epub ahead of print]. Disponível em: https://link.springer.com/article/10.1007\%2Fs00394-016-1221-1

233. Naik S, Bhide V, Babhulkar A, Mahalle N, Parab S, Thakre R, et al. Daily milk intake improves vitamin B-12 status in young vegetarian Indians: an intervention trial. Nutr J. 2013;12(1):136.

234. Brouwer-Brolsma EM, Dhonukshe-Rutten RAM, van Wijngaarden JP, van der Zwaluw NL, van der Velde N, de Groot LCPGM. Dietary Sources of Vitamin B-12 and Their Association with Vitamin B-12 Status Markers in Healthy Older Adults in the B-PROOF Study. Nutrients. 2015;7(9):7781-97.

235. Ye X, Maras JE, Bakun PJ, Tucker KL. Dietary intake of vitamin B6, plasma pyridoxal 5'-phosphate and homocysteine in Puerto Rican adults. J Am Diet Assoc. 2010;110(11):1106-8.

236. Steluti J, Martini LA, Peters BSE, Marchioni DML. Folate, vitamin B6 and vitamin B12 in adolescence: serum concentrations, prevalence of inadequate intakes and sources in food. J Pediatr (Rio J). 2011;87(1):43-9.

237. Vandevijvere S, Geelen A, Gonzalez-Gross M, van't Veer P, Dallongeville J, Mouratidou T, et al. Evaluation of food and nutrient intake assessment using concentration biomarkers in European adolescents from the Healthy Lifestyle in Europe by Nutrition in Adolescence study. Br J Nutr. 2012;12(2013):1-12. 
238. Iglesia I, Dhonukshe-Rutten RAM, Bel-Serrat S, Doets EL, Cavelaars AEJM, Van 't Veer P, et al. Association between vitamin B12 intake and EURRECA's prioritized biomarkers of vitamin B12 in young populations: A systematic review. Public Health Nutr. 2013;16(10):1843-60.

239. Mann NJ, Li D, Sinclair AJ, Dudman NPB, Guo XW, Elsworth GR, et al. The effect of diet on plasma homocysteine concentrations in healthy male subjects. Eur J Clin Nutr. 1999;53(11):895-9.

240. Pounis G, Castelnuovo AFD, Lorgeril M, Krogh V, Siani A, Arnout J, et al. Folate intake and folate serum levels in men and women from two European populations: The IMMIDIET project. Nutrition. 2014;30(7-8):822-30.

241. Hatzis CM, Bertsias GK, Linardakis M, Scott JM, Kafatos AG. Dietary and other lifestyle correlates of serum folate concentrations in a healthy adult population in Crete, Greece: a cross-sectional study. Nutr J. 2006;5(5). 
APÊNDICES 


\section{APÊNDICE A - Descrição dos componentes do Índice de Qualidade da Dieta Revisado e respectiva classificação dos alimentos e ingredientes de preparações utilizados para o cálculo do questionário semiquantitativo de frequência alimentar.}

Frutas totais: Foram incluídas neste componente todas as frutas, com ou sem casca e sucos de frutas. Os alimentos e ingredientes de preparações do QSFA classificados para o cálculo deste componente foram: abacate, ameixa, amora, banana, caqui, carambola, damasco seco, graviola, kiwi, laranja, maçã, mamão, manga, melancia, melão, morango, pera, pêssego, romã, suco de laranja, suco de limão, suco de uva, uva e uva passa.

Frutas inteiras: Foram incluídas neste componente somente as frutas inteiras. Todos os sucos de frutas foram excluídos.

Vegetais totais e leguminosas: Foram incluídas neste componente todas as verduras e legumes. As leguminosas foram incluídas somente quando o grupo "Carnes, ovos e leguminosas" atingiu a recomendação, sendo computado apenas o seu excedente. Os alimentos e ingredientes de preparações do QSFA classificados para o cálculo deste componente foram: abóbora, abobrinha, acelga, agrião, alface, alho, batata doce, berinjela, beterraba, brócolis, cebola, cebolinha, cenoura, chicória, cogumelos, couve manteiga, couve-flor, escarola, espinafre, gengibre, molho de tomate, pepino, pimentão amarelo, pimentão verde, pimentão vermelho, quiabo, repolho, rúcula, salsão, salsinha e tomate.

Vegetais verdes-escuros, alaranjados e leguminosas: Foram incluídos neste componente todos os vegetais verde-escuros e alaranjados. As leguminosas foram incluídas somente quando o grupo "Carnes, ovos e leguminosas" atingiu a recomendação, sendo computado apenas o seu excedente. Os alimentos e ingredientes de preparações do QSFA classificados para o cálculo deste componente foram: abóbora, acelga, agrião, batata doce, brócolis, cenoura, chicória, couve manteiga, escarola, espinafre, rúcula e salsinha.

Cereais totais: Foram incluídos neste componente todos os grãos, tubérculos, raízes, preparações feitas à base de farinha, além de todos os alimentos e preparações incluídos no componente "Cereais integrais". Os alimentos e ingredientes de preparações do QSFA classificados para o cálculo deste componente foram: amido, amido de milho, arroz parboilizado, batata inglesa, biscoito água e sal, biscoito de maisena, biscoito recheado, cereal 
matinal, chocolate em pó diet, farinha de araruta, farinha de arroz, farinha de mandioca, farinha de trigo refinada, macarrão, mandioca, pão branco, pipoca e salgadinho tipo chips.

Cereais integrais: Foram incluídos neste componente os grãos inteiros (com farelo, gérmen e endosperma) e as preparações feitas à base de farinhas integrais. Os alimentos e ingredientes de preparações do QSFA classificados para o cálculo deste componente foram: arroz integral, aveia, barra de cereal, farinha de milho, farinha de trigo integral, fubá, granola, macarrão integral e trigo para quibe.

Leite e derivados: Foram incluídos neste componente todos os tipos de leite, seus produtos derivados e bebidas à base de soja (tais como sucos). Foram excluídos deste grupo todos os produtos derivados de leite com alto teor de lipídios, tais como requeijão, creme de leite e manteiga. Os alimentos e ingredientes de preparações do QSFA classificados para o cálculo deste componente foram: bebida à base de soja, iogurtes (integral, desnatado, frutado ou não), leite fluído (desnatado, integral ou semidesnatado), leite em pó integral e queijos (cottage, cheddar, fresco, mozarela, parmesão e ricota).

Carnes, ovos e leguminosas: Foram incluídos neste componente todos os tipos de carnes, ovos e produtos à base de soja (com exceção do leite de soja). As leguminosas foram incluídas até este grupo atingir a pontuação máxima, sendo o excedente considerado simultaneamente nos grupos "Vegetais totais e leguminosas" e "Vegetais verde-escuros, alaranjados e leguminosas". Os alimentos e ingredientes de preparações do QSFA classificados para o cálculo deste componente foram: carnes (bovina, de aves, de peixes e suína), concentrado proteico de soja, linguiça, mortadela, ovos, peito de peru, presunto, proteína texturizada de soja, salsicha, soja e vísceras.

Óleos: Foram incluídas neste componente todas as gorduras líquidas à temperatura ambiente, tais como os óleos utilizados nas preparações culinárias, margarinas, molhos de salada de origem vegetal e não hidrogenados e gordura mono e poli-insaturadas de peixes e de oleaginosas. Gorduras de origem animal não foram incluídas neste componente. Os alimentos e ingredientes de preparações do QSFA classificados para o cálculo deste componente foram: óleos vegetais (azeite de oliva, óleo de canola, óleo de milho, óleo de soja), margarina, maionese, peixes e oleaginosas (castanha do Brasil, castanha de caju, amêndoas, amendoim, coco e creme de avelã). 
GORD AA (calorias provenientes de gorduras sólidas, álcool e açúcar de adição): Uma vez que o software de cálculo de dietas Nutrition Data System for Research (NDSR) fornece a quantidade de gordura saturada, gordura trans, etanol, carboidratos do álcool e açúcar de adição em cada alimento, incluindo o açúcar adicionado nas preparações em domicílio e no processo industrial, foram utilizados somente seus valores em grama disponibilizados pelo software para o cálculo do componente.

Observação: Uma vez que as leguminosas são computadas em diversos componentes, esses alimentos foram classificados separadamente para depois serem agrupados. Os alimentos e ingredientes de preparações do questionário semiquantitativo de frequência alimentar incluídos neste grupo foram: ervilha, feijões e lentilha. 
ANEXOS 


\section{ANEXO A - Critério de Classificação Econômica Brasil da Associação Brasileira de Empresas de Pesquisa}
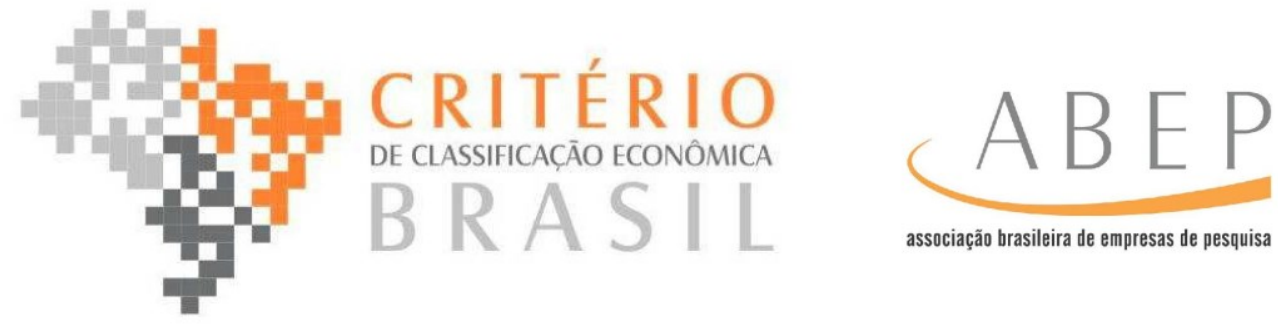

O Critério de Classificação Econômica Brasil, enfatiza sua função de estimar o poder de compra das pessoas e famílias urbanas, abandonando a pretensão de classificar a população em termos de "classes sociais". A divisão de mercado definida abaixo é de classes econômicas.

\section{SISTEMA DE PONTOS}

Posse de itens

\begin{tabular}{llllcc} 
& \multicolumn{3}{c}{ Quantidade de Itens } \\
& 0 & 1 & 2 & 3 & 4 ou + \\
\hline Televisão em cores & 0 & 1 & 2 & 3 & 4 \\
\hline Rádio & 0 & 1 & 2 & 3 & 4 \\
\hline Banheiro & 0 & 4 & 5 & 6 & 7 \\
\hline Automóvel & 0 & 7 & 9 & 9 \\
Empregada mensalista & 0 & 4 & 7 & 4 & 4 \\
Máquina de lavar & 0 & 3 & 4 & 4 & 2 \\
Videocassete e/ou DVD & 0 & 2 & 2 & 2 & 2 \\
Geladeira & 0 & 2 & 2 & 2 & 2 \\
\hline Freezer (aparelho independente ou parte da geladeira duplex) & 0 & 4 & 4 & 4 & 4 \\
\hline
\end{tabular}

Grau de Instrução do chefe de família

Nomenclatura Antiga

Nomenclatura Atual

Analfabeto/ Primário incompleto Analfabeto/ Fundamental 1 Incompleto

Primário completo/ Ginasial incompleto

Fundamental 1 Completo / Fundamental 2 Incompleto

Ginasial completo/ Colegial incompleto

Fundamental 2 Completo/ Médio Incompleto

Colegial completo/ Superior incompleto

Médio Completo/ Superior Incompleto

Superior completo

Superior Completo

\section{CORTES DO CRITÉRIO BRASIL}

\begin{tabular}{|cc|}
\hline Classe & Pontos \\
\hline A1 & $42-46$ \\
\hline A2 & $35-41$ \\
\hline B1 & $29-34$ \\
\hline B2 & $23-28$ \\
\hline C1 & $18-22$ \\
\hline C2 & $14-17$ \\
\hline D & $8-13$ \\
\hline E & $0-7$ \\
\hline
\end{tabular}




\section{PROCEDIMENTO NA COLETA DOS ITENS}

É importante e necessário que o critério seja aplicado de forma uniforme e precisa. Para tanto, é fundamental atender integralmente as definições e procedimentos citados a seguir.

Para aparelhos domésticos em geral devemos:

Considerar os seguintes casos

Bem alugado em caráter permanente

Bem emprestado de outro domicílio há mais de 6

meses

Bem quebrado há menos de 6 meses

Não considerar os seguintes casos

Bem emprestado para outro domicílio há mais de 6

meses

Bem quebrado há mais de 6 meses

Bem alugado em caráter eventual

Bem de propriedade de empregados ou pensionistas

\section{Televisores}

Considerar apenas os televisores em cores. Televisore de uso de empregados domésticos (declaração espontânea) só devem ser considerados caso tenha(m) sido adquirido(s) pela família empregadora.

\section{Rádio}

Considerar qualquer tipo de rádio no domicílio, mesmo que esteja incorporado a outro equipamento de som ou televisor. Rádios tipo walkman, conjunto 3 em 1 ou microsystems devem ser considerados, desde que possam sintonizar as emissoras de rádio convencionais. Não pode ser considerado o rádio de automóvel.

\section{Banheiro}

O que define o banheiro é a existência de vaso sanitário. Considerar todos os banheiros e lavabos com vaso sanitário, incluindo os de empregada, os localizados fora de casa e os da(s) suite(s). Para se considerado, o banheiro tem que ser privativo do domicílio. Banheiros coletivos (que servem a mais de uma habitação) não devem ser considerados.

\section{Automóvel}

Não considerar táxis, vans ou pick-ups usados para fretes, ou qualquer veículo usado para atividades profissionais. Veículos de uso misto (lazer e profissional) não devem ser considerados.

\section{Empregado doméstico}

Considerar apenas os empregados mensalistas, isto é, aqueles que trabalham pelo menos 5 dias por semana, durmam ou não no emprego. Não esquecer de incluir babás, motoristas, cozinheiras, copeiras, arrumadeiras, considerando sempre os mensalistas.

Note bem: o termo empregados mensalistas se refere aos empregados que trabalham no domicílio de forma permanente e/ou continua, pelo menos 5 dias por semana, e não ao regime de pagamento do salário.

\section{Máquina de Lavar}

Considerar máquina de lavar roupa, somente as máquinas automáticas e/ou semiautomática

$\mathrm{O}$ tanquinho NÃO deve ser considerado.

\section{Videocassete e/ou DVD}

Verificar presença de qualquer tipo de vídeo cassete ou aparelho de DVD.

\section{Geladeira e Freezer}

No quadro de pontuação há duas linhas independentes para assinalar a posse de geladeira e freezer respectivamente. A pontuação será aplicada de forma independente:

Havendo geladeira no domicílio, independente da quantidade, serão atribuídos os pontos (4) correspondentes a posse de geladeira; Se a geladeira tiver um freezer incorporado $-2^{\mathrm{a}}$. porta - ou houver no domicílio um freezer independente serão atribuídos os pontos (2) correspondentes ao freezer.

As possibilidades são:

\begin{tabular}{|c|c|}
\hline Não possui geladeira nem freezer & $0 \mathrm{pt}$ \\
\hline $\begin{array}{l}\text { Possui geladeira simples (não duplex) e não } \\
\text { possui freezer }\end{array}$ & 4 pts \\
\hline $\begin{array}{l}\text { Possui geladeira de duas portas e não possui } \\
\text { freezer }\end{array}$ & $6 \mathrm{pts}$ \\
\hline Possui geladeira de duas portas e freezer & $6 \mathrm{pts}$ \\
\hline $\begin{array}{l}\text { Possui freezer mas não geladeira (caso raro } \\
\text { mas aceitável) }\end{array}$ & $2 \mathrm{pt}$ \\
\hline
\end{tabular}




\section{OBSERVACÕES IMPORTANTES}

Este critério foi construído para definir grandes classes que atendam às necessidades de segmentação (por poder aquisitivo) da grande maioria das empresas. Não pode, entretanto, como qualquer outro critério, satisfazer todos os usuários em todas as circunstâncias. Certamente há muitos casos em que o universo a ser pesquisado é de pessoas, digamos, com renda pessoal mensal acima de US\$30.000. Em casos como esse, o pesquisador deve procurar outros critérios de seleção que não o CCEB.

A outra observação é que o CCEB, como os seus antecessores, foi construído com a utilização de técnicas estatísticas que, como se sabe, sempre se baseiam em coletivos. Em uma determinada amostra, de determinado tamanho, temos uma determinada probabilidade de classificação correta, (que, esperamos, seja alta) e uma probabilidade de erro de classificação (que, esperamos, seja baixa). O que esperamos é que os casos incorretamente classificados sejam pouco numerosos, de modo a não distorcer significativamente os resultados de nossa investigação.

Nenhum critério, entretanto, tem validade sob uma análise individual. Afirmações freqüentes do tipo "... conheço um sujeito que é obviamente classe $D$, mas pelo critério é classe B..." não invalidam o critério que é feito para funcionar estatisticamente. Servem porém, para nos alertar, quando trabalhamos na análise individual, ou quase individual, de comportamentos e atitudes (entrevistas em profundidade e discussões em grupo respectivamente). Numa discussão em grupo um único caso de má classificação pode pôr a perder todo o grupo. No caso de entrevista em profundidade os prejuízos são ainda mais óbvios. Além disso, numa pesquisa qualitativa, raramente uma definição de classe exclusivamente econômica será satisfatória.

Portanto, é de fundamental importância que todo o mercado tenha ciência de que o CCEB, ou qualquer outro critério econômico, não é suficiente para uma boa classificação em pesquisas qualitativas. Nesses casos deve-se obter além do CCEB, o máximo de informações (possível, viável, razoável) sobre os respondentes, incluindo então seus comportamentos de compra, preferências e interesses, lazer e hobbies e até características de personalidade.

Uma comprovação adicional da conveniência do Critério de Classificação Econômica Brasil é sua discriminação efetiva do poder de compra entre as diversas regiões brasileiras, revelando importantes diferenças entre elas

\section{RENDA FAMILIAR POR CLASSES}

\begin{tabular}{|c|c|c|}
\hline \multirow[t]{2}{*}{ Classe } & \multirow[t]{2}{*}{ Pontos } & $\begin{array}{l}\text { Renda média familiar } \\
\text { (Valor Bruto em R\$̦) }\end{array}$ \\
\hline & & 2010 \\
\hline $\mathrm{A} 1$ & 42 a 46 & 12.926 \\
\hline $\mathrm{A} 2$ & 35 a 41 & 8.418 \\
\hline B1 & 29 a 34 & 4.418 \\
\hline B2 & 23 a 28 & 2.565 \\
\hline $\mathrm{C} 1$ & 18 a 22 & 1.541 \\
\hline $\mathrm{C} 2$ & 14 a 17 & 1.024 \\
\hline $\mathrm{D}$ & 8 a 13 & 714 \\
\hline$E$ & 0 a 7 & 477 \\
\hline
\end{tabular}




\section{ANEXO B - Questionário semiquantitativo de frequência alimentar}

Nome / Número de Identificação:

\begin{tabular}{|c|c|c|c|c|c|}
\hline LEITE E DERIVADOS & QUANTAS VEZES? & UNIDADE & $\mathbf{P} 25$ & P 50 & $\mathbf{P} 75$ \\
\hline Leite integral & N12345678910 & $\mathrm{D} \quad \mathrm{S} \quad \mathrm{M}$ & $200 \mathrm{ml}$ & $240 \mathrm{ml}$ & $250 \mathrm{ml}$ \\
\hline Leite desnatado & N 12345678910 & $\mathrm{D} \quad \mathrm{S} \quad \mathrm{M}$ & $200 \mathrm{ml}$ & $240 \mathrm{ml}$ & $250 \mathrm{ml}$ \\
\hline Iogurte natural Integral & N 12345678910 & $\mathrm{D} \quad \mathrm{S} \quad \mathrm{M}$ & $80 \mathrm{ml}$ & $120 \mathrm{ml}$ & $140 \mathrm{ml}$ \\
\hline Iogurte com frutas & N 12345678910 & $\mathrm{D} \quad \mathrm{S} \quad \mathrm{M}$ & $80 \mathrm{ml}$ & $120 \mathrm{ml}$ & $140 \mathrm{ml}$ \\
\hline Queijo fresco ou ricota & N 12345678910 & $\begin{array}{lll}\mathrm{D} & \mathrm{S} & \mathrm{M}\end{array}$ & $15 \mathrm{~g}$ & $20 \mathrm{~g}$ & $25 \mathrm{~g}$ \\
\hline Queijos amarelos & N 12345678910 & $\mathrm{D} \quad \mathrm{S} \quad \mathrm{M}$ & $10 \mathrm{~g}$ & $15 \mathrm{~g}$ & $25 \mathrm{~g}$ \\
\hline Requeijão & N 12345678910 & $\begin{array}{lll}\mathrm{D} & \mathrm{S} & \mathrm{M}\end{array}$ & $10 \mathrm{~g}$ & $15 \mathrm{~g}$ & $30 \mathrm{~g}$ \\
\hline PÃES E CEREAIS MATINAIS & QUANTAS VEZES? & UNIDADE & $\mathbf{P} 25$ & $\mathbf{P 5 0}$ & P 75 \\
\hline Pão francês, forma, outros & N12345678910 & $\begin{array}{lll}\mathrm{D} & \mathrm{S} & \mathrm{M}\end{array}$ & $25 \mathrm{~g}$ & $50 \mathrm{~g}$ & $75 \mathrm{~g}$ \\
\hline Pão doce, queijo, croissant & N 12345678910 & $\mathrm{D} \quad \mathrm{S} \quad \mathrm{M}$ & $25 \mathrm{~g}$ & $50 \mathrm{~g}$ & $60 \mathrm{~g}$ \\
\hline Biscoitos doces, salgados ou torradas & N 12345678910 & $\begin{array}{lll}\mathrm{D} & \mathrm{S} & \mathrm{M}\end{array}$ & $30 \mathrm{~g}$ & $52 \mathrm{~g}$ & $65 \mathrm{~g}$ \\
\hline $\begin{array}{l}\text { Aveia, granola, barra de cereais e } \\
\text { sucrilhos }\end{array}$ & N 12345678910 & $\begin{array}{lll}\mathrm{D} & \mathrm{S} & \mathrm{M}\end{array}$ & $20 \mathrm{~g}$ & $38 \mathrm{~g}$ & $40 \mathrm{~g}$ \\
\hline GORDURAS & QUANTAS VEZES? & UNIDADE & P 25 & P 50 & P 75 \\
\hline Margarina comum & N 12345678910 & $\begin{array}{lll}\mathrm{D} & \mathrm{S} & \mathrm{M}\end{array}$ & $4 \mathrm{~g}$ & $6 \mathrm{~g}$ & $10 \mathrm{~g}$ \\
\hline Manteiga & N 12345678910 & $\begin{array}{lll}\mathrm{D} & \mathrm{S} & \mathrm{M}\end{array}$ & $4 \mathrm{~g}$ & $6 \mathrm{~g}$ & $8,5 \mathrm{~g}$ \\
\hline Maionese & N 12345678910 & $\mathrm{D} \quad \mathrm{S} \quad \mathrm{M}$ & $12 \mathrm{~g}$ & $27 \mathrm{~g}$ & $35 \mathrm{~g}$ \\
\hline $\begin{array}{l}\text { CEREAIS, TUBÉRCULOS E } \\
\text { MASSAS }\end{array}$ & QUANTAS VEZES? & UNIDADE & $\mathbf{P} 25$ & P 50 & P 75 \\
\hline Arroz branco & N12345678910 & $\begin{array}{lll}\mathrm{D} & \mathrm{S} & \mathrm{M}\end{array}$ & $60 \mathrm{~g}$ & $75 \mathrm{~g}$ & $100 \mathrm{~g}$ \\
\hline Batata, mandioca, polenta fritas & N 12345678910 & $\begin{array}{lll}\mathrm{D} & \mathrm{S} & \mathrm{M}\end{array}$ & $60 \mathrm{~g}$ & $75 \mathrm{~g}$ & $112 \mathrm{~g}$ \\
\hline Batata, mandioca, polenta (não fritos) & N 12345678910 & $\mathrm{D} \quad \mathrm{S} \quad \mathrm{M}$ & $30 \mathrm{~g}$ & $50 \mathrm{~g}$ & $100 \mathrm{~g}$ \\
\hline Milho verde & N 12345678910 & $\begin{array}{lll}\mathrm{D} & \mathrm{S} & \mathrm{M}\end{array}$ & $48 \mathrm{~g}$ & $66 \mathrm{~g}$ & $103 \mathrm{~g}$ \\
\hline Massas: macarrão, lasanha, nhoque & N 12345678910 & $\mathrm{D} \quad \mathrm{S} \quad \mathrm{M}$ & $100 \mathrm{~g}$ & $125 \mathrm{~g}$ & $200 \mathrm{~g}$ \\
\hline Salgados e tortas & N 12345678910 & $\begin{array}{lll}\mathrm{D} & \mathrm{S} & \mathrm{M}\end{array}$ & $48 \mathrm{~g}$ & $80 \mathrm{~g}$ & $96 \mathrm{~g}$ \\
\hline Pizza & N 12345678910 & $\begin{array}{lll}\mathrm{D} & \mathrm{S} & \mathrm{M}\end{array}$ & $55 \mathrm{~g}$ & $125 \mathrm{~g}$ & $180 \mathrm{~g}$ \\
\hline Farofa, farinha de milho & N 12345678910 & $\mathrm{D} \quad \mathrm{S} \quad \mathrm{M}$ & $15 \mathrm{~g}$ & $20 \mathrm{~g}$ & $30 \mathrm{~g}$ \\
\hline FRUTAS E SUCOS NATURAIS & QUANTAS VEZES? & UNIDADE & P 25 & P 50 & P 75 \\
\hline Laranja, mexerica, pokan & N 12345678910 & $\begin{array}{lll}\mathrm{D} & \mathrm{S} & \mathrm{M}\end{array}$ & $90 \mathrm{~g}$ & $107 \mathrm{~g}$ & $180 \mathrm{~g}$ \\
\hline Banana & N 12345678910 & $\begin{array}{lll}\mathrm{D} & \mathrm{S} & \mathrm{M}\end{array}$ & $40 \mathrm{~g}$ & $65 \mathrm{~g}$ & $120 \mathrm{~g}$ \\
\hline Maçã, pêra & N 12345678910 & $\begin{array}{lll}\mathrm{D} & \mathrm{S} & \mathrm{M}\end{array}$ & $60 \mathrm{~g}$ & $80 \mathrm{~g}$ & $110 \mathrm{~g}$ \\
\hline Mamão, papaya & N 12345678910 & $\begin{array}{lll}\mathrm{D} & \mathrm{S} & \mathrm{M}\end{array}$ & $100 \mathrm{~g}$ & $117 \mathrm{~g}$ & $135 \mathrm{~g}$ \\
\hline Melancia, melão & N 12345678910 & $\mathrm{D} \quad \mathrm{S} \quad \mathrm{M}$ & $81 \mathrm{~g}$ & $132 \mathrm{~g}$ & $150 \mathrm{~g}$ \\
\hline
\end{tabular}




\begin{tabular}{|c|c|c|c|c|c|}
\hline Uva, abacaxi, goiaba (na época) & N 12345678910 & $\begin{array}{lll}\mathrm{D} & \mathrm{S} & \mathrm{M}\end{array}$ & $95 \mathrm{~g}$ & $116 \mathrm{~g}$ & $170 \mathrm{~g}$ \\
\hline Manga, caqui (na época) & N 12345678910 & $\begin{array}{lll}\mathrm{D} & \mathrm{S} & \mathrm{M}\end{array}$ & $20 \mathrm{~g}$ & $40 \mathrm{~g}$ & $60 \mathrm{~g}$ \\
\hline Outras frutas & N 12345678910 & $\begin{array}{lll}\mathrm{D} & \mathrm{S} & \mathrm{M}\end{array}$ & $10 \mathrm{~g}$ & $25 \mathrm{~g}$ & $60 \mathrm{~g}$ \\
\hline Suco de laranja natural & N 12345678910 & $\begin{array}{lll}\mathrm{D} & \mathrm{S} & \mathrm{M}\end{array}$ & $165 \mathrm{ml}$ & $200 \mathrm{ml}$ & $250 \mathrm{ml}$ \\
\hline Suco de outras frutas & N 12345678910 & $\begin{array}{lll}\mathrm{D} & \mathrm{S} & \mathrm{M}\end{array}$ & $165 \mathrm{ml}$ & $200 \mathrm{ml}$ & $250 \mathrm{ml}$ \\
\hline LEGUMINOSAS & QUANTAS VEZES? & UNIDADE & P 25 & P 50 & P 75 \\
\hline Feijão roxo, carioca & N12345678910 & $\begin{array}{lll}\mathrm{D} & \mathrm{S} & \mathrm{M}\end{array}$ & $34 \mathrm{~g}$ & $65 \mathrm{~g}$ & $70 \mathrm{~g}$ \\
\hline Feijoada & N 12345678910 & $\mathrm{D} \quad \mathrm{S} \quad \mathrm{M}$ & $55 \mathrm{~g}$ & $125 \mathrm{~g}$ & $240 \mathrm{~g}$ \\
\hline VERDURAS E LEGUMES & QUANTAS VEZES? & $\overline{\text { UNIDADE }}$ & P 25 & $\mathbf{P 5 0}$ & P 75 \\
\hline Alface, escarola, agrião, rúcula, almeirão & N 12345678910 & $\begin{array}{lll}\mathrm{D} & \mathrm{S} & \mathrm{M}\end{array}$ & $20 \mathrm{~g}$ & $35 \mathrm{~g}$ & $40 \mathrm{~g}$ \\
\hline Repolho, acelga, couve, espinafre & N 12345678910 & D $\quad \mathrm{S} \quad \mathrm{M}$ & $23,5 \mathrm{~g}$ & $33 \mathrm{~g}$ & $50 \mathrm{~g}$ \\
\hline Couve-flor, brócolis & N 12345678910 & $\mathrm{D} \quad \mathrm{S} \quad \mathrm{M}$ & $25 \mathrm{~g}$ & $32 \mathrm{~g}$ & $56 \mathrm{~g}$ \\
\hline Cenoura, abóbora & N 12345678910 & $\begin{array}{lll}\mathrm{D} & \mathrm{S} & \mathrm{M}\end{array}$ & $11 \mathrm{~g}$ & $20 \mathrm{~g}$ & $30 \mathrm{~g}$ \\
\hline Tomate & N 12345678910 & D $\quad \mathrm{S} \quad \mathrm{M}$ & $30 \mathrm{~g}$ & $37 \mathrm{~g}$ & $44 \mathrm{~g}$ \\
\hline Berinjela & N 12345678910 & $\begin{array}{lll}\mathrm{D} & \mathrm{S} & \mathrm{M}\end{array}$ & $20 \mathrm{~g}$ & $30 \mathrm{~g}$ & $62,5 \mathrm{~g}$ \\
\hline Beterraba & N 12345678910 & $\begin{array}{lll}\mathrm{D} & \mathrm{S} & \mathrm{M}\end{array}$ & $18 \mathrm{~g}$ & $30 \mathrm{~g}$ & $48 \mathrm{~g}$ \\
\hline Vagem, chuchu, abobrinha & N 12345678910 & $\mathrm{D} \quad \mathrm{S} \quad \mathrm{M}$ & $12,5 \mathrm{~g}$ & $25 \mathrm{~g}$ & $40 \mathrm{~g}$ \\
\hline Sopas & N 12345678910 & $\begin{array}{lll}\mathrm{D} & \mathrm{S} & \mathrm{M}\end{array}$ & $182 \mathrm{~g}$ & $290 \mathrm{~g}$ & $325 \mathrm{~g}$ \\
\hline CARNES E OVOS & QUANTAS VEZES? & UNIDADE & P 25 & P 50 & P 75 \\
\hline Carne bovina s/ gordura & N12345678910 & $\begin{array}{lll}\mathrm{D} & \mathrm{S} & \mathrm{M}\end{array}$ & $50 \mathrm{~g}$ & $80 \mathrm{~g}$ & $100 \mathrm{~g}$ \\
\hline Carne bovina c/ gordura & N 12345678910 & $\begin{array}{lll}\mathrm{D} & \mathrm{S} & \mathrm{M}\end{array}$ & $50 \mathrm{~g}$ & $80 \mathrm{~g}$ & $100 \mathrm{~g}$ \\
\hline Carne de Porco s/ gordura & N 12345678910 & D $\quad \mathrm{S} \quad \mathrm{M}$ & $50 \mathrm{~g}$ & $80 \mathrm{~g}$ & $100 \mathrm{~g}$ \\
\hline Carne de Porco c/ gordura & N 12345678910 & $\begin{array}{lll}\mathrm{D} & \mathrm{S} & \mathrm{M}\end{array}$ & $50 \mathrm{~g}$ & $80 \mathrm{~g}$ & $100 \mathrm{~g}$ \\
\hline Carne de frango ou de outras aves s/ pele & N 12345678910 & $\begin{array}{lll}\mathrm{D} & \mathrm{S} & \mathrm{M}\end{array}$ & $46 \mathrm{~g}$ & $90 \mathrm{~g}$ & $125 \mathrm{~g}$ \\
\hline Carne de frango ou de outras aves c/ pele & N 12345678910 & $\begin{array}{lll}\mathrm{D} & \mathrm{S} & \mathrm{M}\end{array}$ & $46 \mathrm{~g}$ & $90 \mathrm{~g}$ & $125 \mathrm{~g}$ \\
\hline Peixes & N 12345678910 & $\begin{array}{lll}\mathrm{D} & \mathrm{S} & \mathrm{M}\end{array}$ & $50 \mathrm{~g}$ & $100 \mathrm{~g}$ & $165 \mathrm{~g}$ \\
\hline Lingüiça, salsicha & N 12345678910 & $\begin{array}{lll}\mathrm{D} & \mathrm{S} & \mathrm{M}\end{array}$ & $50 \mathrm{~g}$ & $60 \mathrm{~g}$ & $120 \mathrm{~g}$ \\
\hline Ovo cozido & N 12345678910 & $\begin{array}{lll}\mathrm{D} & \mathrm{S} & \mathrm{M}\end{array}$ & $25 \mathrm{~g}$ & $50 \mathrm{~g}$ & $75 \mathrm{~g}$ \\
\hline Ovo frito & N 12345678910 & $\begin{array}{lll}\mathrm{D} & \mathrm{S} & \mathrm{M}\end{array}$ & $25 \mathrm{~g}$ & $62 \mathrm{~g}$ & $90 \mathrm{~g}$ \\
\hline Presunto, mortadela & N 12345678910 & $\begin{array}{lll}\mathrm{D} & \mathrm{S} & \mathrm{M}\end{array}$ & $10 \mathrm{~g}$ & $15 \mathrm{~g}$ & $25 \mathrm{~g}$ \\
\hline BEBIDAS & QUANTAS VEZES? & UNIDADE & P 25 & P 50 & P 75 \\
\hline Café com açúcar & N 12345678910 & $\begin{array}{lll}\mathrm{D} & \mathrm{S} & \mathrm{M}\end{array}$ & $50 \mathrm{ml}$ & - & $100 \mathrm{ml}$ \\
\hline Chá preto ou mate & N 12345678910 & $\begin{array}{lll}\mathrm{D} & \mathrm{S} & \mathrm{M}\end{array}$ & $85 \mathrm{ml}$ & $165 \mathrm{ml}$ & $200 \mathrm{ml}$ \\
\hline Chá de ervas & N 12345678910 & $\begin{array}{lll}\mathrm{D} & \mathrm{S} & \mathrm{M}\end{array}$ & $85 \mathrm{ml}$ & $165 \mathrm{ml}$ & $200 \mathrm{ml}$ \\
\hline Água & N 12345678910 & $\begin{array}{lll}\mathrm{D} & \mathrm{S} & \mathrm{M}\end{array}$ & $165 \mathrm{ml}$ & $200 \mathrm{ml}$ & $240 \mathrm{ml}$ \\
\hline Sucos artificiais & N 12345678910 & $\begin{array}{lll}\mathrm{D} & \mathrm{S} & \mathrm{M}\end{array}$ & $165 \mathrm{ml}$ & $200 \mathrm{ml}$ & $240 \mathrm{ml}$ \\
\hline Refrigerante diet & N 12345678910 & $\begin{array}{lll}\mathrm{D} & \mathrm{S} & \mathrm{M}\end{array}$ & $100 \mathrm{ml}$ & $165 \mathrm{ml}$ & $250 \mathrm{ml}$ \\
\hline Refrigerante normal & N 12345678910 & $\mathrm{D} \quad \mathrm{S} \quad \mathrm{M}$ & $165 \mathrm{ml}$ & $200 \mathrm{ml}$ & $240 \mathrm{ml}$ \\
\hline
\end{tabular}




\begin{tabular}{|l|c|ccc|ccc|}
\hline Refrigerante fosfatado & N 12345678910 & D & M & $165 \mathrm{ml}$ & $200 \mathrm{ml}$ & $240 \mathrm{ml}$ \\
\hline DOCES E MISCELÂNEAS & QUANTAS VEZES? & UNIDADE & P 25 & P 50 & P 75 \\
\hline Bolo, tortas, pavês & N 12345678910 & D & S & M & $30 \mathrm{~g}$ & $50 \mathrm{~g}$ & $60 \mathrm{~g}$ \\
\hline Chocolate, brigadeiro & N 12345678910 & D & S & M & $20 \mathrm{~g}$ & $30 \mathrm{~g}$ & $42 \mathrm{~g}$ \\
\hline Mel, geléia & N 12345678910 & D & S & M & $9 \mathrm{~g}$ & $13,5 \mathrm{~g}$ & $18 \mathrm{~g}$ \\
\hline Sorvetes, milk-shake & N 12345678910 & D & S & M & $70 \mathrm{~g}$ & $115 \mathrm{~g}$ & $160 \mathrm{~g}$ \\
\hline Pudins, doces com leite & N 12345678910 & D & S & M & $50 \mathrm{~g}$ & $65 \mathrm{~g}$ & $80 \mathrm{~g}$ \\
\hline Doces de frutas & N 12345678910 & D & S & M & $30 \mathrm{~g}$ & $40 \mathrm{~g}$ & $55 \mathrm{~g}$ \\
\hline Pipoca, salgadinho chips, outros & N 12345678910 & D & S & M & $20 \mathrm{~g}$ & $50 \mathrm{~g}$ & $75 \mathrm{~g}$ \\
\hline Açúcar & N 12345678910 & D & S & M & $12 \mathrm{~g}$ & $24 \mathrm{~g}$ & $48 \mathrm{~g}$ \\
\hline Achocolatado & N 12345678910 & D & S & M & $4 \mathrm{~g}$ & $8 \mathrm{~g}$ & $16 \mathrm{~g}$ \\
\hline
\end{tabular}

1)

\begin{tabular}{|l|l|lll|}
\hline $\begin{array}{l}\text { Com que frequência você usa gordura ou óleo no } \\
\text { preparo de suas refeições? }\end{array}$ & N 12345678910 & D & S & M \\
\hline $\begin{array}{l}\text { Quantas porções de vegetais (verduras e legumes) você } \\
\text { costuma comer, sem incluir batatas ou saladas de } \\
\text { maionese? }\end{array}$ & N 12345678910 & D & S & M \\
\hline $\begin{array}{l}\text { Quantas porções de frutas você costuma comer, sem } \\
\text { incluir sucos de frutas? }\end{array}$ & N 12345678910 & D & S & M \\
\hline
\end{tabular}

2) Por favor, informe qualquer outro alimento ou preparação que você costuma comer ou beber e que não tenha sido citado aqui

\begin{tabular}{|l|l|l|}
\hline ALIMENTO & FREQUÊNCIA & PORÇ ̃̃O \\
\hline & & \\
\hline & & \\
\hline & & \\
\hline
\end{tabular}

3) Quantas refeições você faz por dia?

4) Que tipo de óleo/gordura você costuma usar no cozimento/preparo de refeições?
(00) Não usa
(04) Óleo de soja/milho/outros
(01) Margarina
(05) Bacon
(02) Manteiga
(06) Banha
(03) Azeite de oliva
(99) Não sabe/não cozinha 
5) Quando você come carne de boi/vaca ou de porco, você costuma comer a gordura visível?
(1) Sempre
(2) Algumas vezes
(3) Raramente ou não come

B - Quando você come carne de frango, costuma comer a pele?
(1) Sempre
(2) Algumas vezes
(3) Raramente ou não come

6) Você costuma acrescentar sal na comida depois de pronta?
(1) Sempre
(2) Algumas vezes
(3) Raramente ou não come

7) Quando você come queijo/requeijão, iogurte/sorvete, maionese/molhos para salada, com que frequência esses alimentos são do tipo light?

- Iogurte / sorvete
(1) Sempre
(2) Algumas vezes
(3) Raramente ou não come

Não sabe

- Maionese / molhos
(1) Sempre
(2) Algumas vezes
(3) Raramente ou não come

Não sabe

- Queijo / requeijão
(1) Sempre
(2) Algumas vezes
(3) Raramente ou não come

Não sabe 
ANEXO C - Parecer do Comitê de Ética em Pesquisa do Hospital das Clínicas da Faculdade de Medicina de Ribeirão Preto da Universidade de São Paulo

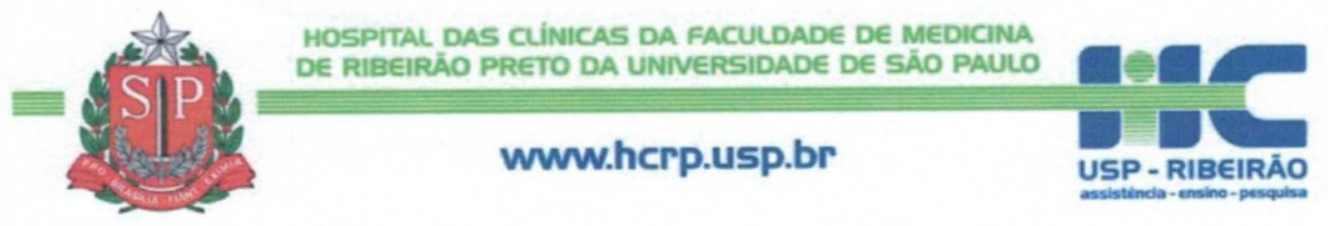

Ribeirão Preto, 11 de maio de 2011

Oficio $n^{\circ} 1606 / 2011$

$\mathrm{CEP} / \mathrm{MGV}$

Prezadas Senhoras,

ANALISAR INTERAÇÕES GENE-NUTRIENTE EM CRIANÇAS E ADOLESCENTES OBESO " foi analisado pelo Comitê de Ética em Pesquisa, em sua $323^{a}$ Reunião Ordinária realizada em 09/05/2011 e enquadrado na categoria: APROVADO, bem como 0 Termo de Consentimento Livre e Esclarecido, de acordo com o Processo HCRP $n^{\circ}$ $14255 / 2010$.

Este Comitê segue integralmente a Conferência Internacional de Harmonização de Boas Práticas Clínicas (IGH-GCP), bem como a Resolução no 196/96 CNS/MS.

Lembramos que devem ser apresentados a este CEP, o Relatório Parcial e o Relatório Final da pesquisa.

Atenciosamente.

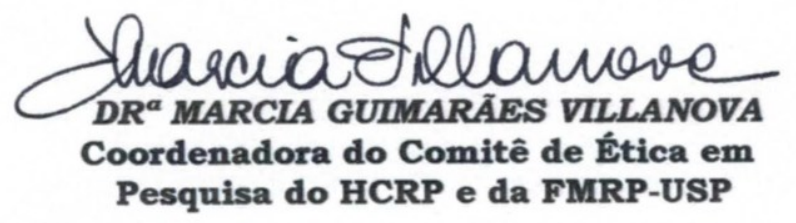

Ilustríssimas Senhoras

CRISTINA MARIA MENDES RESENDE

PROF ${ }^{a}$ DR $^{\text {a }}$ JACQUELINE PONTES MONTEIRO (Orientadora)

Depto. de Puericultura e Pediatria 
ANEXO D - Parecer da Comissão Nacional de Ética em Pesquisa ${ }^{1}$

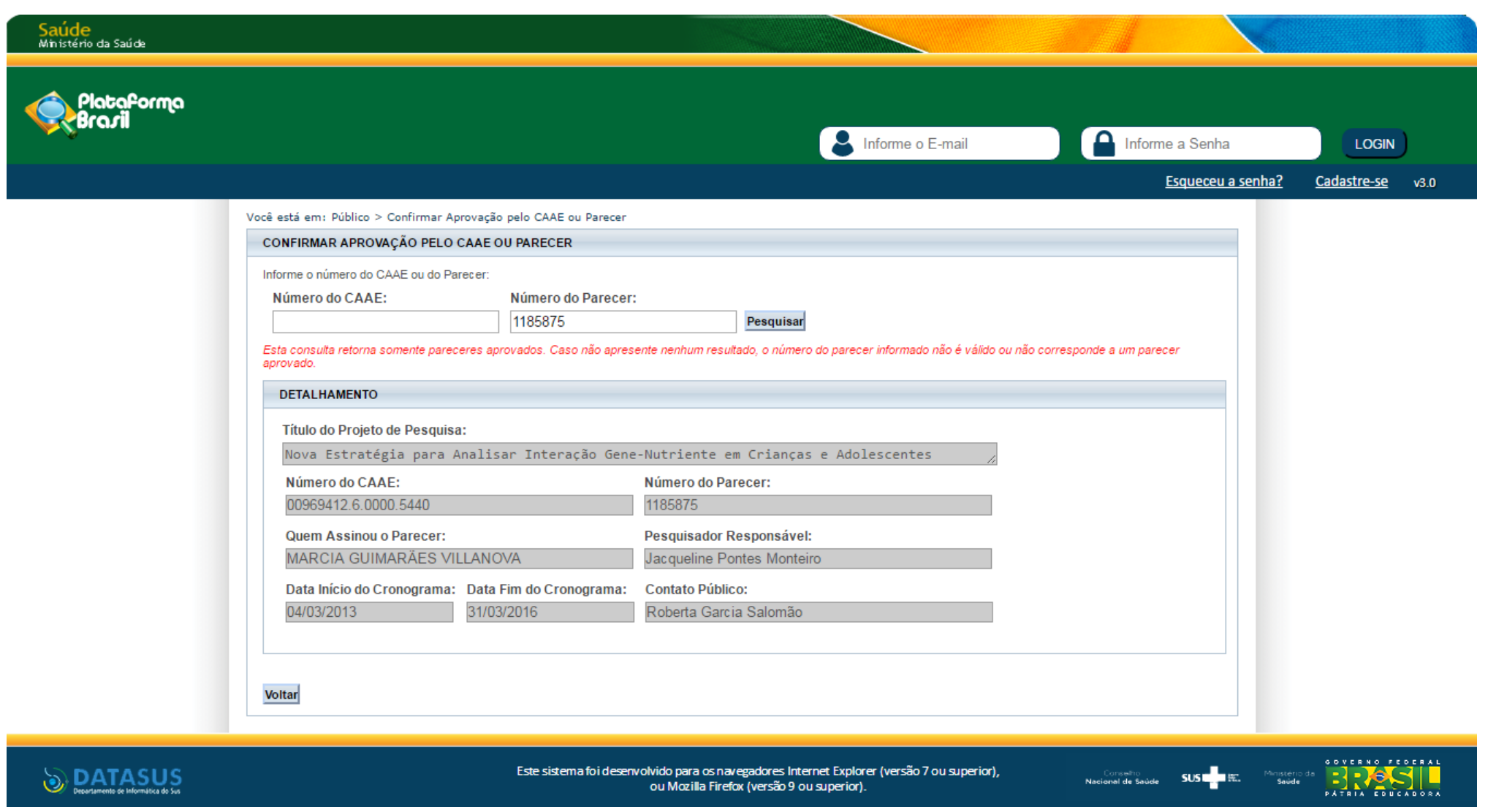

${ }^{1}$ Brasil. Ministério da Saúde. Plataforma Brasil. [Internet]. Brasília, DF: Ministério da Saúde; 2017 [citado 30 mai. 2017]. Disponível em: http://aplicacao.saude.gov.br/plataformabrasil/login.jsf 


\title{
ANEXO E - Termo de Assentimento Livre e Esclarecido
}

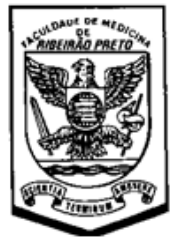

\author{
UNIVERSIDAdE dE SÄO PAULO \\ Faculdade de Medicina de Ribeiräo Preto \\ Departamento De Puericultura e Pedia tRia
}
Av. Bandeirantes, 3900. Cep 14049-900 - Ribeirão Preto - SP
Telefone: (16) 3602-2573 - FAX: (16) 3602-2700

TERMO DE ASSENTIMENTO PARA CRIANÇAS E ADOLESCENTES

Eu, PROFESSORA DOUTORA JACQUELINE PONTES MONTEIRO e a Nutricionista ROBERTA GARCIA SALOMÃO, pesquisadoras do Departamento de Puericultura e Pediatria da Faculdade de Medicina de Ribeirão Preto (USP-SP), estamos desenvolvendo a pesquisa intitulada "Nova estratégia para analisar interações gene-nutriente em crianças e adolescentes" e estamos convidando você a participar deste trabalho.

A obesidade, em crianças e adolescentes, é uma doença causada pelo excesso da ingestão de calorias. Baixa ingestão de vitaminas e minerais (substâncias vitais para o nosso organismo) pode determinar o aparecimento de doenças associadas à obesidade. Nós achamos que a suplementação de vitaminas e alguns minerais irá melhorar a condição nutricional de crianças e adolescentes por aumentar substâncias no sangue chamadas S-adenosilmetionina (SAM) e S-adenosilhomocisteína (SAH). Os níveis dessas substâncias no seu sangue podem estar associados à condição de saúde ou doença, inclusive a obesidade. Também achamos que os diferentes níveis dessas substâncias (SAM e SAH) estão associados às diferentes variações genéticas (diferenças nos seus genes). O que são genes? São pequenas estruturas no nosso corpo que definem nossa aparência e nossa condição de saúde e de doença. Ou seja, somos o que somos por causa da interação entre estas estruturas internas com o meio em que vivemos.

Este estudo tem como objetivo a melhor compreensão de como a suplementação de vitaminas e minerais pode afetar os níveis no sangue de substâncias específicas e como estes níveis estão associados às mudanças nos genes. A importância destes achados está no fato de que indivíduos com diferentes genes irão necessitar de diferentes orientações sobre alimentação para obterem melhores condições de saúde, ou seja, você receberá uma orientação sobre a alimentação mais adequada para você.

Se você concordar em participar neste estudo, terá que ingerir barrinhas de leite da Nestlé ricas em vitaminas e minerais ( 2 barrinhas para crianças entre 9 e 11 anos e 3 barrinhas para aqueles com idade maior ou igual a 12 anos), durante seis semanas porém apenas durante os dias escolares. Essas barrinhas de leite deverão ser entregues a você no seu colégio, antes do início das aulas e deverão ser comidas imediatamente após a entrega das mesmas, condição IMPORTANTE para a participação neste estudo. Você não receberá as barrinhas aos sábados, domingos e feriados. Você receberá as barrinhas de leite por pesquisadores estrategicamente posicionados em frente à sua escola e em um carro de apoio à pesquisa, a fim de não constranger ou expor você no ambiente escolar.

Você deve encontrar os pesquisadores durante 3 momentos diferentes para coleta de dados importantes para essa pesquisa. Essa coleta de dados durará entre 2 a 3 horas em cada momento. Em cada um destes momentos, você receberá ajuda de custo para pagar transporte (ida e volta) até o local da coleta e pagar almoço para você e para seu responsável legal.

- Momento 1: antes da suplementação

- Momento 2: após 6 semanas de suplementação

- Momento 3: após mais 6 semanas SEM a suplementação 
Em cada momento, as seguintes atividades serão desenvolvidas:

1. Coleta de sangue: $12 \mathrm{ml}$ no momento 1 (4 colheres de sopa cheias) e $9 \mathrm{ml}$ nos momentos 2 e 3 (aproximadamente 3 colheres de sopa cheias).

2. Medidas de peso, estatura e circunferência da cintura.

3. Simples avaliação da quantidade da gordura do seu corpo através de um aparelho chamado impedância bioelétrica, sem qualquer risco, desconforto ou dor.

4. Responder a questionários sobre a alimentação usual, sobre a atividade física e sobre a condição econômica com a ajuda de seus pais ou responsáveis legais.

Na semana que antecede cada coleta de sangue vocês serão procurados pelos pesquisadores para responderem a 3 recordatórios de 24 horas (o que você comeu ou bebeu no dia anterior).

A coleta de sangue será feita por pessoal capacitado para essa função e o risco é mínimo (Riscos: A coleta de sangue tem risco mínimo). Em alguns casos verifica-se pequena luxação no local. Estas amostras serão coletadas após um jejum de pelo menos 6 horas. Será fornecido café de manhã imediatamente após a coleta de sangue. Nenhum outro procedimento do trabalho confere qualquer outro risco a você.

Seu sangue será usado para análise de genes e de outras substâncias no sangue. Para essas análises, seu sangue será enviado para o laboratório de pesquisa do Instituto de Pesquisa em Saúde da Nestlé (NIHS) na cidade de Lausanne, na Suíça e, se necessário, para outros laboratórios externos ligados ao NIHS. No primeiro dia da pesquisa você receberá um número e todos os pesquisadores envolvidos com as dosagens de sangue (NACIONAIS E ESTRANGEIROS) passarão a reconhecer você apenas por esse número e não pelo nome.

Você deverá usar um bracelete que mede o número de passos, a atividade física e o gasto energético da pessoa. Veja a ilustração abaixo. Esse bracelete chama-se "BodyBugg" e não confere desconforto ou qualquer risco a você. Esse bracelete será fornecido pelos pesquisadores e deverá ser usado durante três dias determinados pelo pesquisador. Além disso, o número exato de passos que você dará no dia será medido, durante 8 horas diárias por 7 dias, através de um aparelhinho que pode ser colocado no seu bolso chamado "pedômetro". Os pesquisadores the fornecerão esse aparelhinho também.
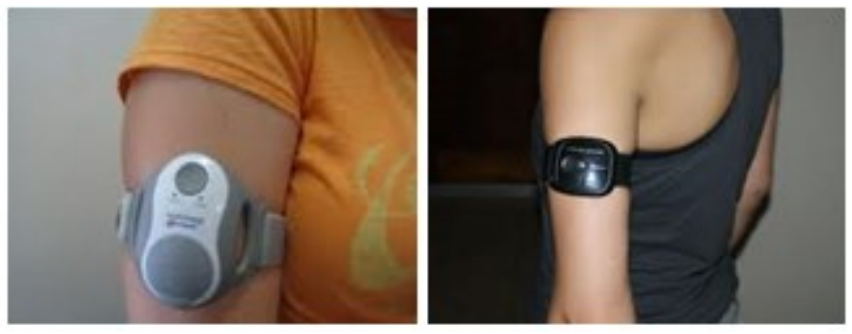

Figura: BodyBug para avaliação da atividade física

Você terá toda a garantia de esclarecimento a respeito da pesquisa, a qualquer momento que precisar. Para isso, você, bem como seus responsáveis, poderão entrar em contato direto com as pesquisadoras JACQUELINE PONTES MONTEIRO (FONE: 16915488 93) e ROBERTA GARCIA SALOMÃO (FONE: 169128 0494), além de poder contatar o comitê de ética em pesquisa do Hospital das Clínicas de Ribeirão Preto, de 8:30hs até 17:00hs, de segunda-feira a sexta-feira, caso julgar necessário (FONE: 16 3602-2228; ENDEREÇO: Av. Bandeirantes sem número. Hospital das Clínicas, andar térreo. Campus USP).

Você também terá a liberdade para se recusar a participar da pesquisa ou retirar seu consentimento, em qualquer fase da pesquisa, sem penalização alguma. 
O benefício desta pesquisa está no fato de que você receberá uma orientação sobre a sua dieta (4 cardápios semanais com substitutos de alimentos), mais adequada à sua realidade. Estes cardápios personalizados só poderão ser entregues após o término de todos os exames de sangue e de todas as análises destes resultados. Além disso, você e seus familiares receberão orientação nutricional geral (BOAS PRÁTICAS DE ALIMENTAÇÃO). Esta última, poderá ser entregue para você e para toda a família, já à partir do final da coleta dos dados.

Não está previsto qualquer dano ou complicação a você decorrentes da pesquisa. Assinale abaixo caso você concorde em ser contatado mais tarde para participar de outras pesquisas.

( ) Concordo em ser contatado mais tarde para participar em outras pesquisas.

( ) Não concordo em ser contatado mais tarde para participar em outras pesquisas.

PARA VOCÊ ENTENDER MELHOR O QUE ESTAMOS PROPONDO, VAMOS CONTAR COMO SERÁ SUA PARTICIPAÇÃO NO PROJETO. VEJA AS FIGURAS ABAIXO:
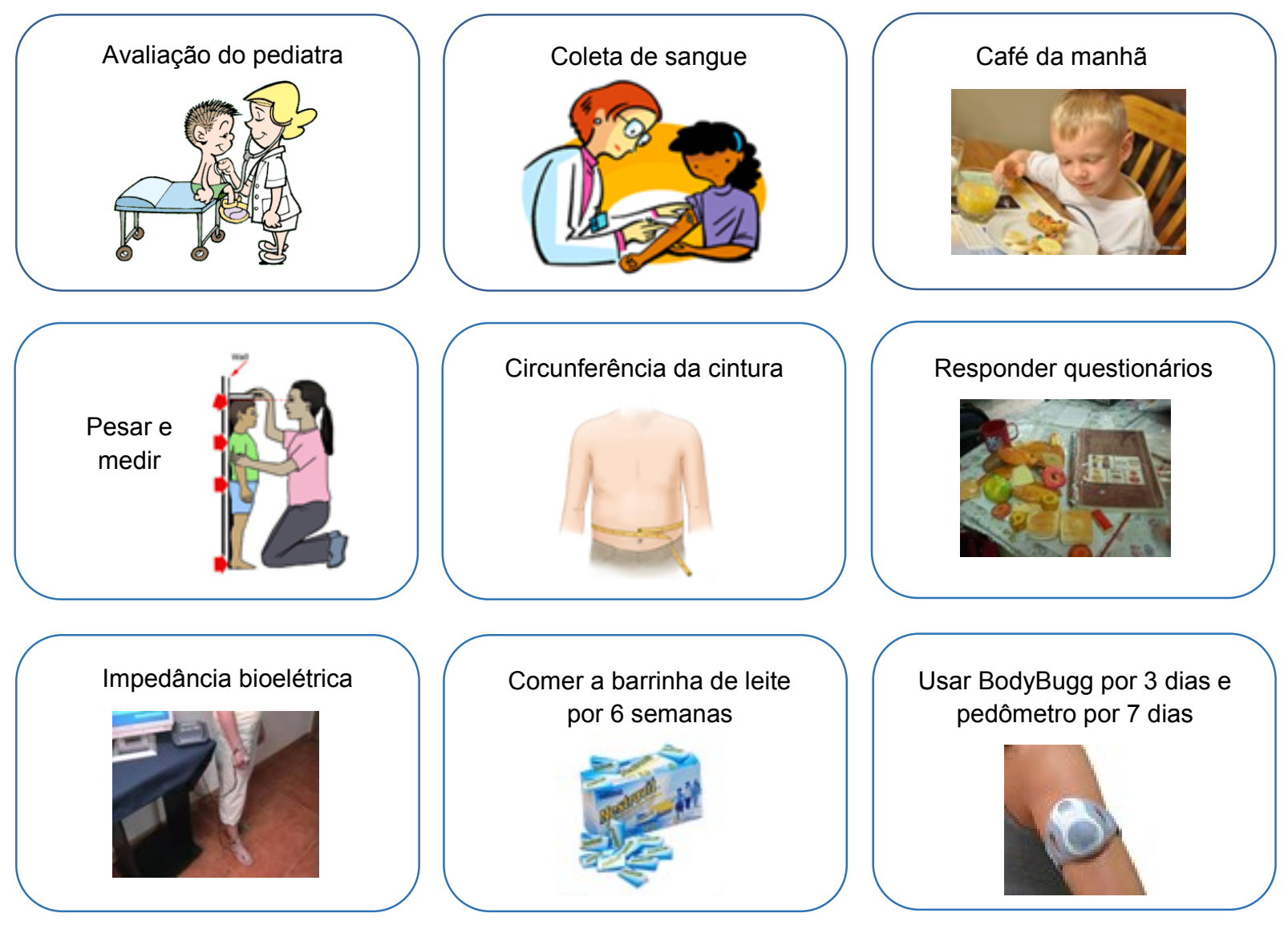

EU abaixo assinado, , confirmo ter recebido

todas as informações sobre a pesquisa a ser desenvolvida e estou ciente de como vou participar. Estou de acordo em participar. Eu tive tempo suficiente para tomar minha decisão. Eu fui informado, pelo pesquisador abaixo, verbalmente ou por escrito sobre os objetivos do estudo bem como sobre os benefícios e desvantagens. Eu estou participando desta pesquisa por livre e espontânea vontade. Eu posso voltar atrás na minha decisão em consentir a minha participação nesta pesquisa a qualquer momento, sem ter que dar uma explicação e sem ser submetido a qualquer consequência desagradável. 
Participante da Pesquisa (criança ou adolescente)

Ribeirão Preto, (data)

Declaração do Investigador: Eu, abaixo assinado, certifico que expliquei à criança ou adolescente, voluntário da pesquisa, a natureza, a significância e os objetivos deste estudo. Eu declaro que tenho cumprido com todas as obrigações relacionadas a este ensaio clínico.

Roberta Garcia Salomão

Ribeirão Preto, (data)

Jacqueline Pontes Monteiro

Ribeirão Preto, (data) 


\title{
ANEXO F - Termo de Consentimento Livre e Esclarecido
}

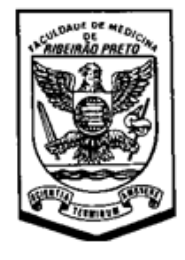

\author{
UNIVERSIDAde de Säo PAULO \\ Faculdade de Medicina de Ribeiräo Preto \\ Departamento De Puericultura e Pedia tria
}

Av. Bandeirantes, 3900. Cep 14049-900 - Ribeirão Preto - SP

Telefone: (16) 3602-2573 - FAX: (16) 3602-2700

\section{TERMO DE CONSENTIMENTO LIVRE E ESCLARECIDO PARA OS PAIS}

\section{Eu, PROFESSORA DOUTORA JACQUELINE PONTES MONTEIRO e a Nutricionista ROBERTA} GARCIA SALOMÃO, pesquisadoras do Departamento de Puericultura e Pediatria da Faculdade de Medicina de Ribeirão Preto (USP-SP), estamos desenvolvendo a pesquisa intitulada "Nova estratégia para analisar interações gene-nutriente em crianças e adolescentes" e estamos convidando seu filho (a) a participar deste trabalho.

A obesidade e suas complicações são causadas pelo excesso da ingestão de calorias, mas também a baixa ingestão de vitaminas e minerais pode determinar o aparecimento de doenças associadas à obesidade. Nós achamos que a suplementação de vitaminas e alguns minerais (substâncias vitais para o nosso organismo) irá melhorar a condição nutricional de crianças e adolescentes por aumentar substâncias chamadas $S$ adenosilmetionina (SAM) e S-adenosilhomocisteína (SAH) no sangue. Os níveis dessas substâncias no sangue de seu (sua) filho (a) podem estar associados à condição de saúde ou doença, inclusive a obesidade. Também achamos que os diferentes níveis dessas substâncias (SAM e SAH) estão associados às diferentes variações genéticas (diferenças nos genes de cada indivíduo). O que são genes? São pequenas estruturas no nosso corpo que definem nossa aparência e nossa condição de saúde e de doença. Ou seja, somos o que somos por causa da interação entre estas estruturas internas com o meio em que vivemos. A importância destes achados está no fato de que indivíduos com diferentes genes irão necessitar de diferentes orientações sobre alimentação para obterem melhores condições de saúde, ou seja, seu (sua) filho (a) receberá uma orientação sobre a alimentação mais adequada para ele (a). Essa pesquisa se justifica por que cada indivíduo responde diferentemente a um tratamento nutricional, conforme as interações entre gene e o meio ambiente em que vive. Exemplo: pessoas obesas respondem diferentemente a uma intervenção nutricional; umas emagrecem muito facilmente, enquanto outras têm uma enorme dificuldade para emagrecer. Dessa forma, com os resultados dessa pesquisa pretendemos descobrir em que grupo de resposta (valores de SAM e SAH) seu (sua) filho (a) se encontra, para melhor orientarmos sua alimentação.

Diante disso, essa pesquisa tem como objetivos:

(1) analisar a resposta da razão SAM/SAH à suplementação de um conjunto de vitaminas e minerais (barrinha de leite da Nestlé - 5 gramas - suplementada com vitaminas e minerais) em indivíduos. Essa barrinha de leite (2 barrinhas para crianças entre 9 e 11 anos e 3 barrinhas para aqueles com idade igual ou superior a 12 anos) deverão ser entregues nos colégios dos participantes, antes do início das aulas e deverão ser comidas imediatamente após a entrega das mesmas, condição IMPORTANTE para a participação neste estudo. Cada participante receberá as barrinhas de leite por pesquisadores estrategicamente posicionados em frente às escolas e em um carro de apoio à pesquisa, a fim de não constranger ou expor seu (sua) filho (a) no ambiente escolar. Cada participante deverá ingerir as barrinhas durante 6 semanas, apenas durante os 5 dias letivos. Aos sábados, domingos e feriados, os participantes não receberão as barrinhas. 
(2) analisar variações genéticas no DNA e associar à resposta determinada pela razão SAM/SAH. Para isso, não procuraremos especificamente um gene, mas qualquer diferença genética que tenha relação com a resposta acima.

(3) avaliar a ingestão de energia e nutrientes através da aplicação de recordatórios de 24 horas (perguntaremos a seu (sua) filho (a) o que comeu e bebeu no dia anterior) e questionários de frequência alimentar para crianças e adolescentes. Estes resultados serão utilizados para avaliação da ingestão habitual de energia, proteínas, gorduras, açucares, vitaminas e minerais para que possamos achar possíveis alterações na dieta habitual que possam interferir nos resultados.

(4) verificar como as proteínas e outras substâncias, tais como vitaminas e lipídios, no sangue de seu (sua) filho (a) respondem à suplementação de vitaminas e minerais. O que são proteínas? Conjunto de pequenas estruturas corporais que são responsáveis pela estrutura, defesa e transporte no seu corpo. O que são lipídios? São as gorduras no sangue.

(5) separar os participantes do estudo em diferentes grupos, conforme os níveis de SAM e SAH e associar esses grupos com os resultados genéticos e de metabólitos no sangue. Dessa forma poderemos orientar quais são os alimentos que devem ser mais ingeridos e quais são aqueles que devem ser menos ingeridos, para ter melhor saúde.

A coleta de dados acontecerá em 3 momentos diferentes na unidade da Casa 5 do Curso de Nutrição e Metabolismo, na rua das Paineiras no Campus da USP em Ribeirão Preto:

- Momento 1: antes da suplementação

- Momento 2: após 6 semanas de suplementação

- Momento 3: após mais 6 semanas SEM a suplementação

Em cada um destes momentos o participante receberá ajuda de custo para pagar transporte (ida e volta) até o local da coleta e almoço do participante e de seu representante legal. Em cada um dos momentos os participantes terão seu sangue colhido: $12 \mathrm{ml}$ no momento 1 (4 colheres de sopa cheias) e $9 \mathrm{ml}$ nos momentos 2 e 3 (aproximadamente 3 colheres de sopa cheias); terão o peso, a altura e a circunferência da cintura medidos, assim como avaliação simples da quantidade das gordura do corpo através de um aparelho chamado impedância bioelétrica, sem qualquer risco, desconforto ou dor; e responderão a questionários sobre a alimentação usual, sobre a atividade física e sobre a condição econômica. O seu (sua) filho (a) poderá ser auxiliado por você, no preenchimento dos questionários. 0 tempo previsto para toda a coleta de dados em cada momento é de 2 a 3 horas no total.

Crianças e adolescentes, além da ajuda dos pais ou responsáveis responderão as perguntas sobre hábitos alimentares com a ajuda de um álbum fotográfico com o tamanho das porções de cada alimento. Dessa forma, será possível indicar a foto que mais se parece com a quantidade ingerida pelo participante. Na semana que antecede cada coleta de sangue os participantes serão procurados pelos pesquisadores para responderem a 3 recordatórios de 24 horas (o que você comeu ou bebeu no dia anterior).

A coleta de sangue será feita por pessoal capacitado para essa função e o risco é mínimo (Riscos: A coleta de sangue tem risco mínimo). Em alguns casos verifica-se pequena luxação no local da coleta de sangue. Estas amostras serão coletadas após um jejum de pelo menos 6 horas. Será fornecido café de manhã imediatamente após a coleta de sangue. Nenhum outro procedimento do trabalho confere qualquer outro risco a seu (sua) filho (a).

Com o objetivo de medir o número de passos, a atividade física e o gasto energético de seu filho (a), cada participante deverá usar um bracelete durante três dias. Veja a ilustração abaixo. Esse bracelete é chamado BodyBugg", será fornecido pelos pesquisadores e não confere desconforto ou qualquer risco ao indivíduo. 

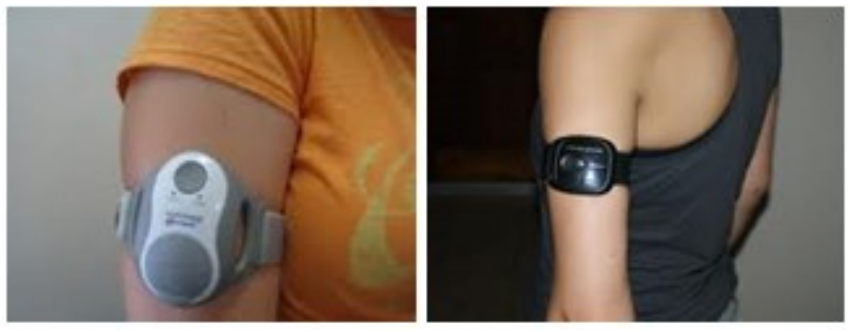

Figura: BodyBugg para avaliação da atividade física

ua criança terá toda a garantia de esclarecimento a respeito da pesquisa, a qualquer momento que precisar. Para isso, sua criança, bem como os responsáveis legais, poderão entrar em contato direto com as pesquisadoras JACQUELINE PONTES MONTEIRO (FONE: 16915488 93) e ROBERTA GARCIA SALOMÃO (FONE: 169128 0494), além de poder contatar o comitê de ética em pesquisa do Hospital das Clínicas de Ribeirão Preto, de 8:30hs até 17:00hs, de segunda-feira a sexta-feira, caso julgar necessário (FONE: 16 3602-2228; ENDEREÇO: Av. Bandeirantes sem número. Hospital das Clínicas, andar térreo. Campus USP).

As amostras de sangue serão enviadas para análise da genotipagem (pesquisa de variações genéticas) e dos metabólitos (vitaminas, proteínas, gorduras) para o laboratório de pesquisa do Instituto de Pesquisa em Saúde da Nestlé (NIHS) na cidade de Lausanne, na Suiça. Caso seja necessário, para análises específicas, tais como análises de proteínas e lipídios, as amostras também poderão ser encaminhadas para outros laboratórios externos ligados ao NIHS. Isso se deve ao fato de que estes laboratórios estão altamente capacitados para analisar todas as amostras e estão, em conjunto com a Professora Dra. Jacqueline Pontes Monteiro, coordenando essa pesquisa. Após o término de todas as análises para o presente projeto, todas as amostras de seu (sua) filho (a) serão descartadas, respeitando-se as normas vigentes de órgãos técnicos competentes, a confidencialidade e a autonomia dos participantes. Os dados genéticos de seu (sua) filho (a) não serão divulgados e nem ficarão acessíveis a terceiros. A duração desta pesquisa, desde a coleta dos dados até as análises dos resultados pode durar até 3 anos.

IMPORTANTE: Seu (sua) filho (a) tem garantia de sigilo, que assegure a sua privacidade, e os resultados serão publicados, sem que em nenhum momento seja divulgada a identidade de seu (sua) filho (a). Cada participante receberá um número, no primeiro dia de pesquisa, e todos os pesquisadores envolvidos com as dosagens de sangue (NACIONAIS E ESTRANGEIROS) passarão a reconhecer seu (sua) filho (a) apenas por esse número e não pelo nome. Cada participante terá a opção de escolher entre ser informado ou não sobre resultados de seus exames bem como pode ter acesso a seus dados genéticos, assim como tem o direito de retirá-los de bancos onde se encontrem armazenados a qualquer momento. Todos os resultados serão digitados em um banco de dados e a identidade de seu (sua) filho (a) será substituída por um número. Apenas a coordenadora local (Profa. Dra. Jacqueline Pontes Monteiro), terá acesso ao número que está associado ao nome, para que ela possa descobrir em que grupo de resposta seu (sua) filho (a) se encontra, para fornecer a orientação nutricional individualizada.

Seu (sua) filho (a) também terá a liberdade para se recusar a participar da pesquisa ou retirar seu consentimento, em qualquer fase da pesquisa, sem penalização alguma.

O benefício desta pesquisa está no fato de que indivíduos com diferentes padrões de variação genética irão necessitar de diferentes orientações sobre alimentação para obterem melhores condições de saúde, ou seja, sua criança receberá uma orientação sobre a sua dieta (4 cardápios semanais com substitutos de alimentos), mais adequada à sua realidade. Estes cardápios personalizados só poderão ser entregues após o término de todos os exames de sangue e de todas as análises destes resultados. Além disso, você e sua criança receberão orientação nutricional geral (BOAS PRÁTICAS DE ALIMENTAÇÃO). Esta última, poderá ser entregue para toda a família, já 
a partir do final da coleta dos dados. A fim de acompanharmos melhor o estilo de vida e possíveis alterações que possam interferir nos resultados, visitas domiciliares deverão ocorrer (4 visitas no total, entre 17 e $18 \mathrm{hs}$ e visitas adicionais em caso de seu filho (a) faltar na escola e de termos que entregar a barrinha de leite na sua residência). Não está previsto qualquer dano ou complicação a seu (sua) filho (a) decorrentes da pesquisa. Um pediatra estará no local da pesquisa durante toda a coleta de dados, caso seja necessário. Entretanto, se a sua criança sentir que sofreu qualquer dano a si mesmo por ter participado da pesquisa, o pesquisador principal, a Instituição e o patrocinador assumem a responsabilidade de dar assistência integral e prover indenização determinada por direito, caso assim seja judicialmente estabelecido.

Assinale abaixo caso você concorde em ser contatado mais tarde para permitir a participação de seu (sua) filho (a) em outras pesquisas.

( ) Concordo em ser contatado mais tarde para permitir a participação de meu (minha) filho (a) em outras pesquisas.

( ) Não concordo em ser contatado mais tarde para permitir a participação de meu (minha) filho (a) em outras pesquisas.

EU

abaixo assinado, responsável por que:
RG: confirmo

- Li e entendi todas as informações contidas neste TERMO DE CONSENTIMENTO LIVRE E ESCLARECIDO PARA OS PAIS a mim fornecido e que estou consciente dos meus direitos.

- Eu recebi, de forma satisfatória, todas as respostas às minhas perguntas no que diz respeito à participação de meu (minha) filho (a) nesta pesquisa.

- Eu tive tempo suficiente para tomar a minha decisão.

- Eu fui informado de que indenização será dada, em caso de dano ao meu filho (a) considerado relacionado a este estudo.

- Eu estou consciente de que os dados pessoais de meu (minha) filho (a) serão enviados e processados, na condição de anonimato, para Instituição Internacional a fim de alcançar os objetivos da pesquisa. Eu concordo que os pesquisadores do estudo, bem como autoridades e membros do comitê de ética vejam todos os dados de nosso (a) filho (a) para exame e verificação desde que os dados de meu (minha) filho (a) permaneçam em confidencialidade.

- Eu concordo que meu filho (a) forneça amostras biológicas necessárias para este estudo. Eu confirmo que tenho sido informado (a) de que os dados derivados deste estudo e as amostras biológicas coletadas serão usadas para pesquisa científica que pode resultar, quando aplicável, em publicações e desenvolvimento de produtos. Quando os resultados do estudo forem publicados, os dados serão divulgados com estrita confidencialidade e a identidade de meu (minha) filho (a) nunca será revelada.

- Nós tomamos a decisão em permitir a participação de nosso (a) filho (a) neste estudo por livre e espontânea vontade.

- $\quad$ Eu autorizo a participação de meu (minha) filho (a).

- Eu posso voltar atrás na minha decisão em consentir a participação do meu (minha) filho (a) nesta pesquisa a qualquer momento, sem ter que dar uma explicação e sem ser submetido a qualquer consequência desagradável. 
Responsável legal

Ribeirão Preto, (data)

Declaração do Investigador: Eu, abaixo assinado, certifico que expliquei aos pais, ou responsáveis legais do voluntário da pesquisa, a natureza, a significância e os objetivos deste estudo. Eu declaro que tenho cumprido com todas as obrigações relacionadas a este ensaio clínico. Se eu me tornar conhecedor, em qualquer momento durante este estudo, de informação que possa afetar o consentimento dos pais ou responsáveis legais do voluntário da pesquisa no que diz respeito à sua participação, eu concordo em informá-los imediatamente.

Roberta Garcia Salomão

Ribeirão Preto, (data)

Jacqueline Pontes Monteiro

Ribeirão Preto, (data) 